\title{
Evaluation of Radiometers in Full- Time Use at the National Renewable Energy Laboratory Solar Radiation Research Laboratory
}

S.M. Wilcox and D.R. Myers

Technical Report NREL/TP-550-44627

December 2008 


\section{Evaluation of Radiometers in Full- Time Use at the National Renewable Energy Laboratory Solar Radiation Research Laboratory}

\author{
S.M. Wilcox and D.R. Myers
}

Prepared under Task Nos. CP09.3301 and PVD9.3110
Technical Report NREL/TP-550-44627

December 2008

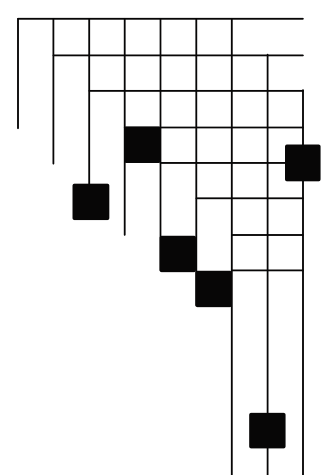




\section{NOTICE}

This report was prepared as an account of work sponsored by an agency of the United States government. Neither the United States government nor any agency thereof, nor any of their employees, makes any warranty, express or implied, or assumes any legal liability or responsibility for the accuracy, completeness, or usefulness of any information, apparatus, product, or process disclosed, or represents that its use would not infringe privately owned rights. Reference herein to any specific commercial product, process, or service by trade name, trademark, manufacturer, or otherwise does not necessarily constitute or imply its endorsement, recommendation, or favoring by the United States government or any agency thereof. The views and opinions of authors expressed herein do not necessarily state or reflect those of the United States government or any agency thereof.

Available electronically at http://www.osti.gov/bridge

Available for a processing fee to U.S. Department of Energy and its contractors, in paper, from:

U.S. Department of Energy

Office of Scientific and Technical Information

P.O. Box 62

Oak Ridge, TN 37831-0062

phone: 865.576 .8401

fax: 865.576 .5728

email: mailto:reports@adonis.osti.gov

Available for sale to the public, in paper, from:

U.S. Department of Commerce

National Technical Information Service

5285 Port Royal Road

Springfield, VA 22161

phone: 800.553 .6847

fax: 703.605.6900

email: orders@ntis.fedworld.gov

online ordering: http://www.ntis.gov/ordering.htm 


\section{Preface}

This report describes the evaluation of the relative performance of the complement of solar radiometers deployed at the National Renewable Energy Laboratory (NREL) Solar Radiation Research Laboratory (SRRL). The evaluation represents a limited sample of instruments (usually one) from various manufacturers, and thus should not be viewed as representative of a specific manufacturer or model of instrument, but only of the instruments at hand for the evaluation. We report an analysis of 12 global (total hemispherical) horizontal radiometers three direct beam pyrheliometers, and two diffuse pyranometers in full-time use at SRRL. Data for 12 months were retrieved from the SRRL Baseline Measurement System and included the test instrument measurements and data for a computed reference data set. Not all test instruments had a full 12-month period of record as noted in the report. This report offers no explicit conclusion about instrument performance, as it is aimed at a very general array of applications with a wide range of instrumentation and accuracy requirements. 


\section{Acknowledgments}

The continually scrupulous work of Afshin Andreas, Beverly Kay, Peter Gotseff, and Ibrahim Reda in maintaining the complement of instruments at the Solar Radiation Research Laboratory and performing exacting and demanding outdoor radiometer calibrations is gratefully acknowledged. The leadership of Thomas Stoffel, Resource Integration Group Manager, and David Mooney, Center Director, in setting the high standards for operations of the Solar Radiation Research Laboratory is appreciated. The United States Department of Energy Solar Energy Technology Program supported this work under DOE prime contract number DE-AC3699-GO10337. 


\section{Table of Contents}

List of Figures .......................................................................................................................................... vi

List of Tables........................................................................................................................................... ix

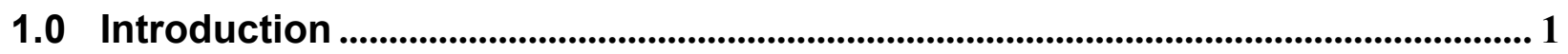

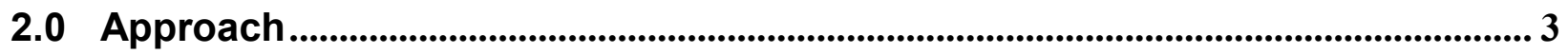

2.1 Evaluation of Global Horizontal Pyranometers........................................ 3

2.2 Evaluation of Direct Normal Pyrheliometers............................................... 6

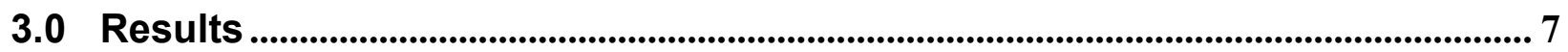

3.1 Pyranometer Sub-Hourly 1-Minute Data ............................................... 7

3.2 Averaged Data: Monthly and Annual Average Daily Totals ......................... 7

3.3 Pyrheliometer and Cavity Pyrheliometer Comparisons ............................... 13

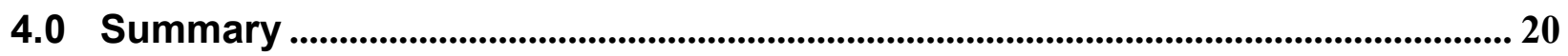

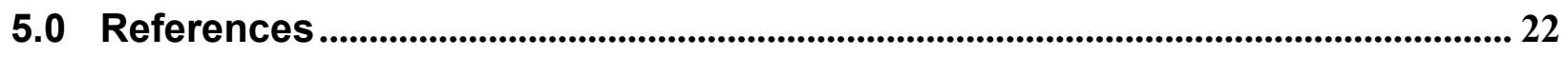

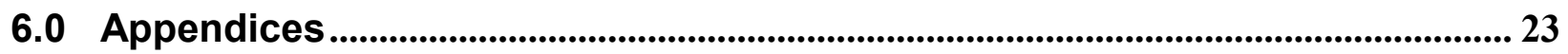




\section{List of Figures}

Figure 1-1. General SRRL configuration (left) with instrument platform (oriented north-south) located west of building. North is to the top, east to the right of the photograph. Instrument platform (right) with solar tracking instruments to the left (south) and horizontal instruments to right (north)........................................................................................................................................ 1

Figure 1-2. Schematic layout of relative positions of radiometers in the study, with representative photographs of the instruments as deployed. 2

Figure 3-1. Mean percent differences from reference global irradiance for pyranometers as function of zenith angle. See Appendix A, Table A1 for instrument list. 9

Figure 3-2. Percent standard deviations of differences from reference global irradiance for pyranometers as function of zenith angle. See Appendix A, Table A-1 for instrument list......... 10

Figure 3-3. Summary of means and standard deviations of differences (in percent) between test radiometers and reference irradiance Monthly Mean Daily Total. See Appendix A, Table A-1 for instrument list.

Figure 3-4. Percent difference between Monthly Mean Daily Totals of test radiometers and reference irradiance.. See Appendix A, Table A1 for instrument list.

Figure 3-5. Difference between MMDT of Corrected and Uncorrected RSR and SPN1 Diffuse and reference diffuse. Note SPN1 data available only for months 8 to11..................................... 13

Figure 3-6. Pseudo time series plot of differences between reference AHF cavity radiometer and K\&Z CH1 010256, Eppley NIP 31173E6, and Eppley NIP 257926E6. (Data in chronological order from individual calibration days which may be separated by periods from a week to many months; sometimes indicated by discontinuities.)

Figure 3-7. Differences in $\mathrm{W} / \mathrm{m}^{2}$ between reference AHF cavity radiometer and Kipp $\mathrm{CH} 1$ 010256, Eppley NIP 31173E6, and Eppley NIP 25792E6 during broadband calibrations as function of time of day.

Figure 3-8. Percent differences between the three test instrucments and reference cavity pyrheliometer as function of zenith angle bins during BORCAL. Means and standard deviations (1 sigma, also in percent) for each $10^{\circ}$ zenith angle bin shown at center of bin.

Figure 3-9. Percent difference in Monthly Mean Daily Totals for NIP, SPN1, RSR Corrected and Uncorrected from the Kipp and Zonen CH1 010256.

Figure 3-10. Average (dots) and standard deviation (1 sigma error bars) of percent difference between NIP 31137 and CH 1 by zenith angle over 11 months (169538 pts). Month $1=$ July 2007; Month $11=$ May 2008. 
Figure 3-11. Histogram of percent differences between NIP 31137E6 and CH1 over all Zenith angles. Mean value of percent difference is $0.20 \%$, standard deviation of $1.98 \%$........................ 20

Figure B-1. Uncorrected Eppley PSP: PSP 25782F3 .......................................................... 26

Figure B-1(a). One-minute data set percent differences; PSP Uncorrected .................................. 26

Figure B-1(b). Daily total percent difference; PSP Uncorrected ..................................................... 26

Figure B-2. Corrected Eppley PSP_C 25782F3 ....................................................................... 27

Figure B-2(a). One-minute data set percent differences. PSP, Corrected. ................................... 27

Figure B-2(b). Daily total percent difference; PSP, Corrected....................................................... 27

Figure B-3. PSP Ventilated Uncorrected 28402F3 .............................................................. 28

Figure B-3(a). One-minute data set percent differences; PSP, Ventilated, Uncorrected.............. 28

Figure B-3(b). Daily total percent difference; PSP, Ventilated, Uncorrected. ............................... 28

Figure B-4. PSP Ventilated and Corrected PSP_V_C 28402F3 .............................................. 29

Figure B-4(a). One-minute data set percent differences; PSP, Ventilated, Corrected.................. 29

Figure B-4(b). Daily total percent difference; PSP, Ventilated, Corrected. .................................. 29

Figure B-5. Kipp \& Zonen CM22 (Ventilated) 010034 ................................................................ 30

Figure B-5(a). One-minute data set percent difference; CM22, Ventilated. .................................. 30

Figure B-5(b). Daily total percent difference; CM22, Ventilated. ............................................. 30

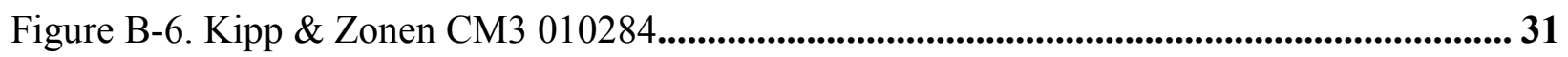

Figure B-6(a). One-minute data set percent differences; CM3......................................................... 31

Figure B-6(b). Daily total percent difference; CM3 ...................................................................... 31

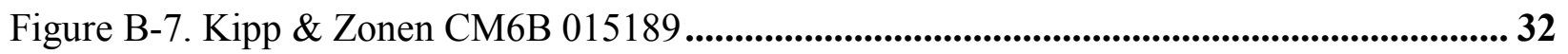

Figure B-7(a). One-minute data set percent differences; CM6B............................................... 32

Figure B-7(b). Daily total percent difference; CM6B. ............................................................... 32

Figure B-8. Li-Cor LI 200 PY28257 ............................................................................................ 33

Figure B-8(a). One-minute data set percent diccerens; LI-200 PY .......................................... 33

Figure B-8(b). Daily total percent difference Li-200........................................................................ 33

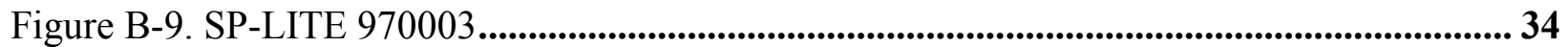

Figure B-9(a). One-minue data set percent differences; SP Lite Global. ......................................... 34

Figure B-9(b). Daily total percent difference; SP Lite Global........................................................ 34

Figure B-10. Irradiance, Inc. RSR2 -Global Uncorrected PY37627 ...................................... 35

Figure B-10(a). One-minute data set percent differences; RSR2 Global Uncorrected................. 35

Figure B-10(b). Daily total percent difference; RSR2 Global Uncorrected. ................................ 35

Figure B-11. Irradiance, Inc. RSR2 global Corrected PY37627 .................................................36

Figure B-11(a). One-minute data set percent differences; RSR2 Global Corrected...................... 36

Figure B-11(b). Daily total percent difference RSR2 Global Corrected. .................................... 36 
Figure B-12. TSP1 - 940703 .................................................................................................. 37

Figure B-12(a). One-minute data set percent differences; TSP1 Global. ................................... 37

Figure B-12(b). Daily total percent difference TSP1 Global...................................................... 37

Figure B-13. TSP700 0212-02 (Ventilated)....................................................................... 38

Figure B-13(a). One-minute data set percent difference; TSP700 Global, Ventilated................. 38

Figure B-13(b). Daily total percent difference; TSP7000 Global, Ventilated............................... 38

Figure B-14. SPN1 GLOBAL A168 (4 months of data Feb 2008 -May 2008)........................... 39

Figure B-14(a). One-minute data set percent differences; SPNI Global. ...................................... 39

Figure B-14(b). Daily total percent difference; SPN1 Global....................................................... 39

Figure B-15. SPN1 DIRECT A168 (4 months of data Feb 2008 -May 2008) .............................. 40

Figure B-15(a). One-minute data set percent differences; SPN1 Direct. ..................................... 40

Figure B-15(b). Daily total percent difference; SPN1 Direct. ................................................... 40

Figure B-16. RSR2 Direct Uncorrected (11 months of data Jul 2007 -May 2008) ...................... 41

Figure B-16(a). One-minute data set percent differences: RSR2 Direct Uncorrected. ................. 41

Figure B-16(b). Daily total percent difference RS2 Direct Uncorrected........................................ 41

Figure B-17. RSR Direct Corrected (11 months of data Jul 2007 - May 2008) .......................... 42

Figure B-17(a). One-minute data set percent differences; RSR2 Direct Corrected. ..................... 42

Figure B-17(b). Daily total percent difference; RSR2 Direct Corrected........................................ 42

Figure B-18. SPN1 Diffuse A168 (4 months of data Feb 2008 -May 2008)................................. 43

Figure B-18(a). One-minute data set percent differences; SPN1 Diffuse. ................................... 43

Figure B-18(b). Daily total percent difference; SPN1 Diffuse. ................................................ 43

Figure B-19. RSR2 Diffuse Corrected (11 months of data Jul 2007-May 2008) .......................... 44

Figure B-19(a). One-minute data set percent differences; RSR2 Diffuse Corrected. ................... 44

Figure B-19(b). Daily total percent difference RSR2 Diffuse Corrected. ...................................... 44

Figure B-20. RSR2 Diffuse Uncorrected (11 months of data Jul 2007 -May 2008)................... 45

Figure B-20(a). One-minute data set percent differences; RSR2 Diffuse Uncorrected. ............... 45

Figure B-20(b). Daily total percent difference RSR2 Diffuse Uncorrected. .................................. 45 


\section{List of Tables}

Table 3-1. Instrument performance by zenith angle (sub-hourly; one-minute), monthly mean daily total, and annual mean biases............................................................................................................ 8

Table 3-2. Table of statistics for percent differences in daily total irradiances versus reference irradiance

Table 3-3. Monthly Mean Daily Total Percent differences from Ref Global Horizontal ............. 12

Table 3-4. Diffuse Horizontal RSR and SPN1 ……............................................................................ 13

Table 3-5. Kipp \& Zonen $010256 \mathrm{CH} 1 \mathrm{Z}$ angle statistics .................................................................... 14

Table 3-6. Eppley Nip 25792 Z angle statistics........................................................................................ 14

Table 3-7. Eppley Nip 31137 Z angle statistics............................................................................ 14

Table 3-8. Direct Normal Comparison Eppley NIP, RSR and SPN1 with CH1 (mean percent difference in MMDT) by month; month $1=$ JULY 2007; month 11 = MAY 2008 ......................... 18

Table 3-9. Average percent differences between NIP 1 and CH 11 -minute data by 10 degree zenith angle bin over 11 months (169538 pts) Month 1 = JULY 2007; Month 11 = MAY 2008 ............... 19

Table A-1. The instruments evaluated and calibration uncertainties.................................................. 23

Table B-1. Statistical summary 1minute data by zenith angle bin PSP 25782F3............................ 26

Table B-2. Statistical summary 1-minute data by zenith angle bin PSP 25782F3 (Corrected).... 27

Table B-3. Statistical summary 1-minute data by zenith angle bin PSP 28402F3 (Ventilated,

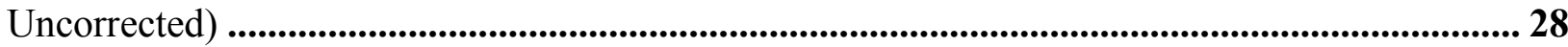

Table B-4. Statistical summary 1-minute data by zenith angle bin PSP 28402F3 (Ventilated, Corrected) (..................................................................................................................................................... 29

Table B-5. Statistical summary 1-minute data by zenith angle bin CM22 010034 (Ventilated).. 30

Table B-6. Statistical summary 1-minute data by zenith angle bin CM3 010284.......................... 31

Table B-7. Statistical summary 1-minute data by zenith angle bin CM6B 015189 ....................... 32

Table B-8. Statistical summary 1-minute data by zenith angle bin Li-200 PY28257 .................... 33

Table B-9. Statistical summary 1-minute data by zenith angle bin SP-LITE 970003................... 34 
Table B-10. Statistical summary 1-minute data by zenith angle bin RSR2 Global Uncorrected. 35

Table B-11. Statistical summary 1-minute data by zenith angle bin RSR2 Global Corrected..... 36

Table B-12. Statistical summary 1-minute data by zenith angle bin TSP1 Global ........................ 37

Table B-13. Statistical summary 1-minute data by zenith angle bin TSP700 Global ....................38

Table B-14. Statistical summary 1-minute data by zenith angle bin SPN1 Global........................ 39

Table B-15. Statistical summary 1-minute data by zenith angle bin SPN1 Direct.......................... 40

Table B-16. Statistical summary 1-minute data by zenith angle bin RSR2 Direct Uncorrected.. 41

Table B-17. Statistical summary 1-minute data by zenith angle bin RSR2 Direct Corrected....... 42

Table B-18. Statistical summary 1-minute data by zenith angle bin SPN1 Diffuse....................... 43

Table B-19. Statistical summary 1-minute data by zenith angle bin RSR2 Diffuse Corrected.... 44

Table B-20. Statistical summary 1-minute data by zenith angle bin RSR2 Diffuse Uncorrected.45 


\section{Introduction}

The Solar Radiation Research Laboratory (SRRL) at the National Renewable Energy Laboratory (NREL) regularly collects measurements from approximately 100 solar and metrological instruments as part of its Baseline Measurement System (BMS). These measurements are available to the public within a few seconds of logging via the NREL Measurement and Instrumentation Data Center (http://www.nrel.gov/midc/srrl_bms). Figure 1-1 shows the general configuration of SRRL and the instrument platform (to left, or west, of building) where the instruments are deployed.
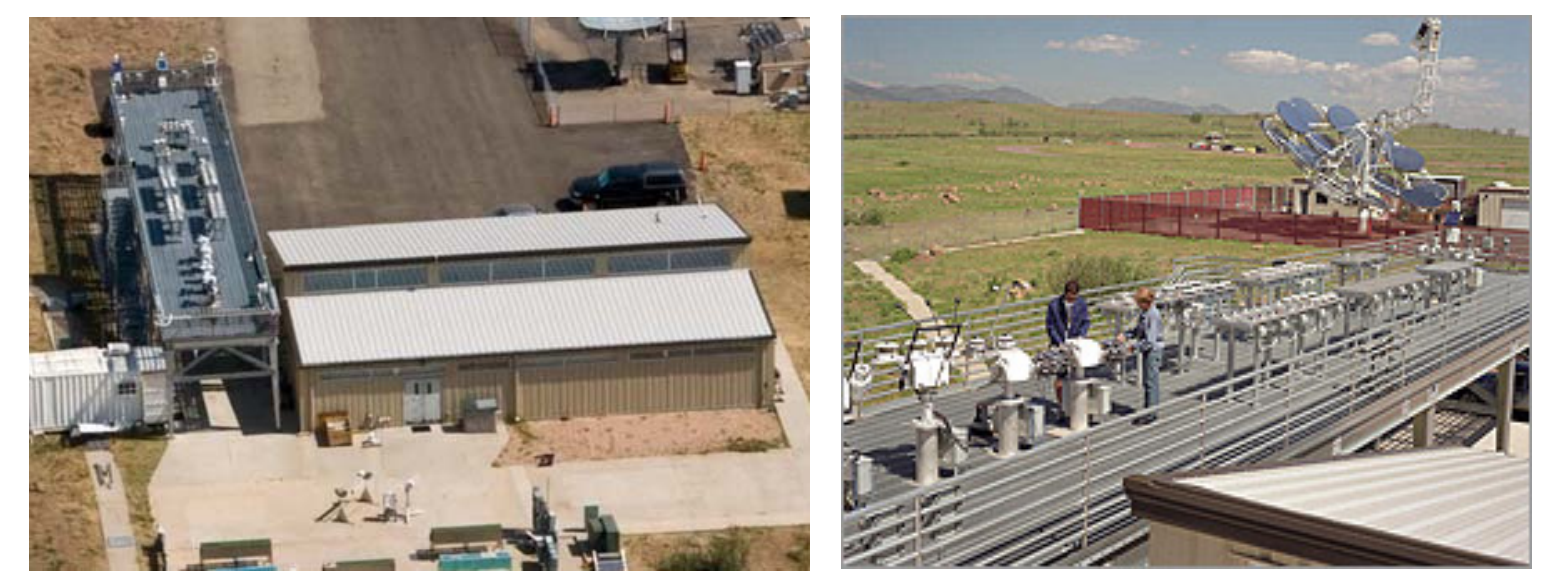

Figure 1-1. General SRRL configuration (left) with instrument platform (oriented north-south) located west of building. North is to the top, east to the right of the photograph. Instrument platform (right) with solar tracking instruments to the left (south) and horizontal instruments to right (north).

To support decision making for other projects, this report presents an analysis of 12 global (total hemispherical) horizontal radiometers, three direct beam pyrheliometers, and two diffuse pyranometers in full-time use at SRRL. Relative location of the radiometers is shown on the schematic layout of the SRRL instrument platform in Figure 1-2.

Data for 12 months were retrieved from SRRL's BMS and included the test instrument measurements and data for a reference data set computed from selected instruments. Not all test instruments had a full 12-month period of record as noted in the results. This report offers no explicit conclusion about instrument performance, as it is aimed at a very general array of applications with a wide range of instrumentation and accuracy requirements.

Note that the evaluation of these instruments represents a limited sample of instrument models (usually 1), and these results cannot be used with complete confidence to infer the same results or characteristics for all instruments of the same manufacturer and model. The evaluation used data from NREL's Solar Radiation Research Laboratory and results for instruments may be unique to the climate or geographical conditions at its Golden, Colorado, location (39.74 N latitude, $105.18 \mathrm{~W}$ longitude, and elevation $1829 \mathrm{~m}$ ). Past experience indicates that many of these instruments respond to solar radiation to a different and usually unquantified degree in dissimilar physical environments. 


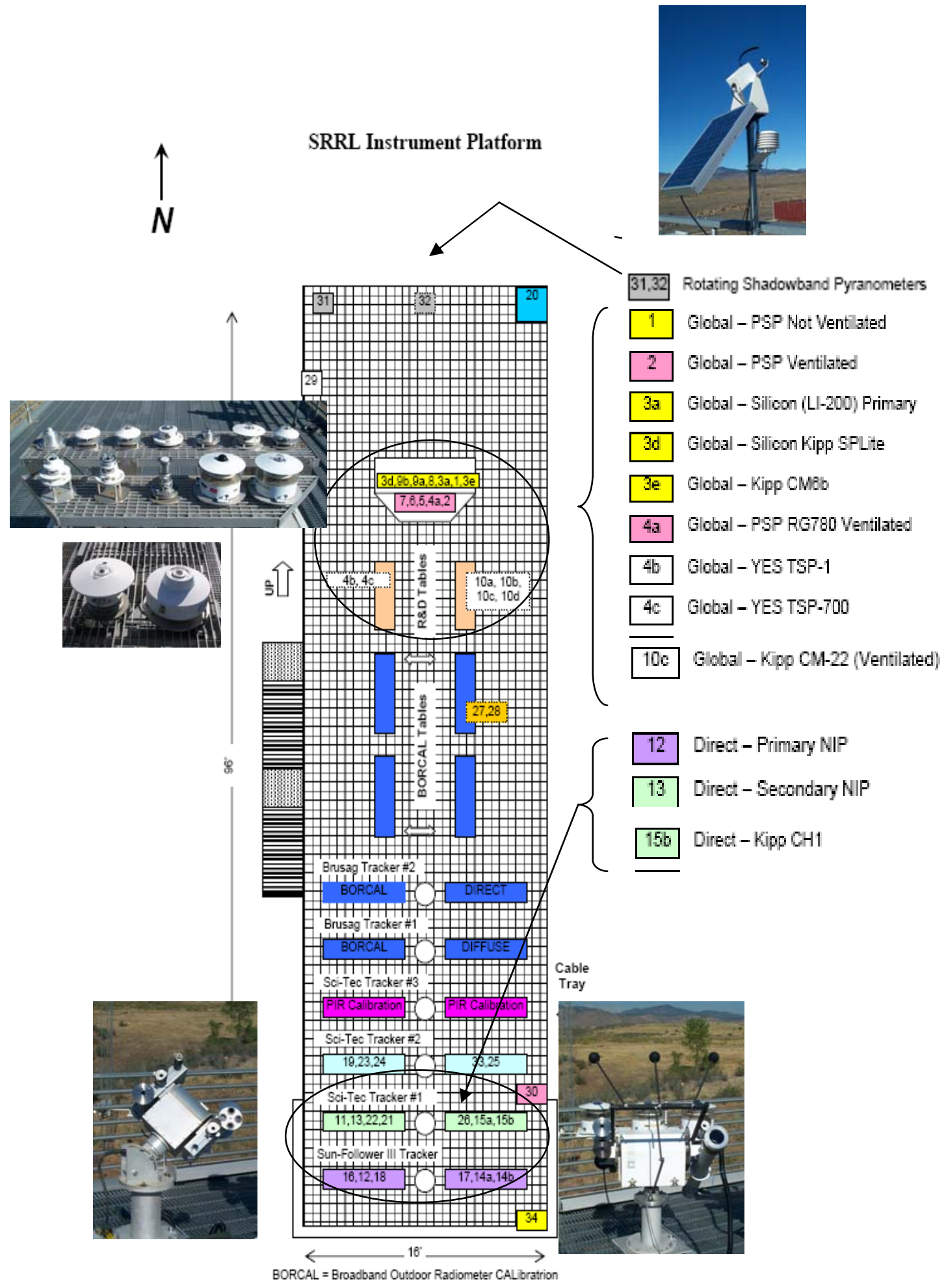

Figure 1-2. Schematic layout of relative positions of radiometers in the study, with representative photographs of the instruments as deployed. 
The evaluation is subdivided into two sections: pyrheliometers (direct beam measurements) and pyranometers (global horizontal and diffuse horizontal measurements). The instruments evaluated are listed in Appendix A in Table A-1. The evaluation numerical results are summarized in Table 3-1. Detailed reports for each individual instrument are shown in Appendices B and C.

\section{Approach}

Two statistical summaries were prepared for each instrument, where sufficient data were available. Data for the 12 months from May 2006 to May 2007 were collected using the Solar Radiation Research Laboratory Baseline Measurement System. Data were recorded as 1-minute averages of 3 second $(0.33 \mathrm{~Hz}, 20$ samples per minute) sampled data using Campbell Scientific CR23X data loggers. This constituted the sub-hourly data set. Subsequently, the sub-hourly data sets were aggregated into hourly average data (mean of 601 -minute averages), daily totals (sum of all sunup 1-minute data), and monthly mean daily totals (mean of the daily totals for all days in the month).

For the sub-hourly statistics, the values in the $80^{\circ}$ to $90^{\circ}$ bin are not included in the summary because of sensitivities to environmental error and general low irradiance conditions. The last three entries report the statistics for the Eppley Laboratories NIP 27592E6, 31137E6, and Kipp and Zonen CH1 010256 with respect to an absolute cavity radiometer [1], an Eppley Laboratories Automatic Hickey-Frieden (AHF) under clear sky conditions only. The monthly and annual statistics NA designation for the pyrheliometers are due to the limited duration data set (see section 2.2 on pyrheliometer evaluations).

\subsection{Evaluation of Global Horizontal Pyranometers}

Data for the portion of the study pertaining to pyranometers were collected under all sky conditions throughout a year (data quality filtering removed about $5 \%$ of the data, and some instruments as noted had a short period of record). Two independently evaluated instruments were used to create a computed global hemispherical irradiance data set against which the pyranometers' measured global hemispherical irradiance was compared. Two other independently evaluated instruments were used to validate and quality assess (QA) the reference data set and reject data inconsistent among those four instruments (computed global and QA instruments, respectively, see section 2.1.2). The computed global hemispherical (henceforth "Computed Global") and QA instruments are identified below.

\subsubsection{Computed Global Irradiance}

Computed from: Direct beam * $\operatorname{COS}(Z)+$ Diffuse

Direct Beam: Kipp \& Zonen CH1 Serial No. 010256

Cal. Factor $=91.881 \mathrm{~W} / \mathrm{m}^{2} / \mathrm{mV}$

Responsivity(Rs) @ $45^{\circ}=10.884 \mu \mathrm{V} / \mathrm{W} / \mathrm{m}^{2}$

CALIBRATION Uncertainty: $+0.60 \%-0.56 \%$ (for $30^{\circ} \leq \mathrm{Z} \leq 60^{\circ}$ )

Diffuse: Eppley 8-48 Serial No. 32331

Cal Factor $=112.77 \mathrm{~W} / \mathrm{m}^{2} / \mathrm{mV}$

Responsivity (Rs) @ $45^{\circ}=8.868 \mu \mathrm{V} / \mathrm{W} / \mathrm{m}^{2}$

CALIBRATION Uncertainty: $+1.95 \%-1.89 \%$ (for $30^{\circ} \leq \mathrm{Z} \leq 60^{\circ}$ ) 


\subsubsection{Quality Assessment and Filtering of Reference Irradiance Data}

The direct and diffuse irradiance measurements used to calculate the reference computed global irradiance data were evaluated against an independent global irradiance calculated from different direct beam and diffuse instruments listed below. SERI QC [2] was used to validate the measurements. SERI QC uses clearness index Kt for global, Kd for Diffuse, and Kn for direct beam (ratio of measured data to top of the atmosphere or extraterrestrial data of the same type, direct beam, and direct component on a horizontal) to check that the balance of the component sum equation $\mathrm{Kt}=\mathrm{Kn}+\mathrm{Kd}$ is "true" within a tolerance of \pm 0.03 units. SERI QC generated flags for each data set. Any 1-minute data record without a SERI QC flag of 1 (zenith angle $>80^{\circ}$ ) or 3 (within the \pm 0.03 tolerance limit) was rejected from the reference data set (approximately $5 \%$ of the data were rejected). In our experience, a flag of three indicates data from a wellmaintained station.

\begin{tabular}{|c|c|c|c|c|}
\hline Period & Serial \# & $\begin{array}{l}\text { Cal Fac } \\
\mathrm{W} / \mathrm{m}^{2} / \mathrm{mV}\end{array}$ & $\begin{array}{l}\mathrm{RS} @ 45 \\
\mu \mathrm{V} / \mathrm{W} / \mathrm{m}^{2}\end{array}$ & $\begin{array}{l}\text { Uncertainty } \\
\left(30^{\circ} \leq \mathrm{Z} \leq 60^{\circ}\right)\end{array}$ \\
\hline 16-05-2006-08-06-2007 & $31137 \mathrm{E} 6$ & 117.78 & 8.4905 & $+0.98 /-0.92 \%$ \\
\hline $08-06-2007-18-06-2008$ & $31137 \mathrm{E} 6$ & 117.59 & 8.5043 & $+1.11 /-1.03 \%$ \\
\hline $18-07-2008-31-05-2008$ & $31137 \mathrm{E} 6$ & 117.61 & 8.5024 & $+1.10 /-1.00 \%$ \\
\hline
\end{tabular}

QA Diffuse $=$ Kipp \& Zonen CM22 (Shading ball) radiometers:

\begin{tabular}{lcccl} 
Period & Serial \# & $\begin{array}{c}\text { Cal Fac } \\
\mathrm{W} / \mathrm{m}^{2} / \mathrm{mV}\end{array}$ & $\begin{array}{c}\mathrm{RS} @ 45 \\
\mu \mathrm{V} / \mathrm{W} / \mathrm{m}^{2}\end{array}$ & $\begin{array}{l}\text { Uncertainty } \\
\left(30^{\circ} \leq \mathrm{Z} \leq 60^{\circ}\right)\end{array}$ \\
\hline $01-06-2007-13-06-2007$ & 010046 & 107.72 & 9.2832 & $+1.24 /-1.14 \%$ \\
$13-06-2007-23-05-2008$ & 010034 & 91.704 & 10.905 & $+1.81 /-1.50 \%$ \\
$23-05-2008-31-05-2008$ & 010046 & 107.56 & 9.2972 & $+1.45 /-1.67 \%$
\end{tabular}

The two diffuse instruments- $8-48$ and CM22 - were chosen for the two roles of computing global irradiance and QA so as to remove the possibility of using the CM22 in computing reference irradiance for the global CM22.

\subsubsection{Uncertainties of the Method}

The evaluation data set was retrieved from the Solar Radiation Research Laboratory Baseline Measurement System recorded at 1-minute averages of $3 \mathrm{sec}(0.33 \mathrm{~Hz}, 20$ samples per minute $)$ sampled data using Campbell Scientific CR23X data loggers:

01-06-2007 to 29-10-2007: CR23X s/n 3416 Factory Cal 01/25/2001

29-10-2007 to 31-05-2008: CR23X s/n 1162 Calibrated 01/19/2007

The manufacturer's specified accuracy is $\pm 0.025 \%$ of Full Scale Range (FSR typically $+/-50$ $\mathrm{mV}$, meaning FSR is $100 \mathrm{mV}) 0^{\circ} \mathrm{C}$ to $40^{\circ} \mathrm{C}$. So in the $50 \mathrm{mV}$ range: accuracy: $\pm 0.025 \mathrm{mV}=25$ microvolts $(\mu \mathrm{V})$ with $1.67 \mu \mathrm{V}$ resolution. Thus, the data logger contribution to uncertainty is $\sim$ $\pm 25 \mu \mathrm{V} \pm 1.67 \mu \mathrm{V}$ which is approximately $\pm 26.7 \mu \mathrm{V}$. 
Radiometer responsivities are generally $<\sim 5.0$ to $10.0 \mu \mathrm{V} / \mathrm{Wm}^{-2}$, i.e., $1.0 \mathrm{Wm}^{-2}$ generates 5 to $10 \mu \mathrm{V}$ of signal. The $26.7 \mu \mathrm{V}$ logger uncertainty equates to approximately 5 watts or 2.7 watts (absolute) in BOTH reference and TEST instruments, or $\sim 1.0 \%$ to $0.5 \%$ of reading at midrange values of $500 \mathrm{Wm}^{-2}$, and $2 \%$ or $1 \%$ of $1000 \mathrm{Wm}^{-2}$ readings. We will be conservative and select the average of the larger uncertainties, $1.5 \%$, for the data logger contribution to overall uncertainty.

Combined uncertainty in the computed reference irradiance is estimated from the weighted contribution of the beam and diffuse components, ranging from $\pm 1.0 \%$ for extremely clear (nearly all direct beam) to $\pm 2.5 \%$ overcast (all diffuse, or high zenith angles). The mean of the 250,9811 -minute reference uncertainties is $1.8 \% \pm 0.5 \%$. Total uncertainty in the comparisons is determined from the square root of the mean squared uncertainties, plus twice the standard deviation squared, plus the logger uncertainty contribution squared or $\left(1.8^{2}+(2 * 0.5)^{2}+1.5^{2}\right)=$ $\pm 2.5 \%$. Thus reference and data irradiances within $\pm 2.5 \%$ of each other are considered identical.

For each 1-minute data point, global irradiance from each test instrument was compared with the concurrent computed global irradiance, and the difference between them calculated as a percent (test irradiance minus computed irradiance divided by computed irradiance). The resulting data set was used to calculate "sub-hourly" percent mean bias differences and standard deviations. The computed global irradiance data and test instrument global irradiance data were summed into daily total irradiance, and monthly means of daily total, which were compared by calculating percent differences as for the 1-minute data.

Table A-1 in Appendix A lists the instruments evaluated. In the case of the Kipp \& Zonen CM22 global horizontal measurement, because of calibration and deployment schedules, two physical instruments were used for this evaluation. The table also shows the uncertainty in the responsivity (Rs) derived from NREL's Broadband Outdoor Radiometer Calibration (BORCAL) Radiometer Calibration and Characterization ( $\mathrm{RCC}$ ) procedures [3]. Those uncertainties are assigned based on the range of responsivities computed during the BORCAL process between zenith angles of $30^{\circ}$ and $60^{\circ}$. Since the Rs is specified at $\mathrm{Z}=45^{\circ} \pm 0.2^{\circ}$, the $30^{\circ}$ to $60^{\circ} \mathrm{Z}$ angle range is used to indicate the variability in Rs over zenith angles with $\pm 15^{\circ}$ of the calibration point. Thus these uncertainties are a less comprehensive measure of performance than the results in this evaluation. The calibration results are represented as valid only for the environmental conditions existing on the day of the calibration, whereas this evaluation encompasses data and environmental conditions for an entire year. The calibration responsivity for each instrument was used to calculate irradiance for the instruments, but the calibration uncertainty of the test instruments was not used for this evaluation. It is provided to show the expected uncertainty in the determination of irradiances using the specified responsivity in the range of zenith angles from $30^{\circ}$ to $60^{\circ}$.

\subsubsection{Special Considerations}

All data where the absolute value of the computed global irradiance was less than $10 \mathrm{Wm}^{-2}$, or differences between the computed irradiance and the test irradiance were $>100 \%$ were eliminated. This removed issues with computing the ratios of small irradiance values and transient effects from differing time constants which were seen to inordinately contribute to 'percentage difference' results. An additional 3\% of the 250,000 data points were removed from the analysis using these criteria. 
At the latitude of the SRRL, the minimum zenith angle in summer is 17 degrees, so there is no 0 to 10 degree zenith angle bin data.

The entire suite of instruments was maintained with daily cleaning five days per week by NREL staff. The effects of snow accumulation and frost in the wintertime may not have been completely removed from the data set. The QA process on the reference data set likely removed most snow effects for both the reference and test data set. But individual instruments may have accumulated snow at different rates under different conditions, and the effects of snow and frost may be present for some test instruments. Additionally, some instruments had the benefit of ventilators, which tends to mitigate frost and snow accumulation. These effects may show up as a negative or positive bias on certain days, increasing the scatter of data.

Zenith angle and thermal corrections for the Eppley PSP were developed by the National Renewable Energy Laboratory and are neither supplied by the manufacturer nor part of instrument output. The corrections require special calibrations and additional instrumentation (pyrgeometer) and were included in this study for consideration by the user. Corrections for the Irradiance Rotating Shadowband Radiometer (RSR2) are supplied by the manufacturer and corrected data are included as part of the instrument output.

\subsection{Evaluation of Direct Normal Pyrheliometers}

The absolute cavity radiometer (Eppley Automatic Hickey-Freidan) is the reference for NREL calibrations and for this work is presumed to be the pyrheliometer with the lowest uncertainty available [4]. Although a full year of data in varying conditions and seasons - such as that used for the pyranometer evaluations above - is desired, it is not practical to deploy the cavity full time because its aperture is open to the elements and internal components are subject to water or soiling.

For this evaluation we collected reference cavity radiometer data from all NREL calibration events from 2002 to 2007 and matched this reference data with three pyrheliometers from the SRRL baseline system (Eppley NIPs 25792E6 and 31137E6 and Kipp \& Zonen CH1 010256). Because known and accepted uncertainties in the NREL calibrations are similar to expected differences among pyrheliometers, if there were different responsivities in use for an instrument in the different calibration events over the study period (e.g., see Table A-1), these responsivities were averaged. This removed noise effects of calibration uncertainty and also provided the opportunity to detect sensitivity drift with time (none were observed).

The portion of the study pertaining to pyrheliometers used only clear sky conditions (as mandated by the calibration events). Although the instruments are assumed to be linear in sensitivity with irradiance, overall performance could vary under different sky conditions. However, this may not detract from the usefulness of evaluation results presented here since performance under clear skies may be of greatest interest to solar power conversion applications.

\subsubsection{Uncertainties for the Direct Normal Pyrheliometer Evaluation:}

The NREL BORCAL process has a nominal uncertainty contribution from the cavity radiometer and low thermal and high precision data logging system (which is about five times more accurate than the routine monitoring data logger) of about $0.5 \%$. 


\section{$3 \quad$ Results}

\subsection{Pyranometer Sub-Hourly 1-Minute Data}

Table 3-1 and Figures 3-1 and 3-2 display a summary of the percent differences between the computed reference irradiances and the instrument data. The first two columns of Table 3-1 are for the sub-hourly (1-minute) data for each instrument or instrument configuration over all zenith angle ranges. The $3^{\text {rd }}$ and $4^{\text {th }}$ columns of Table $3-1$ shows the percent bias error in monthly mean daily totals and annual average daily total data between the computed reference and the instrument data. Since the biases changed as a function of zenith angle (and hence as a function of the month of the year) a range of bias differences is shown, from minimum to maximum magnitude. Typically the minimum bias with respect to zenith angle is for the low zenith angle data (summer), and maximum bias occurs with the largest zenith angle bin (80 to 90 degrees) and winter data (highest average zenith angles for the year).

The majority of the pyranometers ( 9 of the 13 ) have a bias between $\pm 1 \%$ to $\pm 5 \%$ from the computed reference irradiance 1 minute data. These are the CM22 Ventilated, CM6B, PSP Ventilated and Corrected, TSP1, TSP700, SP LITE, LI200, and RSR2 Corrected and Uncorrected. Of these, four have a bias error less than equal to $\pm 2 \%$ in the 1-minute data. These are the RSR2 Corrected, CM6B, CM22 Ventilated, and SP LITE. The standard deviation of the differences from the 1-minute reference irradiance are less than $\pm 6 \%$ for the CM22 Ventilated, TSP700, RSR2 Corrected and Uncorrected, PSP Ventilated and Corrected, and LI200.

Two of the instruments (RSR2 and SPN1), while strictly pyranometer-based, provide direct normal irradiance (DNI) through calculation from the measured global and diffuse irradiances. DNI values from these instruments are included in the pyranometer results.

\subsection{Averaged Data: Monthly and Annual Average Daily Totals}

Of the 13 pyranometers, all but two have a mean bias difference from the computed reference irradiance Monthly Mean Daily Totals (MMDT) of less than $\pm 5 \%$ all year long. The two exceptions are the PSP Uncorrected and PSP Ventilated Uncorrected, which underestimate winter irradiances by more than $7 \%$ due to poor cosine response with respect to the $45^{\circ}$ zenith angle responsivity for these instruments.

In terms of annual average daily total (AADT) irradiance, all instruments agree with the computed reference irradiance annual average daily total irradiance within $\pm 3 \%$, except the PSP Uncorrected, which has a mean bias of $-3.9 \%$. Eight of the instruments have less than $\pm 2 \%$ bias from the computed reference irradiance AADT (CM22 Ventilated, SP Lite, TSP700, CM3, CM6B, LI200, RSR2 Corrected, and PSP Corrected.) Five of these have less than $\pm 1 \%$ bias from the AADT of the computed reference irradiance (CM22 Ventilated, CM6B, LI200, RSR2 Corrected, and PSP Corrected).

Note there is insufficient coverage of the year by the Delta-T SPN1 radiometer to make an adequate comparison with the other pyranometers with respect to the annual daily totals. The MMDT for this instrument only span 4 months in the winter and spring seasons 
Various combinations of mean bias error, standard deviation of the bias error, MMDT bias and AADT bias would result in different 'rankings' of the performance of the instruments with respect to the computed reference irradiance, which has an estimated uncertainty of $\pm 2.5 \%$.

Figure 3-1 shows that for zenith angles less than $60^{\circ}$, all of the pyranometer mean bias errors are less than $\pm 5 \%$. Figure 3-2 shows that for all but the $\mathrm{CM} 3$ pyranometer, the standard deviation of the differences from the computed reference irradiance is also less than $5 \%$ for zenith angles less than $60^{\circ}$.

Thus, it is imperative to note that the largest contribution to differences of all of the pyranometers with respect to the computed reference irradiance are due to issues with cosine response of the instruments for zenith angles greater than $60^{\circ}$.

Table 3-1. Instrument performance by zenith angle (sub-hourly; 1-minute), monthly mean daily total, and annual mean biases.

\begin{tabular}{|l|l|l|l|l|}
\hline \multirow{2}{*}{$\begin{array}{c}\text { Instrument (see Table A1 in } \\
\text { Appendix A) }\end{array}$} & \multicolumn{1}{|c|}{$\begin{array}{c}\text { Sub-hourly Uncertainty \% } \\
\text { (range of bins to } 80^{\circ} \text { Zenith) }\end{array}$} & \multicolumn{2}{c|}{$\begin{array}{c}\text { Mean Daily Total } \\
\text { Uncertainty \% }\end{array}$} \\
\cline { 2 - 5 } & $\begin{array}{c}\text { Bias } \% \\
\text { max } / \text { min }\end{array}$ & $\begin{array}{c}\text { Standard } \\
\text { Deviation } \\
\%\end{array}$ & $\begin{array}{c}\text { Monthly } \\
\text { Bias \% } \\
\text { (monthly } \\
\text { bins) max } / \\
\text { min }\end{array}$ & $\begin{array}{c}\text { Annual Bias } \\
\%\end{array}$ \\
\hline CM22_Vent & +0.6 to +0.4 & 2 to 3 & $\begin{array}{l}+0.77 \text { to } \\
+0.18\end{array}$ & +0.48 \\
\hline CM6B & +0.8 to -0.3 & 4 to 7 & $\begin{array}{l}+0.87 \text { to }- \\
1.96\end{array}$ & +0.15 \\
\hline CM3 & +0.1 to -7.4 & 2 to 7 & $\begin{array}{l}+0.37 \text { to }- \\
1.84\end{array}$ & -1.23 \\
\hline PSP_Vent_C & +0.0 to -3.1 & 2 to 6 & $\begin{array}{l}-0.06 \text { to }- \\
5.13\end{array}$ & -2.08 \\
\hline PSP_C & +5.7 to -0.3 & 2 to 11 & $\begin{array}{l}+1.17 \text { to }- \\
3.27\end{array}$ & +0.79 \\
\hline PSP_Vent_U & +1.6 to -11.3 & 2 to 8 & $\begin{array}{l}+0.01 \text { to }- \\
8.38\end{array}$ & -3.88 \\
\hline PSP_U & +2.5 to -7.5 & 2 to 9 & $\begin{array}{l}+0.42 \text { to }- \\
10.3\end{array}$ & -2.78 \\
\hline TSP700 & -0.8 to -2.5 & 4 to 6 & $\begin{array}{l}+1.50 \text { to }- \\
0.01\end{array}$ & +1.09 \\
\hline TSP1 & +3.2 to +0.4 & 2 to 12 & $\begin{array}{l}+4.59 \text { to }- \\
0.41\end{array}$ & +2.32 \\
\hline SPN1 (Glo)* & -0.3 to -3.7 & 4 to 7 & $\begin{array}{l}-0.67 \text { to }- \\
6.04\end{array}$ & $*$ \\
\hline SPN1 (Dir)* & +8.1 to +3.0 & 19 to 24 & $\begin{array}{l}+15.4 \text { to }- \\
7.90\end{array}$ & $*$ \\
\hline
\end{tabular}

\footnotetext{
${ }^{1}$ Infrared correction for unVentilated pyranometer using Ventilated pyrgeometer to measure net Infrared
} 


\begin{tabular}{|l|l|l|l|l|}
\hline SPN1 (Dif)* & -13.8 to -4.3 & 7 to 11 & $\begin{array}{l}-12.9 \text { to }- \\
10.4\end{array}$ & $*$ \\
\hline SP_LITE & +1.4 to +0.8 & 4 to 7 & $\begin{array}{l}+1.39 \text { to } \\
+0.02\end{array}$ & +1.35 \\
\hline LI200_TOT & +2.8 to -2.0 & 3 to 8 & $\begin{array}{l}+1.92 \\
2.01\end{array}$ & +0.93 \\
\hline RSR2_C (Glo)*** & +1.0 to -1.2 & 4 to 6 & $\begin{array}{l}+0.53 \text { to }- \\
2.54\end{array}$ & -0.73 \\
\hline RSR2_C (Dir)** & -3.5 to -7.5 & 16 to 19 & $\begin{array}{l}-0.59 \\
8.81\end{array}$ & -6.60 \\
\hline RSR2_C (Dif) & -0.2 to +3.0 & 5 to 6 & $\begin{array}{l}-1.06 \text { to } \\
+3.03\end{array}$ & +1.00 \\
\hline RSR2_U (Glo)** & -0.8 to -2.5 & 4 to 6 & $\begin{array}{l}-0.81 \text { to }- \\
3.59\end{array}$ & -2.17 \\
\hline RSR2_U (Dir)** & +1.3 to +0.5 & 17 to 20 & $\begin{array}{l}-2.07 \text { to } \\
+3.37\end{array}$ & +1.04 \\
\hline RSR2_U (Dif)** & -12.0 to -15.0 & 13 to 16 & $\begin{array}{l}-19.3 \text { to }- \\
19.6\end{array}$ & -14.1 \\
\hline NIP 31137 DNI** & -0.2 to +0.4 & 1.7 to 2.1 & $\begin{array}{l}-0.30 \text { to } \\
+1.20\end{array}$ & +0.10 \\
\hline NIP 25792E6/Cav & +0.79 to -0.28 & 0.5 to 0.7 & N/A & N/A \\
\hline NIP 31137E6/Cav & +0.46 to -0.53 & 0.4 to 0.6 & N/A & N/A \\
\hline CH1 010256/Cav & +0.23 to +0.10 & 0.4 to 0.5 & N/A & N/A \\
\hline
\end{tabular}

* Partial period of record (4 months); ** Partial period of record (11 months); ${ }^{+}$Average $\%$ difference in annual daily totals

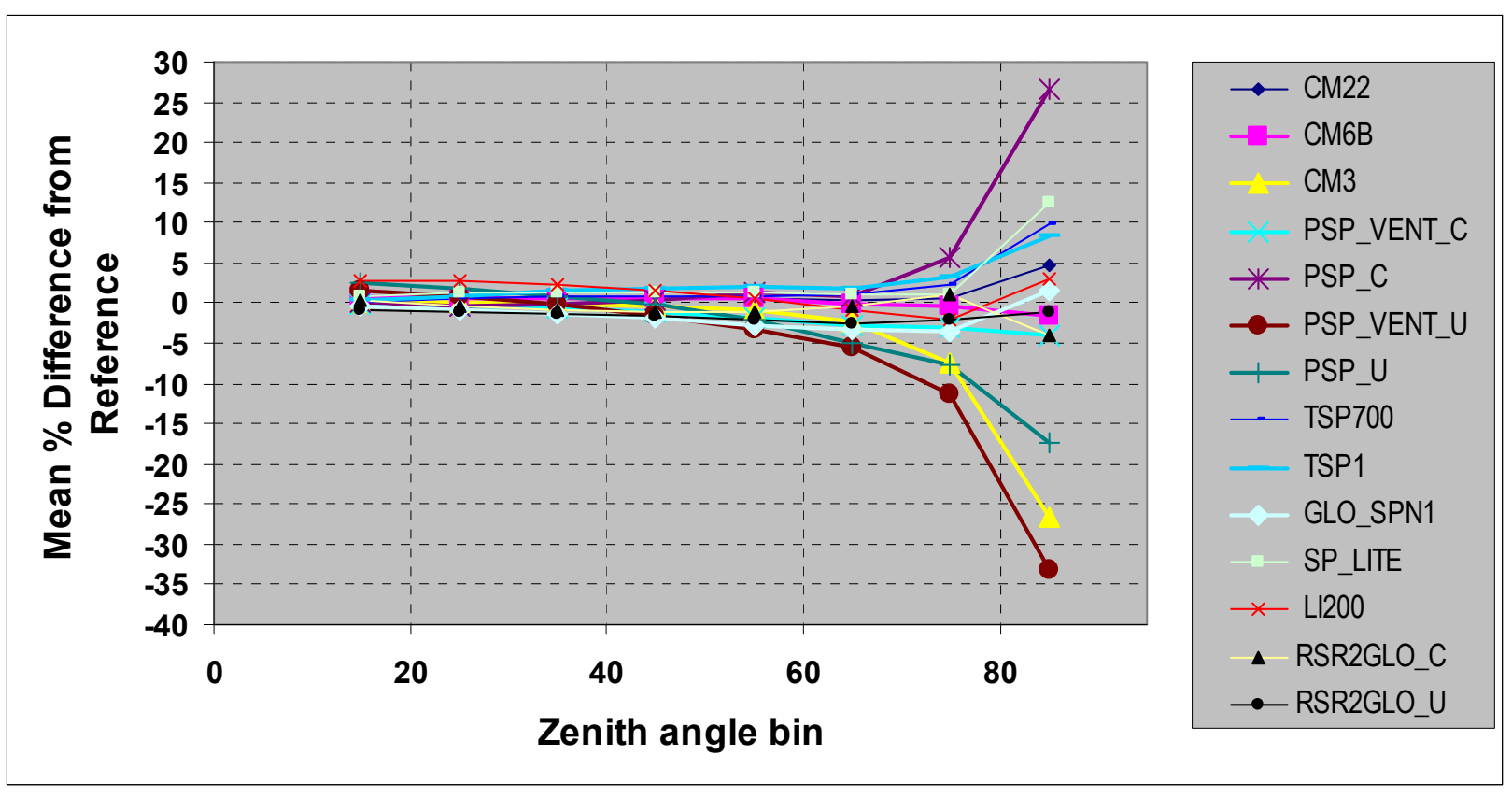

Figure 3-1. Mean percent differences from reference global irradiance for pyranometers as function of zenith angle. See Appendix A, Table A-1 for instrument list. 


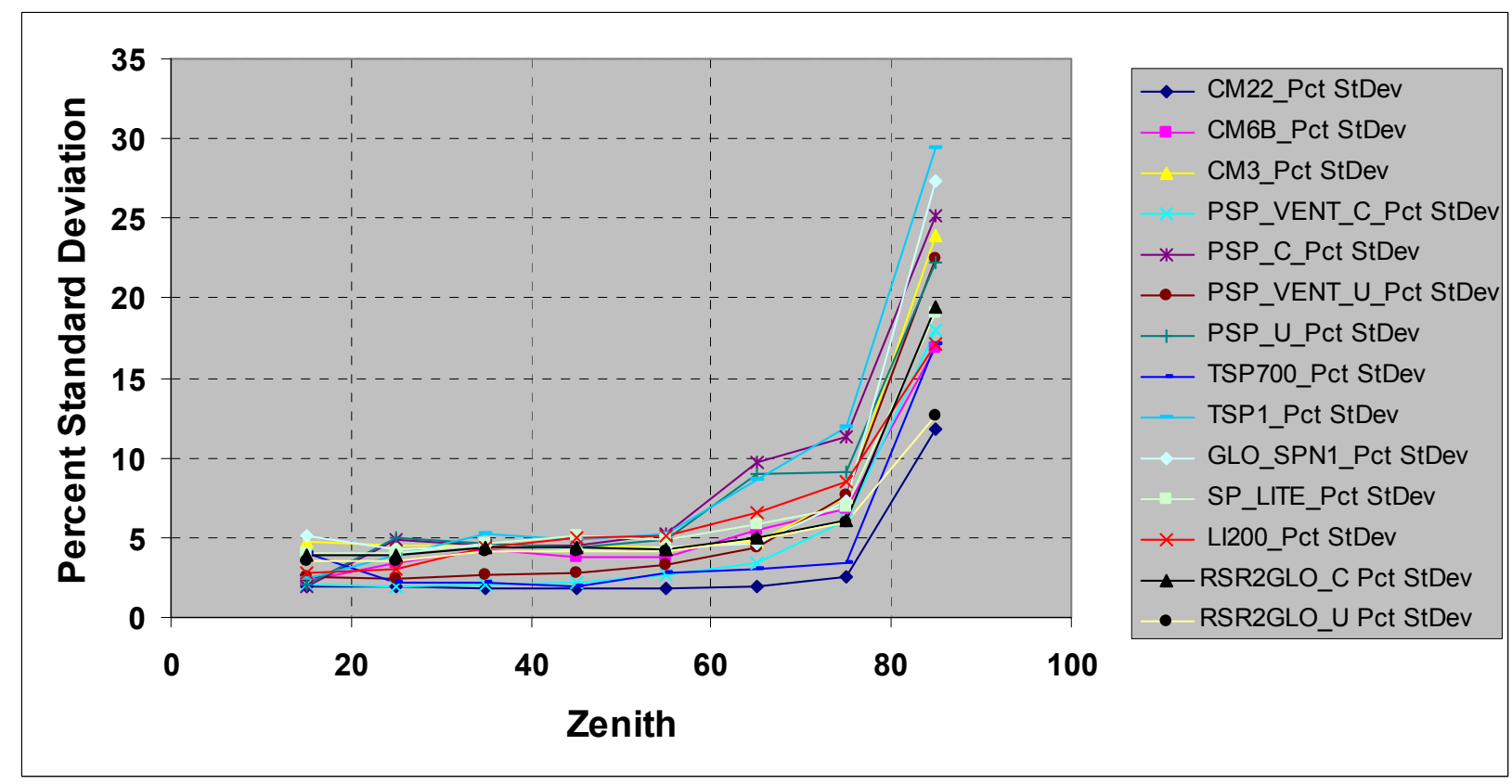

Figure 3-2. Percent standard deviations of differences from reference global irradiance for pyranometers as function of zenith angle. See Appendix A, Table A-1 for instrument list.

Figure 3-3 is a bar chart of the mean difference between the MMDT of test and computed reference global (and the SPN1 Direct and Diffuse with respect to the CH1 direct and CM22 diffuse MMDT) irradiances. The error bars represent the standard deviation of the MMDT differences in percent of the mean irradiance.

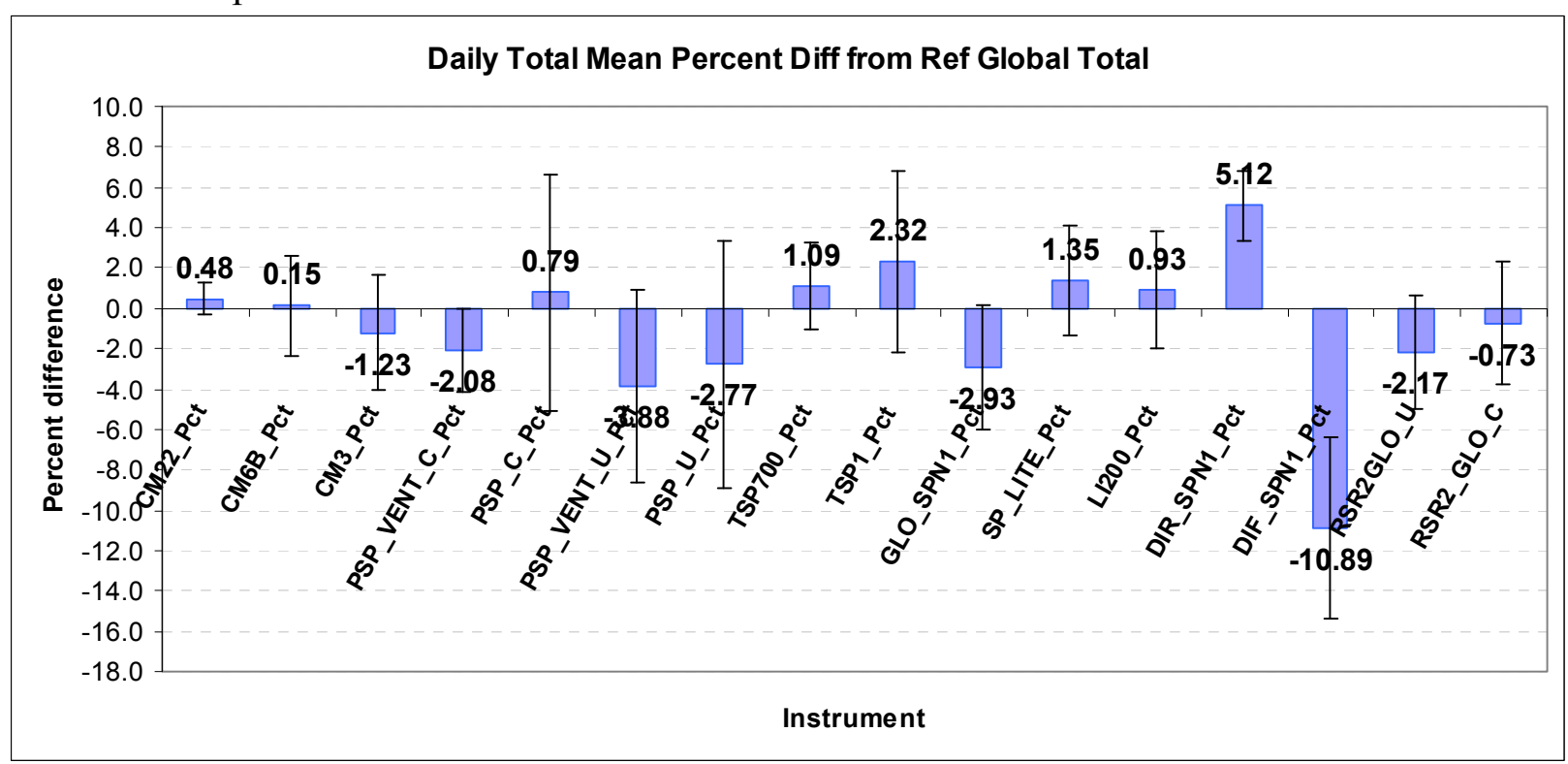

Figure 3-3. Summary of means and standard deviations of differences (in percent) between test radiometers and reference irradiance Monthly Mean Daily Total. See Appendix A, Table A-1 for instrument list. 
Table 3-2 shows the data of Figure 3-3 in tabular form, as well as the range of differences in MMDT in percent.

Table 3-2. Table of statistics for percent differences in daily total irradiances versus reference irradiance.

\begin{tabular}{|c|c|c|c|c|c|c|}
\hline & $\begin{array}{l}\text { Count } \\
\text { (N) }\end{array}$ & Mean & $\begin{array}{l}\text { StDev } \\
\text { (sd) }\end{array}$ & Maximum & Minimum & Range \\
\hline CM22_VENT_Pct & 366 & 0.480 & 0.788 & 5.8 & -4.6 & 10.4 \\
\hline CM6B_Pct & 366 & 0.151 & 2.495 & 9.3 & -23.8 & 33.1 \\
\hline CM3_Pct & 366 & -1.230 & 2.854 & 5.3 & -39.3 & 44.6 \\
\hline PSP_VENT_C_Pct & 366 & -2.081 & 2.098 & 3.2 & -12.2 & 15.4 \\
\hline PSP_C_Pct & 366 & 0.792 & 5.856 & 45.3 & -55.5 & 100.8 \\
\hline PSP_VENT_U_Pct & 366 & -3.880 & 4.759 & 1.2 & -58.3 & 59.5 \\
\hline PSP_U_Pct & 366 & -2.775 & 6.096 & 8.3 & -59.8 & 68.1 \\
\hline TSP700_Pct & 366 & 1.086 & 2.177 & 7.1 & -35 & 42.1 \\
\hline TSP1_Pct & 366 & 2.320 & 4.467 & 27.2 & -31.6 & 58.8 \\
\hline GLO_SPN1_Pct & 152 & -2.928 & 3.121 & 6.8 & -14.7 & 21.5 \\
\hline SP_LITE_Pct & 366 & 1.352 & 2.714 & 15.6 & -20.8 & 36.4 \\
\hline LI200_Pct & 366 & 0.928 & 2.935 & 12.2 & -23.9 & 36.1 \\
\hline DIR_SPN1_Pct ${ }^{*}$ & 144 & 4.197 & 17.79 & 91.0 & -66.8 & 157.8 \\
\hline RSR2_U (Glo $)^{* *}$ & 341 & -2.174 & 2.812 & 11.5 & -35.7 & 47.2 \\
\hline RSR2_U (Dir) ${ }^{* *}$ & 329 & 1.043 & 9.269 & 39.0 & -82.7 & 121.7 \\
\hline RSR2_C (Glo)** & 341 & -0.733 & 3.015 & 14.2 & -47.4 & 47.7 \\
\hline RSR2_C (Dir) ${ }^{* *}$ & 330 & -4.626 & 10.48 & 65.4 & -97.8 & 163.2 \\
\hline
\end{tabular}

* Only 4 months of valid data (Feb 2008-May 2008); ** 11 months of data (July 07 to May 08)

Figure 3-3 and Table 3-2 summarize results for the aggregated months in the study. Figure 3-4 and Table 3-3 show the month to month variability of the differences in MMDT for the global hemispherical irradiances. Six units, the SPN1 Global, Corrected PSP, Corrected Ventilated PSP, Uncorrected PSP, Uncorrected Ventilated PSP, and TSP1 pyranometers exceed $+/-2 \%$ difference for one or more months of the year, typically in the winter (month 7 is December, 2007) months. The TSP1 MMDT are 4\% too high in the spring (Feb, Mar, Apr) months. The Corrected PSP MMDT difference is $-3 \%$ only for one month (Dec). Note that the SPN1 Global data was present for January (month 8) to May (month 12). 


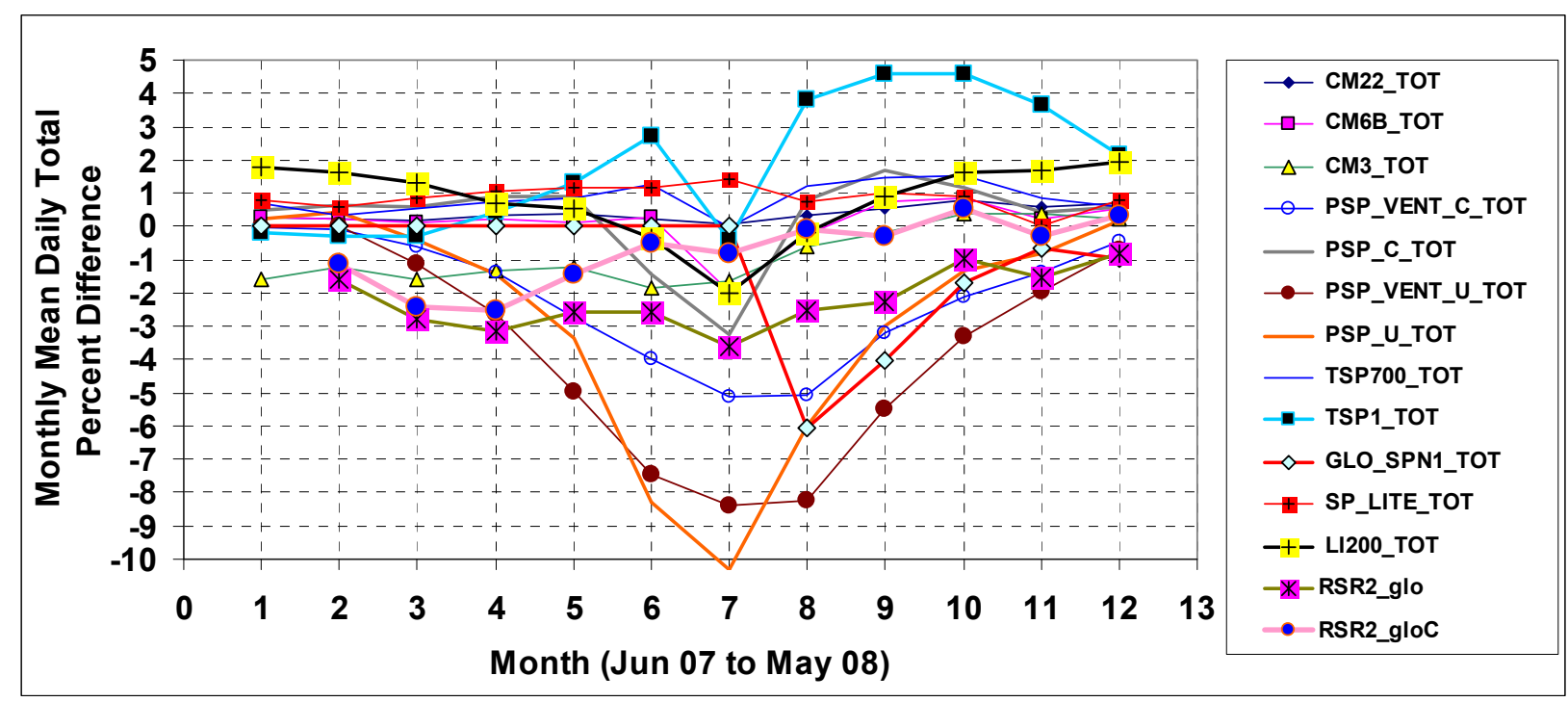

Figure 3-4. Percent difference between Monthly Mean Daily Totals of test radiometers and reference irradiance.. See Appendix A, Table A1 for instrument list.

Table 3-3 shows the tabular data presented in Figure 3.4. Shaded cells highlight MMDT differences that exceed $+/-2.5 \%$.

Table 3-3. Monthly Mean Daily Total Percent differences from Ref Global Horizontal (CH1 + Diff)

\begin{tabular}{|c|c|c|c|c|c|c|c|c|c|c|c|c|}
\hline & $\begin{array}{l}\text { JUN } \\
2007 \\
\end{array}$ & $\begin{array}{l}\text { JUL } \\
2007\end{array}$ & $\begin{array}{l}\text { AUG } \\
2007\end{array}$ & $\begin{array}{l}\text { SEP } \\
2007\end{array}$ & $\begin{array}{l}\text { OCT } \\
2007\end{array}$ & $\begin{array}{l}\text { NOV } \\
2007\end{array}$ & $\begin{array}{l}\text { DEC } \\
2007\end{array}$ & $\begin{array}{l}\text { JAN } \\
2008\end{array}$ & $\begin{array}{l}\text { FEB } \\
2008\end{array}$ & $\begin{array}{l}\text { MAR } \\
2008 \\
\end{array}$ & $\begin{array}{l}\text { APR } \\
2008\end{array}$ & $\begin{array}{l}\text { MAY } \\
2008 \\
\end{array}$ \\
\hline $\begin{array}{l}\text { GLO_REF } \\
\text { Wh } / \mathrm{m}^{-2}\end{array}$ & 6749 & 6473 & 5386 & 4503 & 3881 & 2306 & 2211 & 2500 & 3467 & 4597 & 6133 & 6001 \\
\hline CM22_Vent & 0.266 & 0.203 & 0.184 & 0.319 & 0.372 & 0.205 & 0.064 & 0.317 & 0.527 & 0.771 & 0.612 & 0.687 \\
\hline CM6B & 0.293 & 0.230 & 0.117 & 0.246 & 0.138 & 0.264 & -1.960 & -0.241 & 0.753 & 0.870 & 0.227 & 0.554 \\
\hline CM3 & -1.606 & -1.244 & -1.585 & -1.342 & -1.207 & -1.843 & -1.638 & -0.581 & -0.195 & 0.386 & 0.355 & 0.233 \\
\hline PSPVENC & -0.034 & -0.061 & -0.626 & -1.394 & -2.740 & -4.002 & -5.129 & -5.083 & -3.226 & -2.099 & -1.379 & -0.475 \\
\hline PSP_C & 0.509 & 0.665 & 0.611 & 0.904 & 0.897 & -1.461 & -3.268 & 0.802 & 1.696 & 1.173 & 0.454 & 0.569 \\
\hline PSPVENTU & -0.036 & 0.007 & -1.110 & -2.647 & -4.977 & -7.465 & -8.380 & -8.222 & -5.467 & -3.322 & -1.932 & -0.692 \\
\hline PSPU & 0.214 & 0.423 & -0.419 & -1.446 & -3.355 & -8.293 & -10.314 & -5.995 & -3.011 & -1.354 & -0.833 & 0.180 \\
\hline TSP700 & 0.670 & 0.305 & 0.544 & 0.755 & 0.831 & 1.253 & -0.010 & 1.201 & 1.488 & 1.500 & 0.858 & 0.571 \\
\hline TSP1 & -0.209 & -0.313 & -0.270 & 0.423 & 1.337 & 2.719 & -0.411 & 3.793 & 4.589 & 4.597 & 3.657 & 2.169 \\
\hline GLO_SPN1 & -- & --- & --- & -- & --- & --- & 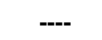 & -6.040 & -4.043 & -1.705 & -0.668 & -0.979 \\
\hline RSR_UNCOR & -- & -1.58 & -2.76 & -3.14 & -2.59 & -2.56 & -3.59 & -2.5 & -2.27 & -0.99 & -1.55 & -0.81 \\
\hline RSR_Corr & -- & -1.13 & -2.42 & -2.54 & -1.42 & -0.48 & -0.78 & 0.08 & -0.32 & 0.53 & -0.30 & 0.34 \\
\hline SP_LITE & 0.798 & 0.569 & 0.823 & 1.039 & 1.182 & 1.182 & 1.393 & 0.743 & 0.982 & 0.921 & 0.021 & 0.809 \\
\hline LI200 & 1.802 & 1.639 & 1.308 & 0.686 & 0.524 & -0.350 & -2.011 & -0.208 & 0.893 & 1.628 & 1.701 & 1.918 \\
\hline
\end{tabular}

As mentioned earlier, the largest contribution to the differences in the winter months is the deviation in response of the instruments as a function of the high zenith angles (greater than $60^{\circ}$ ) in the winter at the location of the Solar Radiation Research Laboratory. 
The diffuse measurements provided by the RSR and SPN1 radiometers were evaluated separately for their relationship to the reference diffuse as shown in Table 3-4 and Figure 3-5.

Table 3-4. Diffuse Horizontal RSR and SPN1 (Mean \% difference in monthly mean daily totals)*

\begin{tabular}{|l|c|l|l|l|l|l|l|l|l|l|l|l||}
\hline & JUN & JUL & AUG & SEP & OCT & NOV & DEC & JAN & FEB & MAR & APR & MAY \\
2007 & 2007 & 2007 & 2007 & 2007 & 2007 & 2007 & 2008 & 2008 & 2008 & 2008 & 2008 \\
\hline \hline $\begin{array}{l}\text { DIFFUSE } \\
\text { REF Wh/m }\end{array}$ & & 1992 & 1770 & 1365 & 1055 & 838 & 814 & 762 & 1214 & 1681 & 1842 & 2260 \\
\hline \hline RSR DIF U \% & --- & -13.22 & -13.42 & -16.10 & -19.35 & -18.82 & -16.19 & -17.88 & -13.14 & -10.85 & -11.61 & -6.35 \\
\hline RSR DIF C \% & --- & -0.64 & -1.06 & -0.40 & 1.31 & 1.47 & $\mathbf{0 . 1 2}$ & $\mathbf{2 . 0 2}$ & $\mathbf{1 . 4 4}$ & $\mathbf{2 . 0 5}$ & $\mathbf{2 . 8 8}$ & $\mathbf{3 . 0 3}$ \\
\hline SPN1 DIF \% & ---- & --- & --- & --- & --- & --- & -- & -- & -12.9 & -11.9 & -11.57 & -10.24 \\
\hline
\end{tabular}

* Month 1 = July 2007; Month 11 = May 2008

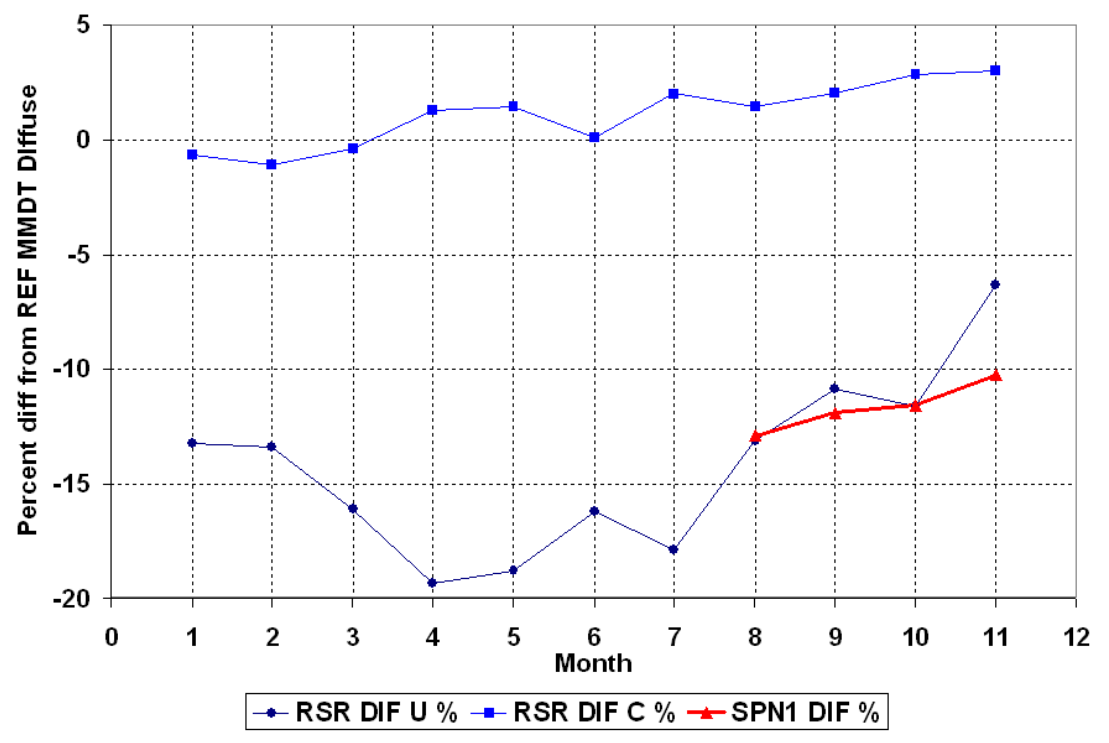

Figure 3-5. Difference between MMDT of Corrected and Uncorrected RSR and SPN1 Diffuse and reference diffuse. Note SPN1 data available only for months 8 to11.

The Corrected RSR Diffuse is typically within 3\% of the reference Diffuse, however the Uncorrected RSR and SPN1 Diffuse readings are significantly low (more than $-10 \%$ ) for all months.

\subsection{Pyrheliometer and Cavity Pyrheliometer Comparisons}

\subsubsection{Cavity pyrheliometer and test pyrheliometer comparison}

The following plots and tables indicate the relative bias and scatter of the data among direct normal measuring instruments with respect to an absolute cavity radiometer reference during scheduled clear-sky calibration events. The uncertainty of the reference instrument (AHF Cavity radiometer) data is nominally $\pm 0.5 \%$, meaning that the bias plots could move up or down by that magnitude and not be significant. Scatter in individual instrument plots within $\pm 0.5 \%$ could be due as much to the reference instrument as the test instrument itself. However, movements in biases relative to other test instruments hold greater significance since each instrument was 
compared against the same reference cavity radiometer data set. All zenith bins are 10 deg wide and the center of bin is the independent variable in plots. Units are percent (\%) deviation from reference irradiance. Tables 3-5, 3-6, and 3-7 show statistics within each zenith angle bin for the differences between the test pyrheliometers and the reference cavity pyrheliometer.

Table 3-5. Kipp \& Zonen $010256 \mathrm{CH} 1 \mathrm{Z}$ angle statistics

$\begin{array}{ccccccc}\begin{array}{l}\text { Zenith } \\ \text { Angle }\end{array} & \begin{array}{c}\text { Count } \\ \text { Bin }\end{array} & \begin{array}{c}\text { Mean } \\ \text { \% }\end{array} & \begin{array}{l}\text { StDev } \\ \text { \% }\end{array} & \begin{array}{l}\text { Maximum } \\ \text { \% }\end{array} & \begin{array}{l}\text { Minimum } \\ \text { \% }\end{array} & \begin{array}{l}\text { Range } \\ \text { \% }\end{array} \\ 15 & 879 & 0.234 & 0.396 & 1.241 & -0.97 & 2.22 \\ 25 & 2107 & 0.115 & 0.419 & 1.442 & -0.98 & 2.42 \\ 35 & 2107 & 0.115 & 0.419 & 1.442 & -0.98 & 2.42 \\ 45 & 2166 & 0.183 & 0.434 & 1.316 & -1.51 & 2.82 \\ 55 & 1847 & 0.150 & 0.441 & 1.342 & -2.30 & 3.64 \\ 65 & 1978 & 0.101 & 0.461 & 1.222 & -4.18 & 5.40 \\ 75 & 1815 & 0.185 & 0.452 & 1.348 & -3.12 & 4.47 \\ 85 & 1698 & 0.222 & 0.479 & 1.780 & -4.96 & 6.74\end{array}$

Table 3-6. Eppley Nip $25792 \mathrm{Z}$ angle statistics

Zenith

$\begin{array}{ccccccc}\begin{array}{l}\text { Angle } \\ \text { Bin }\end{array} & \begin{array}{c}\text { Count } \\ \text { (N) }\end{array} & \begin{array}{l}\text { Mean } \\ \text { \% }\end{array} & \begin{array}{l}\text { StDev } \\ \text { \% }\end{array} & \begin{array}{l}\text { Maximum } \\ \text { \% }\end{array} & \begin{array}{l}\text { Minimum } \\ \text { \% }\end{array} & \begin{array}{c}\text { Range } \\ \text { \% }\end{array} \\ 15 & 879 & -0.284 & 0.494 & 1.230 & -1.66 & 2.90 \\ 25 & 2107 & -0.168 & 0.478 & 1.197 & -1.81 & 3.00 \\ 35 & 2166 & -0.134 & 0.473 & 1.089 & -2.94 & 4.03 \\ 45 & 1847 & 0.0081 & 0.535 & 1.517 & -1.64 & 3.16 \\ 55 & 1978 & 0.1316 & 0.542 & 1.781 & -3.92 & 5.70 \\ 65 & 1815 & 0.3935 & 0.562 & 2.469 & -1.35 & 3.82 \\ 75 & 1697 & 0.7858 & 0.702 & 3.297 & -1.79 & 5.09 \\ 85 & 456 & 1.0388 & 0.799 & 2.828 & -1.21 & 4.04\end{array}$

Table 3-7. Eppley Nip $31137 \mathrm{Z}$ angle statistics

Zenith

$\begin{array}{ccccccc}\begin{array}{c}\text { Angle } \\ \text { Bin }\end{array} & \begin{array}{c}\text { Count } \\ \text { (N) }\end{array} & \begin{array}{l}\text { Mean } \\ \text { \% }\end{array} & \begin{array}{l}\text { StDev } \\ \text { \% }\end{array} & \begin{array}{l}\text { Maximum } \\ \text { \% }\end{array} & \begin{array}{l}\text { Minimum } \\ \text { \% }\end{array} & \begin{array}{l}\text { Range } \\ \text { \% }\end{array} \\ 15 & 879 & -0.528 & 0.351 & 0.422 & -2.46 & 2.88 \\ 25 & 2106 & -0.440 & 0.415 & 0.951 & -1.78 & 2.73 \\ 35 & 2166 & -0.218 & 0.473 & 1.400 & -1.93 & 3.33 \\ 45 & 1847 & -0.055 & 0.547 & 1.454 & -2.33 & 3.79 \\ 55 & 1978 & 0.058 & 0.554 & 1.936 & -4.69 & 6.62 \\ 65 & 1815 & 0.266 & 0.561 & 2.573 & -2.20 & 4.78 \\ 75 & 1698 & 0.458 & 0.603 & 2.665 & -4.42 & 7.09 \\ 85 & 456 & 0.475 & 0.821 & 2.976 & -1.48 & 4.46\end{array}$


Units of all comparisons are percent deviation from the absolute cavity (AHF) reference irradiance

The Direct Normal Irradiance (DNI) comparison was made with only values of the CH1 \& NIP greater than 10 watts to remove very large percentage errors caused by ratios of small numbers.

Figures 3-6 and 3-7 show that the $\mathrm{CH} 1$ demonstrates flat zenith angle response with respect to the reference cavity radiometer and smaller standard deviation over the entire range of zenith angles. The two NIPs have significantly larger mean deviations, which vary by zenith angle; being minimal at low zenith angles and increasing at high zenith angles. The standard deviations of the two NIPs are comparable, and only slightly $(0.1 \%)$ greater then the $\mathrm{CH} 1$ standard deviation.

Figure 3-6 shows the individual deviations from the reference absolute cavity pyrheliometer. The normal baseline monitored data was merged with the cavity radiometer reference data during the clear sky calibration events, and percentage differences between the reference and test irradiances were computed.

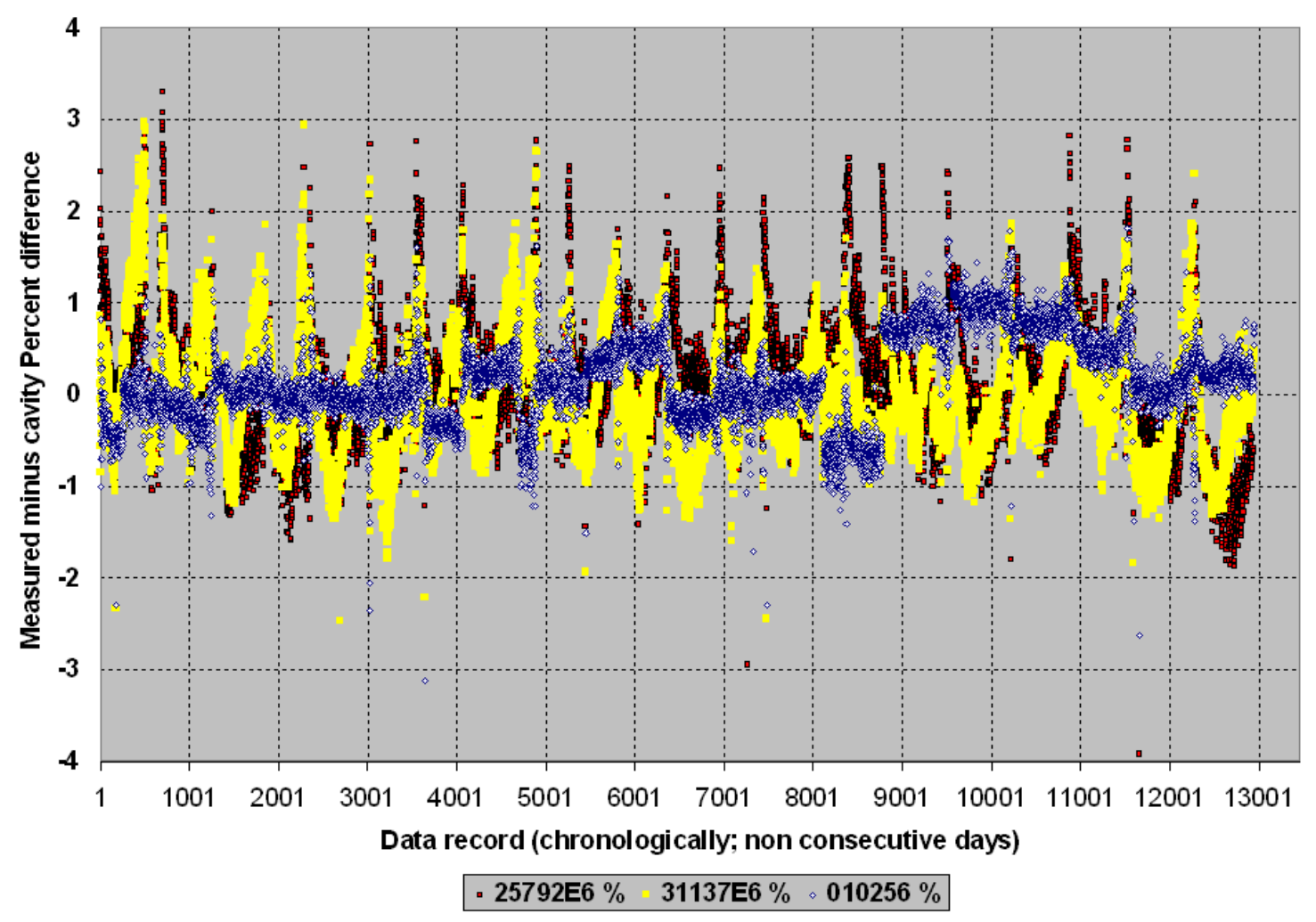

Figure 3-6. Pseudo time series plot of differences between reference AHF cavity radiometer and K\&Z CH1 010256, Eppley NIP 31173E6, and Eppley NIP 257926E6. (Data in chronological order from individual calibration days which may be separated by periods from a week to many months; sometimes indicated by discontinuities.)

Figure 3-7 is the same data as Figure 3-6, but plotted versus time of day for all of the days in Figure 3-6. Note the 'smile' in the NIP data, and rather flatter CH1 curve in Figure 3-7. Figure 3- 
8 shows the variation of the mean percent difference (solid lines) between the reference cavity pyrheliometer and the test pyrheliometers (installed in the baseline monitoring system) as a function of zenith angle bin. The standard deviations of the differences as a function of the zenith angle bin are also shown with the dashed lines. The $\mathrm{CH} 1$ data are almost flat with respect to zenith angle, and the NIP data have increasing differences and standard deviations at increasing zenith angles. The apparent correlation with zenith angle may not be a first-order relationship. There is possibly some other factor causing varying differences in instrument output that also correlates with zenith angle.

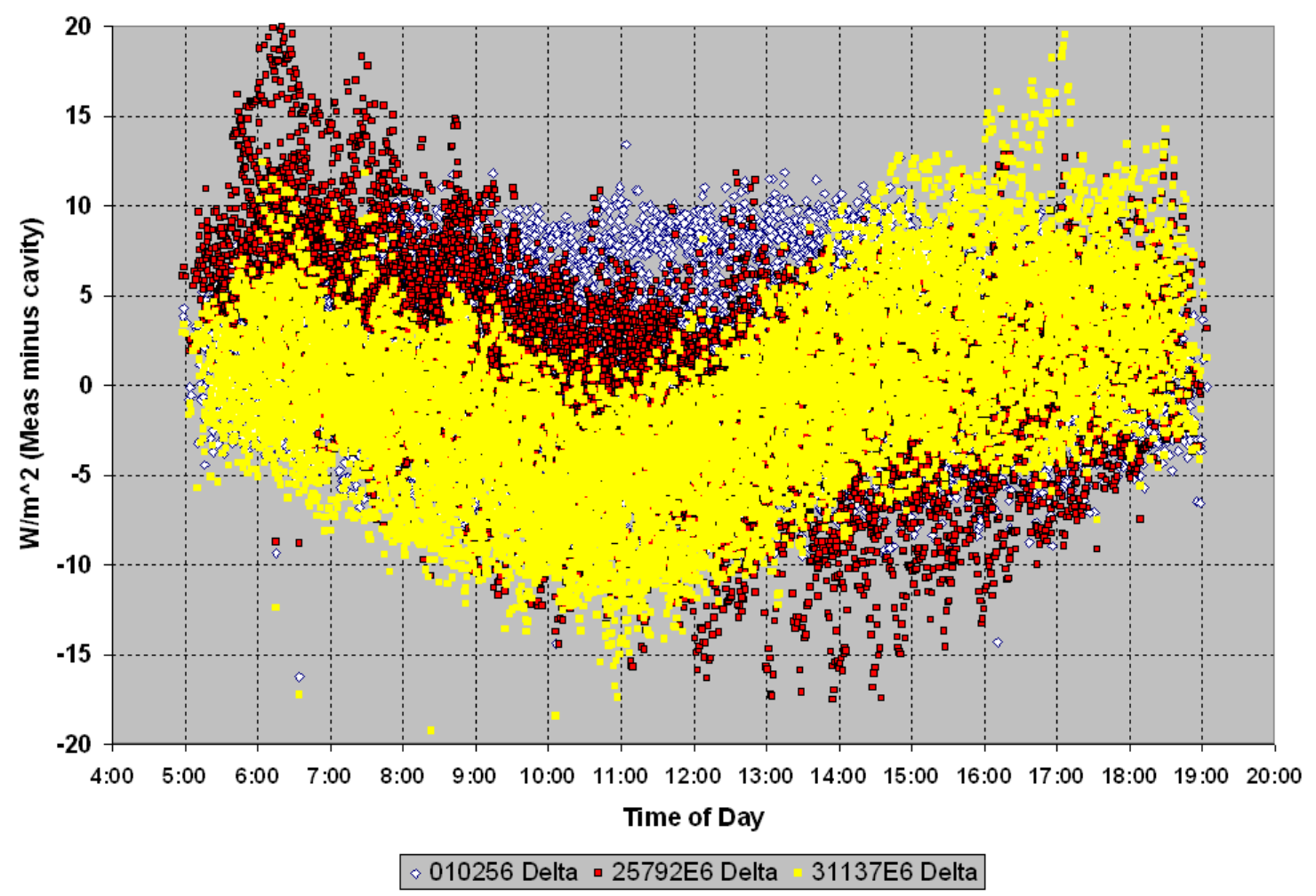

Figure 3-7. Differences in W/m² between reference AHF cavity radiometer and Kipp CH1 010256 , Eppley NIP 31173E6, and Eppley NIP 25792E6 during broadband calibrations as function of time of day. 


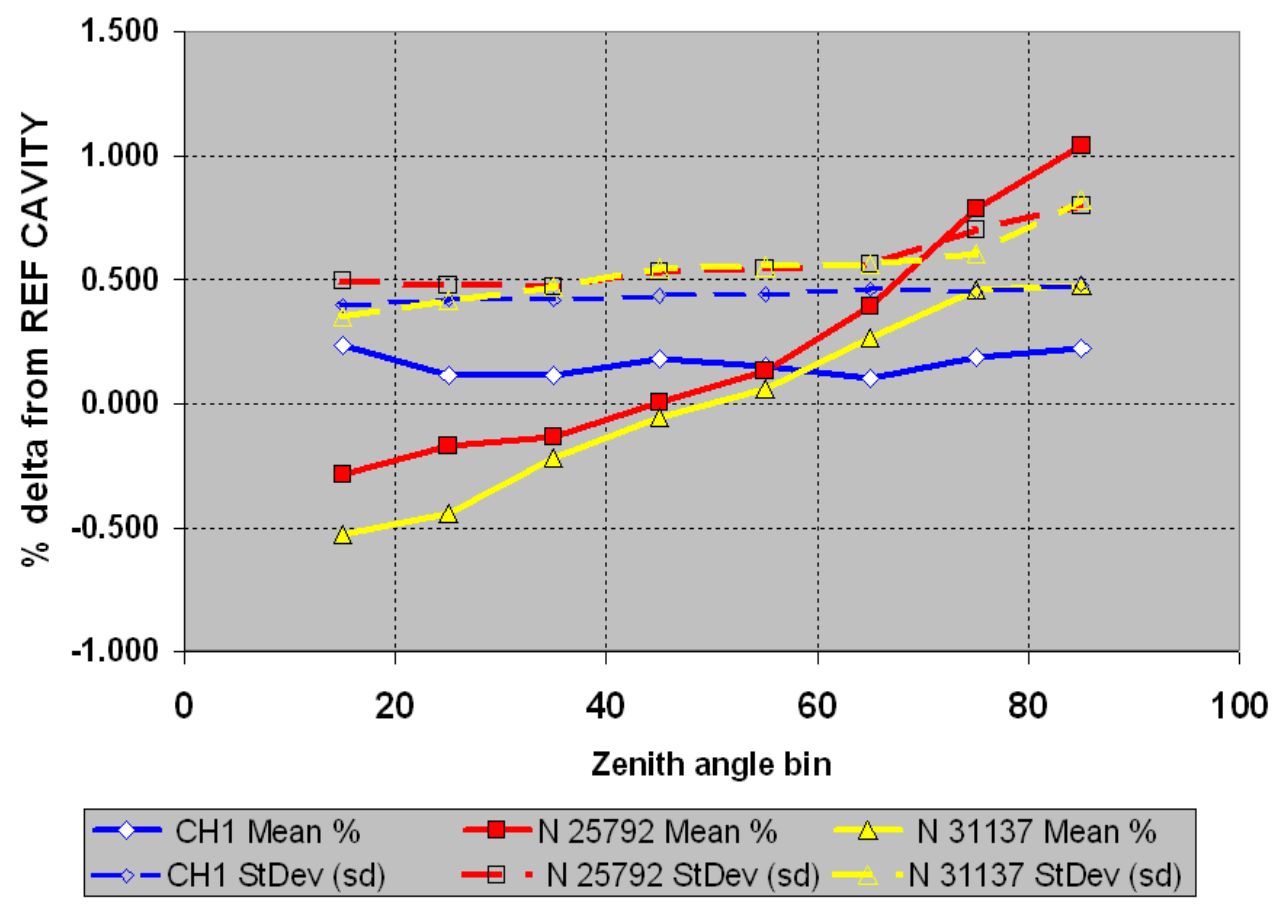

Figure 3-8. Percent differences between the three test instruments and reference cavity pyrheliometer as function of zenith angle bins during BORCAL. Means and standard deviations (1 sigma, also in percent) for each $10^{\circ}$ zenith angle bin shown at center of bin.

\subsubsection{Test Direct Normal Data Comparison with CH1 Pyrheliometer}

We conducted a separate study of the relationship between the Eppley, Kipp and Zonen, and three other direct beam irradiances derived from two other instruments over the period from June 2007 to May 2008. This study used the 1 minute monitored data. Eppley NIP 31137, Kipp and Zonen CH1 010256, direct beam from an Irradiance, Inc. rotating shadowband radiometer (RSR), and a Delta-T, Inc. SPN1 radiometer were studied. The RSR data is provided in two forms, with and without corrections for spectral and cosine effects. The correction scheme is provided by the manufacturer. The SPN1 direct beam data is computed from shaded (Diffuse) and unshaded (global) sensors mounted in the SPN1 instrument, using the manufacturer's calibration factor. The following table 3.8 and Figure 3.9 show percent differences from the $\mathrm{CH} 1$ data in monthly mean daily totals (MMDT) for the other DNI instruments 
Table 3-8. Direct Normal Comparison Eppley NIP, RSR and SPN1 with CH1 (mean percent difference in MMDT) by month; month 1 = JULY 2007; month 11 = MAY 2008

\begin{tabular}{|c|c|c|c|c|c|c|c|c|c|c|c|c|}
\hline & $\begin{array}{l}\text { JUN } \\
2007 \\
\end{array}$ & $\begin{array}{l}\text { JUL } \\
2007\end{array}$ & $\begin{array}{l}\text { AUG } \\
2007\end{array}$ & $\begin{array}{l}\text { SEP } \\
2007\end{array}$ & $\begin{array}{l}\text { OCT } \\
2007\end{array}$ & $\begin{array}{l}\text { NOV } \\
2007\end{array}$ & $\begin{array}{l}\text { DEC } \\
2007\end{array}$ & $\begin{array}{l}\text { JAN } \\
2008\end{array}$ & $\begin{array}{l}\text { FEB } \\
2008\end{array}$ & $\begin{array}{l}\text { MAR } \\
2008\end{array}$ & $\begin{array}{l}\text { APR } \\
2008 \\
\end{array}$ & $\begin{array}{l}\text { MAY } \\
2008\end{array}$ \\
\hline $\begin{array}{l}\text { DIRECT } \\
\text { CH1 } \\
\text { MMDT } \\
\text { Whm }^{-2}\end{array}$ & 7063 & 6109 & 5540 & 5322 & 5936 & 5021 & 4072 & 4922 & 4799 & 5140 & 6648 & 5189 \\
\hline $\begin{array}{l}\text { Eppley } \\
\text { NIP \% } \%\end{array}$ & -0.33 & 1.15 & -0.28 & -0.18 & -0.03 & 0.42 & 0.05 & -0.21 & 0.27 & 0.39 & -0.33 & ---- \\
\hline $\begin{array}{l}\text { RSR DIR } \\
\mathrm{U} \% \Delta\end{array}$ & ---- & 3.37 & 2.74 & 1.46 & 1.47 & 0.45 & 0.76 & 2.99 & -2.07 & -1.46 & -0.64 & 1.80 \\
\hline $\begin{array}{l}\text { RSR DIR } \\
\text { C } \% \Delta\end{array}$ & ---- & -0.59 & -3.74 & -4.58 & -4.19 & -5.13 & -3.86 & -3.90 & -7.28 & -8.81 & -4.60 & -4.00 \\
\hline $\begin{array}{l}\text { SPN1 } \\
\text { DIR \% } \%\end{array}$ & ---- & ---- & ---- & ---- & ---- & ---- & ---- & ---- & -7.59 & +3.89 & +15.42 & +6.00 \\
\hline
\end{tabular}

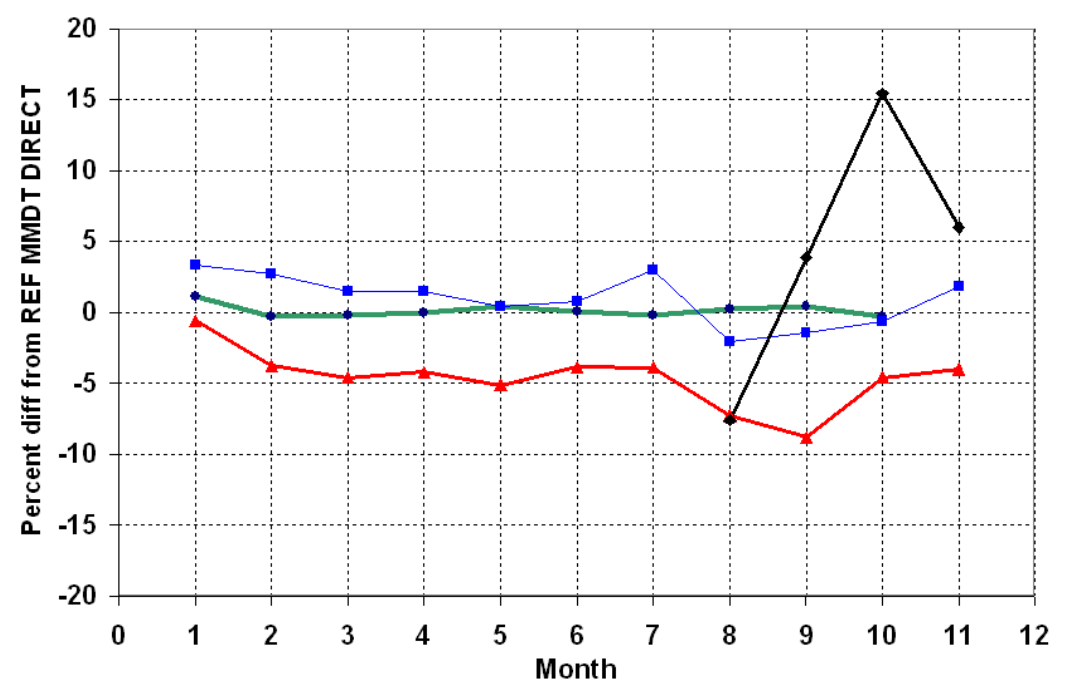

Eppley NIP \% -RSR DIR U \% ־RSR DIR C \% $\rightarrow$ SPN1 DIR \%

Figure 3-9. Percent difference in Monthly Mean Daily Totals for NIP, SPN1, RSR Corrected and Uncorrected from the Kipp and Zonen $\mathrm{CH} 1010256$. 
Table 3-9. Average percent differences between NIP 1 and $\mathrm{CH} 1$ one-minute data by 10 degree zenith angle bin over 11 months (169538 pts) Month 1 = JULY 2007; Month 11 = MAY 2008

$\begin{array}{ccccccc}\begin{array}{l}\text { Zenith } \\ \text { angle } \\ \text { bin }\end{array} & \begin{array}{c}\text { Count } \\ \text { (N) }\end{array} & \begin{array}{l}\text { Mean } \\ \text { \% }\end{array} & \begin{array}{c}\text { StDev } \\ \text { (sd) }\end{array} & \begin{array}{l}\text { Maximum } \\ \text { \% }\end{array} & \begin{array}{l}\text { Minimum } \\ \text { \% }\end{array} & \begin{array}{c}\text { Range } \\ 15\end{array} \\ 4447 & -0.20 & 1.71 & 9.93 & -3.91 & 13.84 \\ 25 & 14162 & 0.01 & 2.21 & 10.00 & -80.10 & 90.10 \\ 35 & 17701 & 0.11 & 2.13 & 10.00 & -26.89 & 36.89 \\ 45 & 21586 & 0.14 & 1.91 & 9.99 & -13.86 & 23.85 \\ 55 & 28766 & 0.23 & 1.96 & 10.00 & -62.44 & 72.44 \\ 65 & 36135 & 0.33 & 2.06 & 10.00 & -60.12 & 70.12 \\ 75 & 27069 & 0.37 & 1.83 & 10.00 & -14.41 & 24.41 \\ 85 & 19672 & 0.06 & 1.83 & 9.98 & -41.68 & 51.67\end{array}$

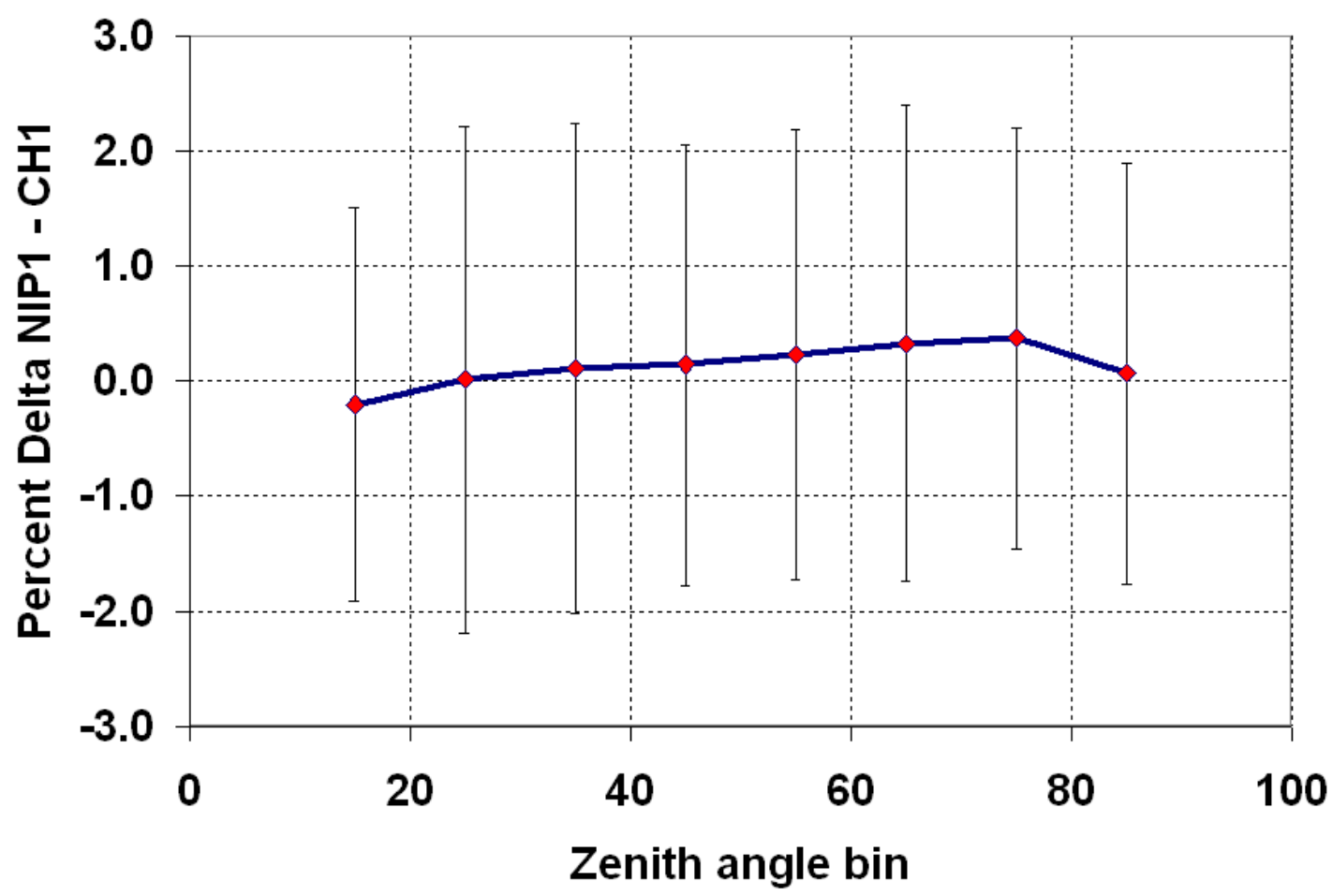

Figure 3-10. Average (dots) and standard deviation (1 sigma error bars) of percent difference between NIP 31137 and CH1 by zenith angle over 11 months (169538 pts).

Figure 3-11 shows a histogram of the percent difference between the NIP 31137 and the CH1 pyrheliometers for the 1-minute sub-hourly data over the 11 month period from July 2007 to May 2008. The mean difference is $0.2 \%$ with a standard deviation of $\pm 1.98 \%$. This implies that over the year, the NIP and $\mathrm{CH} 1$ produce nearly identical average irradiances, but with a variation through the year of about $\pm 2 \%$ ( 1 sigma) between the two. Figures 3.6 and 3.7 suggest the variation is mostly due to responsivity variations in the NIP instruments. 


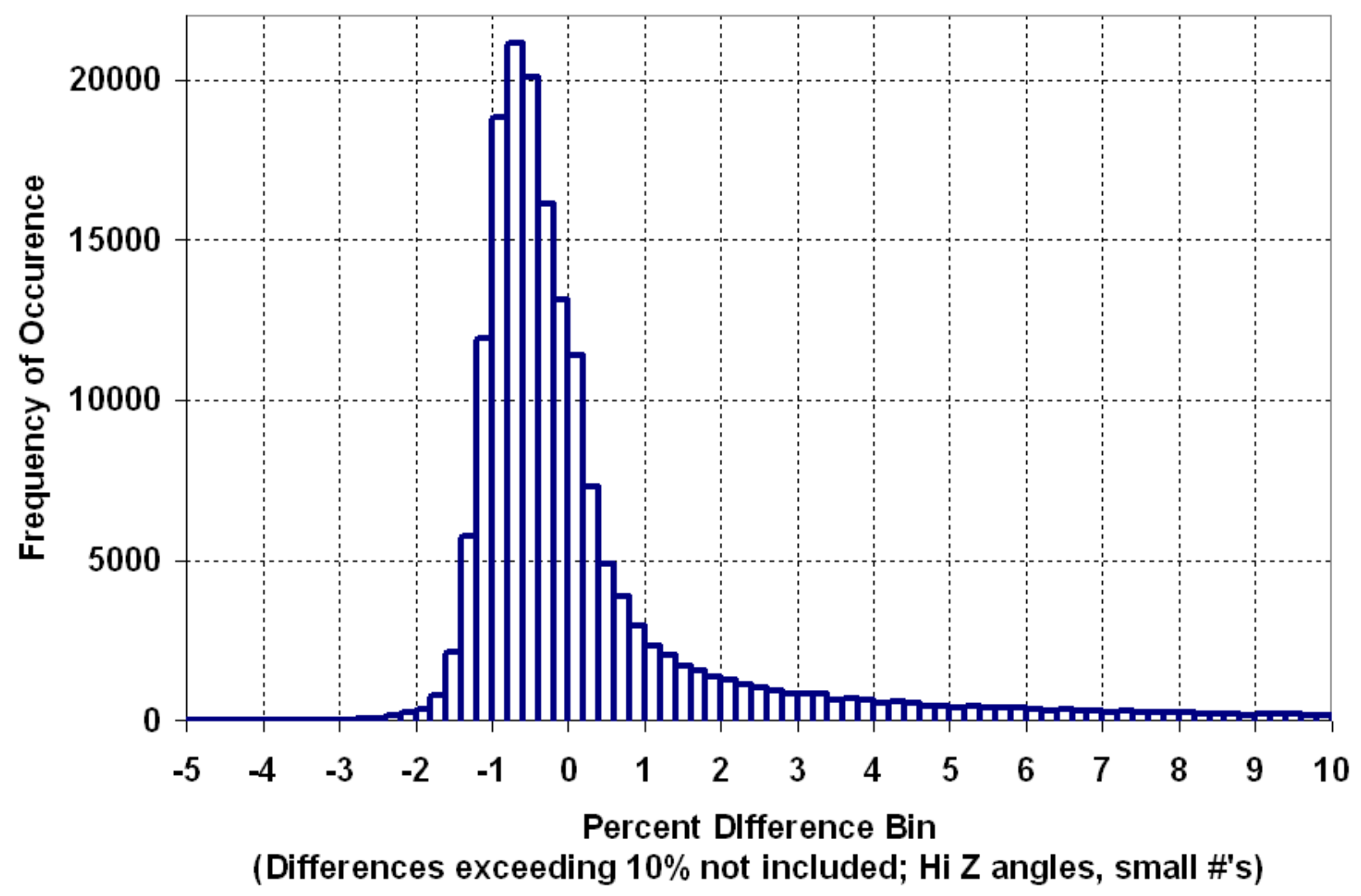

Figure 3-11. Histogram of percent differences between NIP $31137 \mathrm{E} 6$ and $\mathrm{CH} 1$ over all Zenith angles. Mean value of percent difference is $0.20 \%$, standard deviation of $1.98 \%$

\section{Summary}

This study shows that at the NREL SRRL location, for pyranometer data based on a single calibration factor (sometimes in combination with corrections for cosine response and infrared offsets) there is agreement to better than 5\% for all of pyranometers for zenith angles in the range of $30^{\circ}$ to $60^{\circ}$ on a minute by minute basis. However, the various different cosine response curves for the radiometers, in conjunction with a single responsivity assignment (at $45^{\circ}$ zenith angle $\pm 0.2^{\circ}$ ) leads to lack of agreement, exceeding $10 \%$ or $20 \%$ at $70^{\circ}$ zenith angle, and more than $20 \%$ at $80^{\circ}$ zenith angles. Correction and ventilation techniques applied to the data or instruments may not always improve the situation, but rather may add additional sources of uncertainty to the data. The $\pm 5 \%$ range of agreement observed for zenith angles less than $60^{\circ}$ is typical of the quoted uncertainty in sub-hourly pyranometer data over the past 30 years.

Averaging (hourly, daily totals and averages, monthly mean and annual mean daily totals) may help cancel out some of the random variability between instruments. However, as Figure 3.4 demonstrates, there is still the possibility of differences exceeding $5 \%$ among this family of instruments. There are differences (up to $\pm 2 \%$ ) in the responsivity of pyrheliometers from the two different manufacturers' instruments evaluated here. An investigation is ongoing as to the sources of these differences. The design of the instruments and susceptibility to environmental influences are being studied. The $\pm 2 \%$ differences observed among thermopile pyrheliometers, 
including with respect to an absolute cavity pyrheliometer (basic uncertainty $\pm 0.5 \%$ ) is in accordance with the long standing quote of $\pm 2 \%$ uncertainty in direct normal irradiance instruments. 


\section{$5 \quad$ References}

[1] WMO (1996). International Pyrheliometer Comparison VIII. World Meteorological Organization, Geneva, Switzerland.

[2], Maxwell, E.; Wilcox, S.; Rymes, M. (1993). Users Manual for SERI_QC Software: Assessing the Quality of Solar Radiation Data. NREL/TP-463-5608. Golden CO: National Renewable Energy Laboratory.

[3] Myers, D. R.; Stoffel, T. L.; Reda, I.; Wilcox, S. M.; Andreas, A. M. (2002). "Recent Progress in Reducing the Uncertainty in and Improving Pyranometer Calibrations." ASME Journal of Solar Energy Engineering (124:1); pp. 44-50.

[4] Reda, I.; Stoffel, T. L.; Myers, D. R. (1996). Calibration of a Solar Absolute Cavity Radiometer with Traceability to the World Radiometric Reference. NREL/TP-463-20619. Golden CO: National Renewable Energy Laboratory. 


\section{Appendices}

\section{Appendix A—Instrument List}

Table A-1. The instruments evaluated and calibration uncertainties.

\begin{tabular}{|c|c|c|c|c|c|}
\hline Model & Manufacturer & Serial \# & $\begin{array}{l}\text { Installation } \\
\text { Period }\end{array}$ & $\begin{array}{l}\text { Rs @45 } \\
v \mathrm{~V} / \mathrm{W} / \mathrm{m}^{2}\end{array}$ & $\begin{array}{c}\text { CALIBRATION Uncertainty } \\
\%\left[30^{\circ} \leq \mathrm{Z} \leq 60^{\circ}\right]\end{array}$ \\
\hline \multirow[t]{3}{*}{$\begin{array}{l}\text { CM22 (AC } \\
\text { Ventilated) }\end{array}$} & Kipp \& Zonen & 010034 & $\begin{array}{l}06-01-07 \text { to } \\
06-13-07\end{array}$ & 10.896 & $+1.85 /-1.37 \%$ \\
\hline & & 010046 & $\begin{array}{l}06-13-07 \text { to } \\
05-23-08\end{array}$ & 9.3009 & $+1.92 /-1.17 \%$ \\
\hline & & 010034 & $\begin{array}{l}05-23-08 \text { to } \\
05-31-08\end{array}$ & 10.904 & $+1.81 /-1.50 \%$ \\
\hline \multirow[t]{2}{*}{ CM6B } & Kipp \& Zonen & 015189 & $\begin{array}{l}06-01-07 \text { to } \\
06-08-07\end{array}$ & 10.871 & $+2.53 /-1.09 \%$ \\
\hline & & & $\begin{array}{l}06-08-07 \text { to } \\
05-31-08\end{array}$ & 10.912 & $+1.98 /-1.59 \%$ \\
\hline CM3 & Kipp \& Zonen & 010284 & $\begin{array}{l}06-01-07 \text { to } \\
05-31-08\end{array}$ & 9.234 & $\pm 5 \%(?)$ \\
\hline \multirow[t]{3}{*}{ PSP } & Eppley Laboratory & $25782 F 3$ & $\begin{array}{l}06-01-07 \text { to } \\
06-13-07\end{array}$ & 8.8793 & $+3.30 /-4.49 \%$ \\
\hline & & & $\begin{array}{l}06-13-07 \text { to } \\
05-23-08\end{array}$ & 8.8568 & $+2.98 /-5.38 \%$ \\
\hline & & & $\begin{array}{l}05-23-08 \text { to } \\
05-31-08\end{array}$ & 8.7834 & $+3.16 /-5.67 \%$ \\
\hline \multirow[t]{3}{*}{ PSP Corrected ${ }^{1}$} & Eppley Laboratory & $25782 F 3$ & $\begin{array}{l}06-01-07 \text { to } \\
06-13-07\end{array}$ & 9.0368 & $+2.87 /-3.92 \%$ \\
\hline & & & $\begin{array}{l}\text { 06-13-07 to } \\
05-23-08\end{array}$ & 9.0005 & $+2.68 /-4.71 \%$ \\
\hline & & & $\begin{array}{l}\text { 05-23-08 to } \\
05-31-08\end{array}$ & 8.9422 & $+2.78 /-4.65 \%$ \\
\hline \multirow[t]{3}{*}{ PSP (AC Ventilated) } & Eppley Laboratory & $28402 \mathrm{~F} 3$ & $\begin{array}{l}06-01-07 \text { to } \\
06-13-07\end{array}$ & 6.9504 & $+2.24 /-2.85 \%$ \\
\hline & & & $\begin{array}{l}06-13-07 \text { to } \\
05-23-08\end{array}$ & 6.9276 & $+2.37 /-2.88 \%$ \\
\hline & & & $\begin{array}{l}\text { 05-23-08 to } \\
05-31-08\end{array}$ & 6.8796 & $+2.09 /-4.43 \%$ \\
\hline \multirow{3}{*}{$\begin{array}{l}\text { PSP (AC Ventilated) } \\
\text { Corrected } \\
\text { Zenith correction and } \\
\text { Vc }=V-\text { Wnet } * \text { RSnet }\end{array}$} & Eppley Laboratory & $28402 F 3$ & $\begin{array}{l}06-01-07 \text { to } \\
06-13-07\end{array}$ & 7.0901 & $+1.87 /-2.29 \%$ \\
\hline & & & $\begin{array}{l}\text { 06-13-07 to } \\
05-23-08\end{array}$ & 7.0557 & $+2.05 /-2.03 \%$ \\
\hline & & & $\begin{array}{l}05-23-08 \text { to } \\
05-31-08\end{array}$ & 7.0131 & $+1.72 /-3.56 \%$ \\
\hline \multirow[t]{3}{*}{$\begin{array}{l}\text { TSP700 (AC } \\
\text { Ventilated) }\end{array}$} & YES, Inc. & $0212-02$ & $\begin{array}{l}06-01-07 \text { to } \\
06-13-07\end{array}$ & 2876.5 & $+1.40 /-1.04 \%$ \\
\hline & & & $\begin{array}{l}\text { 06-13-07 to } \\
05-23-08\end{array}$ & 2908.5 & $+1.22 /-1.37 \%$ \\
\hline & & & $\begin{array}{l}\text { 05-23-08 to } \\
05-31-08\end{array}$ & 2919.2 & $+1.53 /-1.66 \%$ \\
\hline \multirow[t]{3}{*}{ TSP1 } & YES, Inc. & 940703 & $\begin{array}{l}06-01-07 \text { to } \\
06-13-07\end{array}$ & 2004.1 & $+1.91 /-1.76 \%$ \\
\hline & & & $\begin{array}{l}06-13-07 \text { to } \\
05-23-08\end{array}$ & 2000.1 & $+1.68 /-2.44 \%$ \\
\hline & & & $\begin{array}{l}\text { 05-23-08 to } \\
05-31-08\end{array}$ & 2026.7 & $+1.93 /-2.58 \%$ \\
\hline SPN1 & Delta-T & A168 & $\begin{array}{l}08-23-07 \text { to } \\
05-23-08\end{array}$ & 1000.0 & $\pm 4 \%(?)$ \\
\hline (GLO/DIR/DIF) & & & $\begin{array}{l}05-23-08 \text { to } \\
05-31-08\end{array}$ & 976.01 & $+4.30 /-2.37 \%$ \\
\hline
\end{tabular}




\begin{tabular}{|c|c|c|c|c|c|}
\hline Model & Manufacturer & Serial \# & $\begin{array}{l}\text { Installation } \\
\text { Period }\end{array}$ & $\begin{array}{l}\text { Rs @45 } \\
\mathrm{vV} / \mathrm{W} / \mathrm{m}^{2}\end{array}$ & $\begin{array}{c}\text { CALIBRATION Uncertainty } \\
\%\left[30^{\circ} \leq \mathrm{Z} \leq 60^{\circ}\right]\end{array}$ \\
\hline \multirow[t]{3}{*}{ SP_LITE } & Kipp \& Zonen & 970003 & $\begin{array}{l}06-01-07 \text { to } \\
06-13-07\end{array}$ & 85.298 & $+1.21 /-1.96 \%$ \\
\hline & & & $\begin{array}{l}06-13-07 \text { to } \\
05-23-08\end{array}$ & 85.304 & $+1.80 /-1.75 \%$ \\
\hline & & & $\begin{array}{l}05-23-08 \text { to } \\
05-31-08\end{array}$ & 84.948 & $+1.63 /-2.05 \%$ \\
\hline \multirow[t]{2}{*}{ LII-200 } & Li-Cor & PY28257 & $\begin{array}{l}06-01-07 \text { to } \\
06-13-07\end{array}$ & 13.144 & $+3.06 /-4.50 \%$ \\
\hline & & & $\begin{array}{l}06-13-07 \text { to } \\
05-31-08\end{array}$ & 13.292 & $+3.11 /-5.51 \%$ \\
\hline RSR2 Uncorrected & Irradiance, Inc. & PY37627 & Jun 07-May08 & 10.35 & $+/-5 \%($ not stated $)$ \\
\hline RSR2 Corrected & (GLO/DIR/DIF) & PY37627 & Jun 07-May08 & 10.35 & $+/-5 \%$ (not stated) \\
\hline
\end{tabular}

${ }^{1}$ Non-standard correction using ventilated pyrgeometer 


\section{Appendix B-Global and Diffuse Radiometer Evaluation Detailed Results}

The following plots and tables indicate the relative bias and scatter of the data among instruments. The uncertainty of the reference instrument data is stated in this report as nominally $\pm 2.5 \%$, meaning that the bias plots could move up or down by that magnitude and not be significant. Scatter in individual instrument plots within $\pm 2.5 \%$ could be due as much to the reference instruments as the test instrument itself. However, movements in biases relative to other test instruments hold greater significant since each instrument was compared against the same reference data set.

The section below contains a statistical summary for each instrument, one instrument per page. For each instrument:

- Sub-hourly (1-minute) percent differences versus zenith angle, average and standard deviation percent differences in $10^{\circ}$ wide zenith angle bins and percent differences in daily total irradiance between the reference (computed) global irradiance and test instrument data are shown as a function of zenith angle, zenith angle bin, and date, respectively. Error bars represent the standard deviations of the means. No data where the difference exceeded $100 \%$ in absolute value is included in the statistics mainly to avoid issues with small irradiance values. These time scale measurements are useful for many applications requiring analysis of the resource throughout the entire day.

- Table presenting the numerical data in the first graph.

- A presentation of the entire 1 minute data set of differences between measured and reference irradiances as a function of zenith angles (within plot limits of $\pm 25 \%$ for graph clarity).

- Time series presentation of the daily total data as percent difference between test and reference instruments. This measurement is useful for applications requiring measurements on a daily time scale without regard to hourly or sub-hourly variations. 


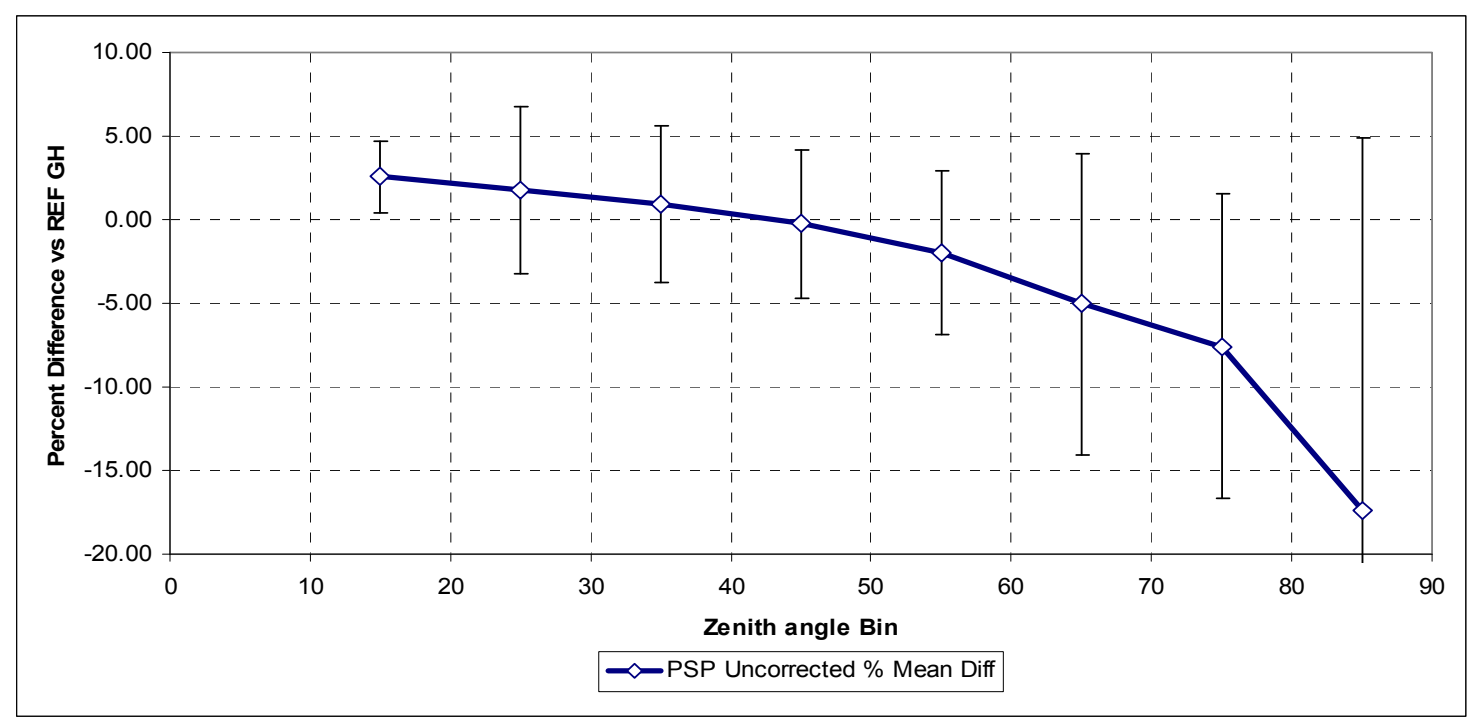

Figure B-1. Uncorrected Eppley PSP: PSP 25782F3

Table B-1. Statistical summary 1-minute data by zenith angle bin PSP $25782 \mathrm{F3}$

\begin{tabular}{|c|c|c|c|c|c|c|}
\hline PSP_U & $\begin{array}{c}\text { Count } \\
\text { (N) }\end{array}$ & $\begin{array}{c}\text { PSP } \\
\text { Uncorrected } \\
\text { \% Mean Diff }\end{array}$ & $\begin{array}{c}\text { StDev } \\
\text { (sd) }\end{array}$ & Maximum & Minimum & Range \\
\hline 15 & 5497 & 2.572 & 2.109 & 41.9 & -28.4 & 70.3 \\
\hline 25 & 19111 & 1.729 & 4.995 & 32.4 & -72.6 & 105.0 \\
\hline 35 & 24260 & 0.921 & 4.657 & 70.1 & -77.5 & 147.5 \\
\hline 45 & 30018 & -0.232 & 4.410 & 29.9 & -77.1 & 107.0 \\
\hline 55 & 39487 & -1.997 & 4.895 & 66.3 & -75.4 & 141.8 \\
\hline 65 & 50754 & -5.047 & 8.973 & 69.3 & -79.9 & 149.2 \\
\hline 75 & 40634 & -7.567 & 9.139 & 63.5 & -80.4 & 143.9 \\
\hline 85 & 39182 & -17.357 & 22.251 & 99.8 & -99.9 & 199.7 \\
\hline
\end{tabular}

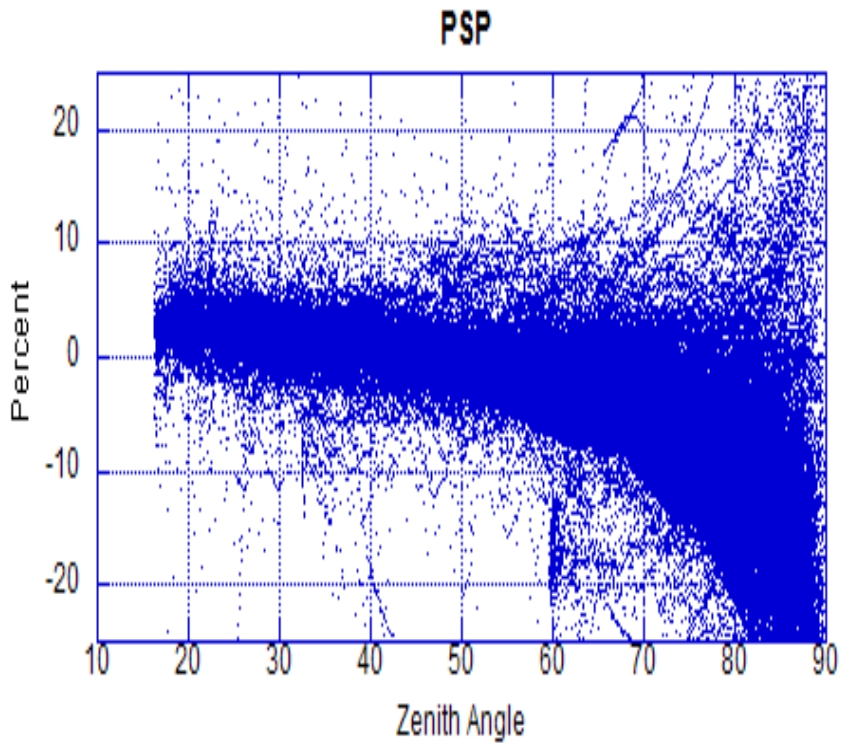

Figure B-1(a). One-minute data set percent differences; PSP Uncorrected

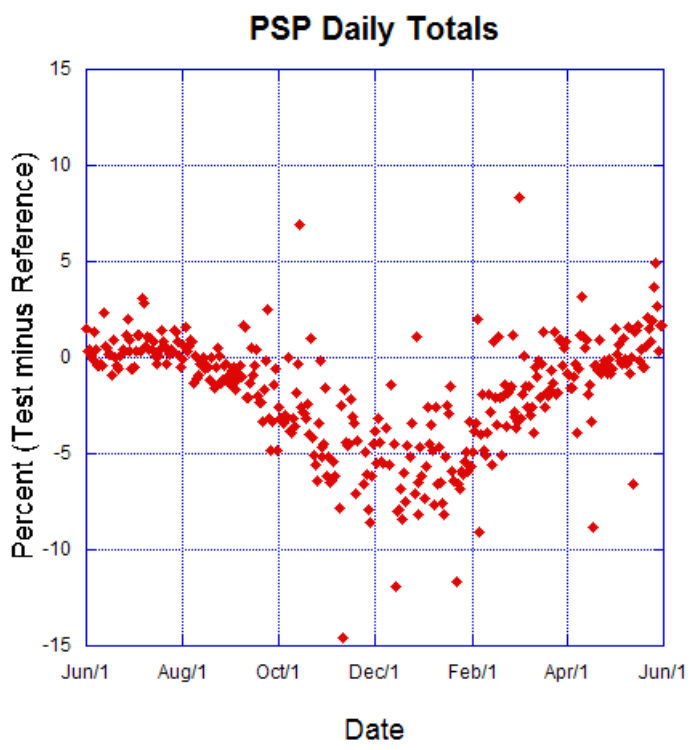

Figure B-1(b). Daily total percent difference; PSP Uncorrected 


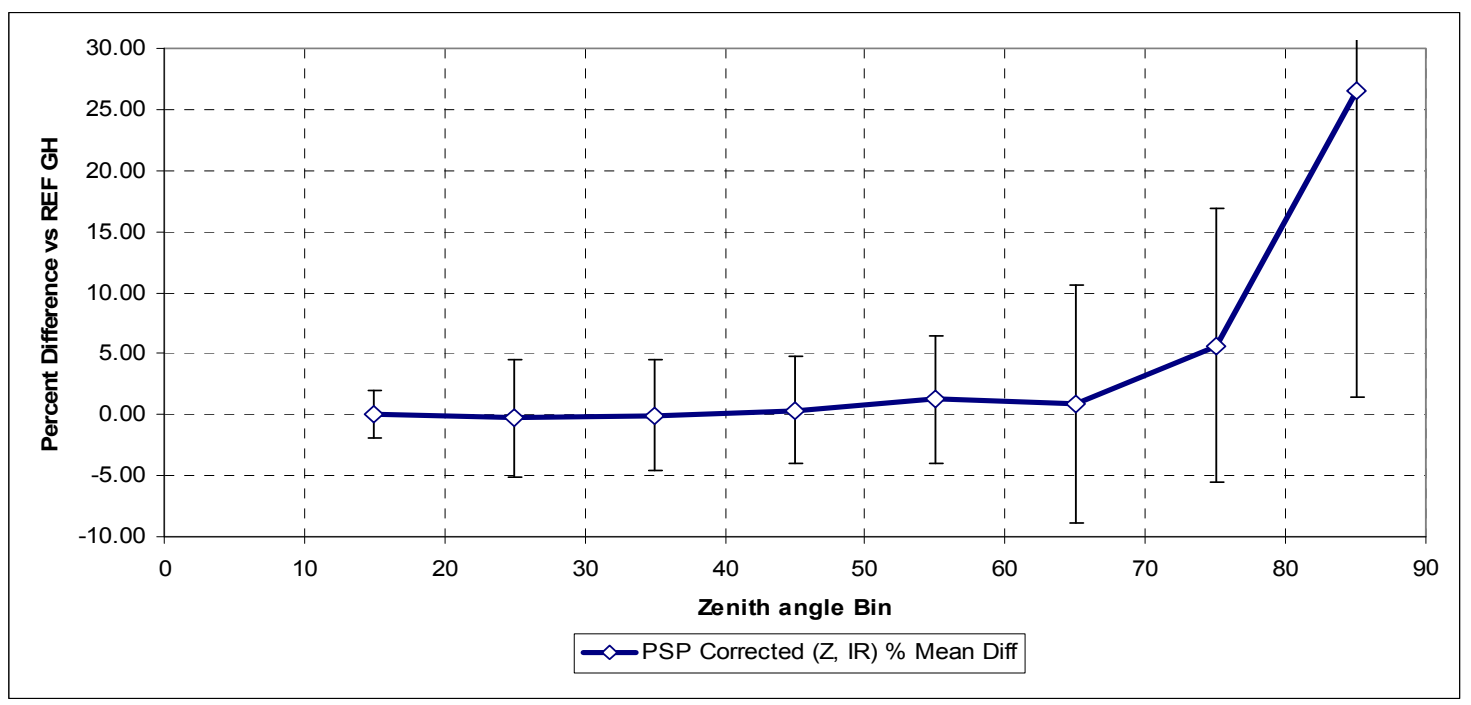

Figure B-2. Corrected Eppley PSP (Corrected for Z angle response and IR offset) PSP_C 25782F3

Table B-2. Statistical summary 1-minute data by zenith angle bin PSP 25782F3 (Corrected)

\begin{tabular}{|c|c|c|c|c|c|c|}
\hline PSP_C & $\begin{array}{c}\text { Count } \\
\mathbf{( N )}\end{array}$ & $\begin{array}{c}\text { PSP } \\
\text { Corrected } \\
(\mathbf{Z}, \mathbf{I R}) \text { \% } \\
\text { Mean Diff }\end{array}$ & $\begin{array}{c}\text { StDev } \\
(\mathbf{s d})\end{array}$ & Maximum & Minimum & Range \\
\hline 15 & 5497 & 0.069 & 1.958 & 39.0 & -29.7 & 68.7 \\
\hline 25 & 19111 & -0.284 & 4.822 & 30.4 & -73.1 & 103.5 \\
\hline 35 & 24260 & -0.060 & 4.527 & 72.2 & -77.7 & 149.9 \\
\hline 45 & 30018 & 0.372 & 4.443 & 32.6 & -77.2 & 109.8 \\
\hline 55 & 39487 & 1.221 & 5.168 & 68.7 & -73.1 & 141.8 \\
\hline 65 & 50753 & 0.877 & 9.774 & 79.2 & -76.5 & 155.7 \\
\hline 75 & 40634 & 5.679 & 11.251 & 86.0 & -76.5 & 162.5 \\
\hline 85 & 36205 & 26.580 & 25.118 & 100.0 & -96.1 & 196.0 \\
\hline
\end{tabular}

PSP (Corrected)

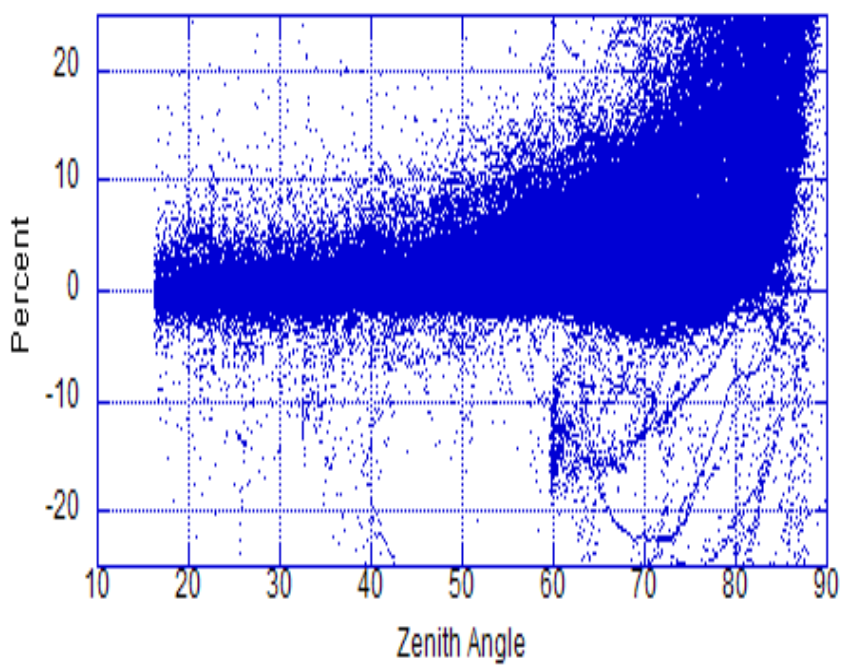

Figure B-2(a). One-minute data set percent differences. PSP, Corrected.

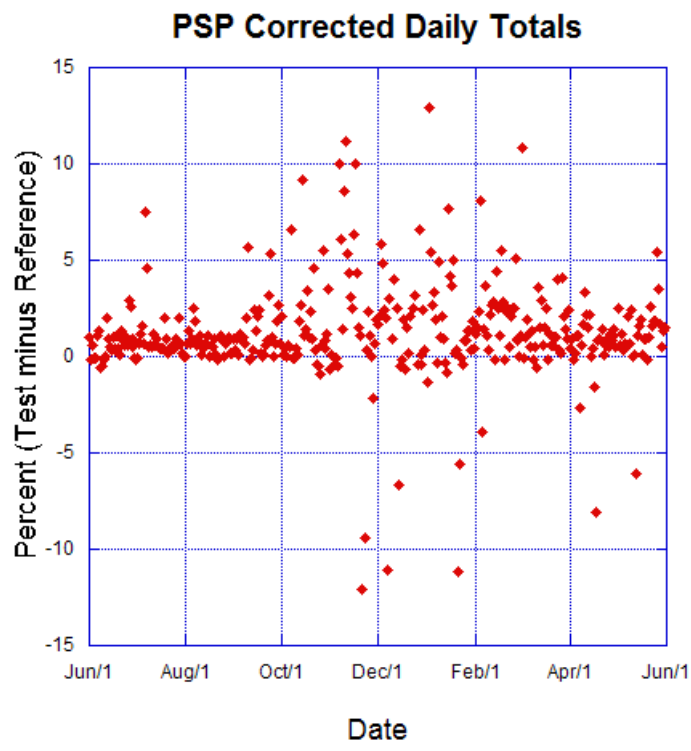

Figure B-2(b). Daily total percent difference; PSP, Corrected. 


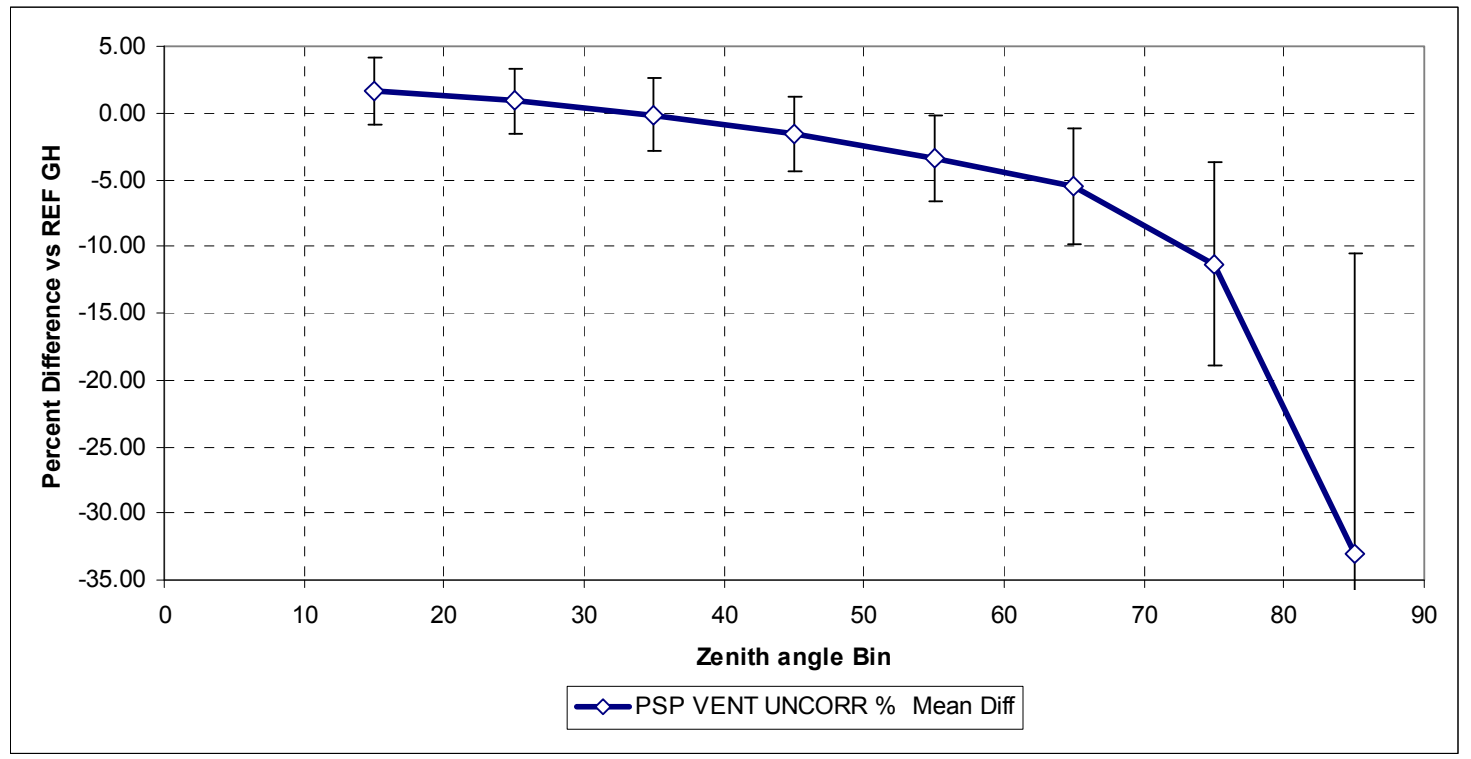

Figure B-3. PSP Ventilated Uncorrected 28402F3

Table B-3. Statistical summary 1-minute data by zenith angle bin PSP 28402F3 (Ventilated, Uncorrected)

\begin{tabular}{|c|c|c|c|c|c|c|}
\hline PSP_V_U & $\begin{array}{c}\text { Count } \\
(\mathbf{N})\end{array}$ & $\begin{array}{c}\text { PSP VENT } \\
\text { UNCOR\% } \\
\text { Mean Diff }\end{array}$ & $\begin{array}{c}\text { StDev } \\
(\mathbf{s d})\end{array}$ & Maximum & Minimum & Range \\
\hline 15 & 5497 & 1.603 & 2.503 & 39.1 & -28.1 & 67.2 \\
\hline 25 & 19111 & 0.912 & 2.429 & 29.6 & -24.1 & 53.7 \\
\hline 35 & 24260 & -0.148 & 2.711 & 64.3 & -28.0 & 92.3 \\
\hline 45 & 30018 & -1.564 & 2.768 & 27.0 & -38.8 & 65.8 \\
\hline 55 & 39487 & -3.390 & 3.229 & 62.5 & -53.5 & 116.0 \\
\hline 65 & 50754 & -5.490 & 4.340 & 65.8 & -73.2 & 139.0 \\
\hline 75 & 40614 & -11.305 & 7.629 & 19.0 & -99.6 & 118.5 \\
\hline 85 & 33743 & -33.084 & 22.538 & 99.2 & -99.9 & 199.2 \\
\hline
\end{tabular}

PSP Ventilated

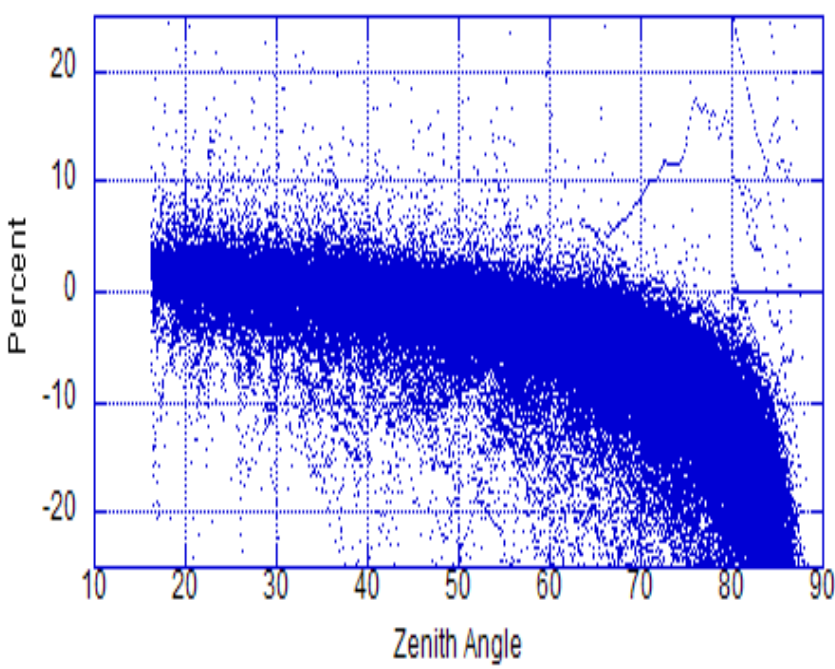

Figure B-3(a). One-minute data set percent differences; PSP, Ventilated, Uncorrected.

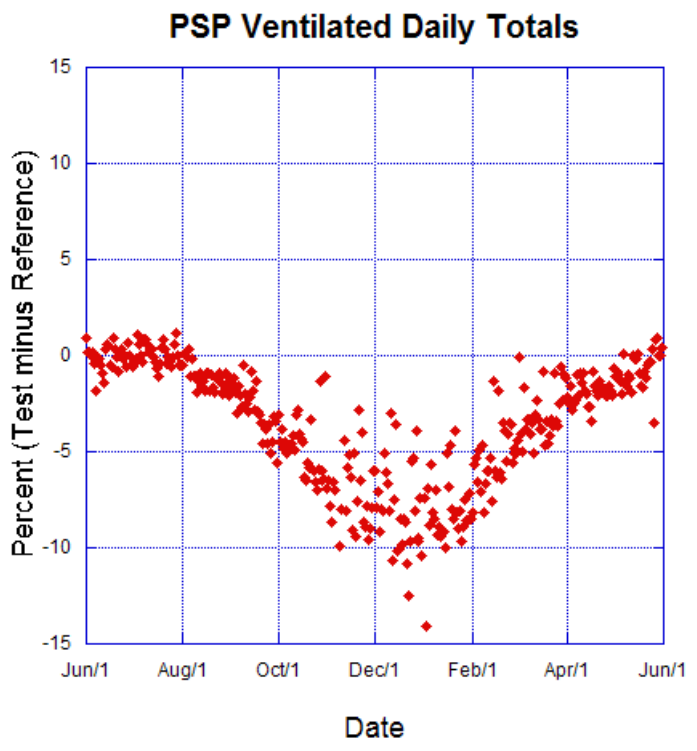

Figure B-3(b). Daily total percent difference; PSP, Ventilated, Uncorrected. 


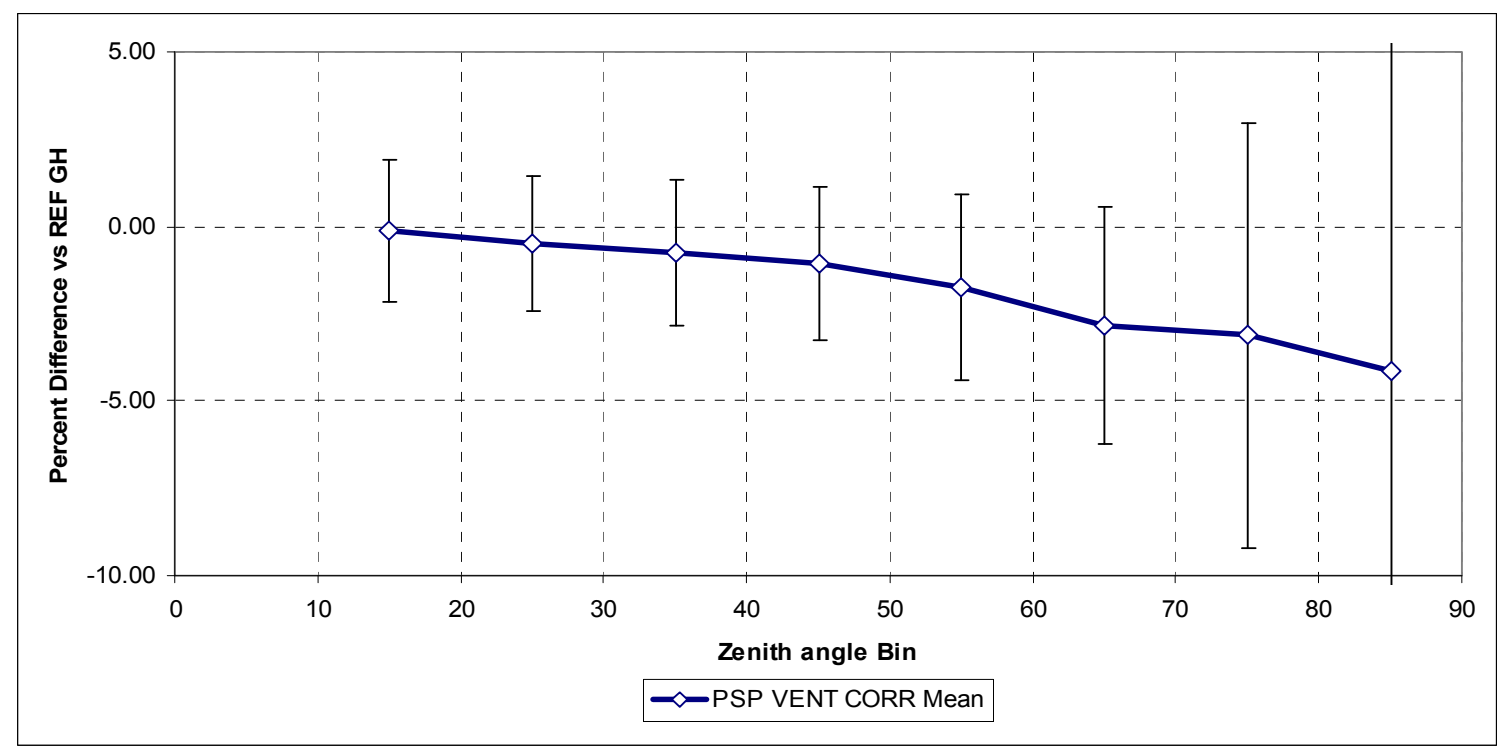

Figure B-4. PSP Ventilated and Corrected PSP_V_C 28402F3

Table B-4. Statistical summary 1-minute data by zenith angle bin PSP 28402F3 (Ventilated, Corrected)

\begin{tabular}{|r|r|r|r|r|r|r|r|}
\hline PSP_V_C & $\begin{array}{c}\text { Count } \\
(\mathbf{N})\end{array}$ & Sum & $\begin{array}{c}\text { PSP } \\
\text { VENT } \\
\text { CORR } \\
\text { Mean }\end{array}$ & $\begin{array}{c}\text { StDev } \\
\mathbf{( s d )}\end{array}$ & Maximum & Minimum & Range \\
\hline 15 & 5497 & -621.3 & -0.113 & 2.039 & 36.9 & -29.0 & 65.9 \\
\hline 25 & 19111 & -9083.12 & -0.475 & 1.943 & 28.5 & -25.3 & 53.9 \\
\hline 35 & 24260 & -18038.3 & -0.744 & 2.077 & 67.3 & -27.0 & 94.3 \\
\hline 45 & 30018 & -32552.2 & -1.084 & 2.191 & 30.2 & -34.7 & 65.0 \\
\hline 55 & 39487 & -69002.7 & -1.747 & 2.679 & 64.9 & -44.3 & 109.2 \\
\hline 65 & 50753 & -144207 & -2.841 & 3.416 & 67.4 & -55.0 & 122.4 \\
\hline 75 & 40632 & -126642 & -3.117 & 6.090 & 33.6 & -99.5 & 133.1 \\
\hline 85 & 38887 & -160636 & -4.131 & 17.940 & 100.0 & -99.9 & 199.9 \\
\hline
\end{tabular}

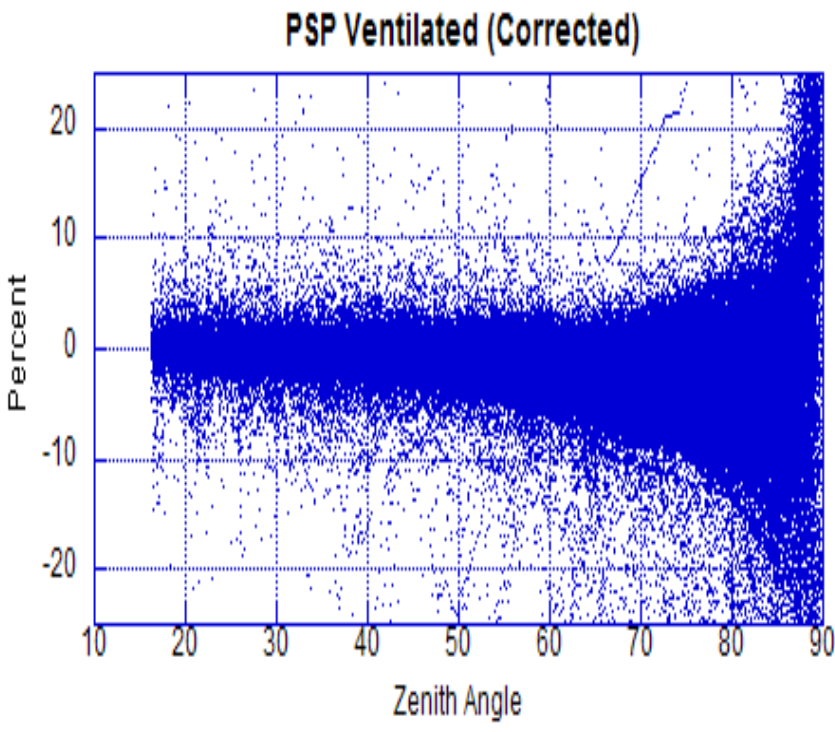

Figure B-4(a). One-minute data set percent differences; PSP, Ventilated, Corrected.

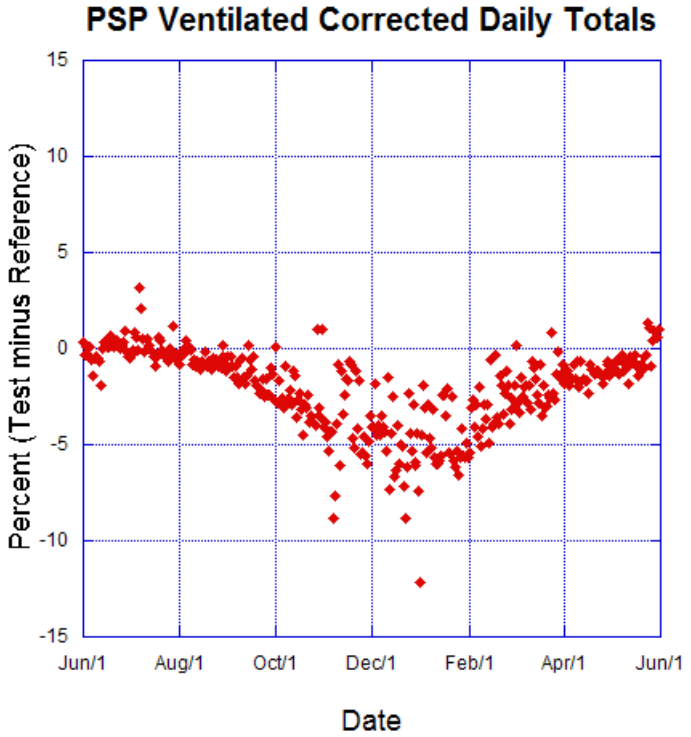

Figure B-4(b). Daily total percent difference; PSP, Ventilated, Corrected. 


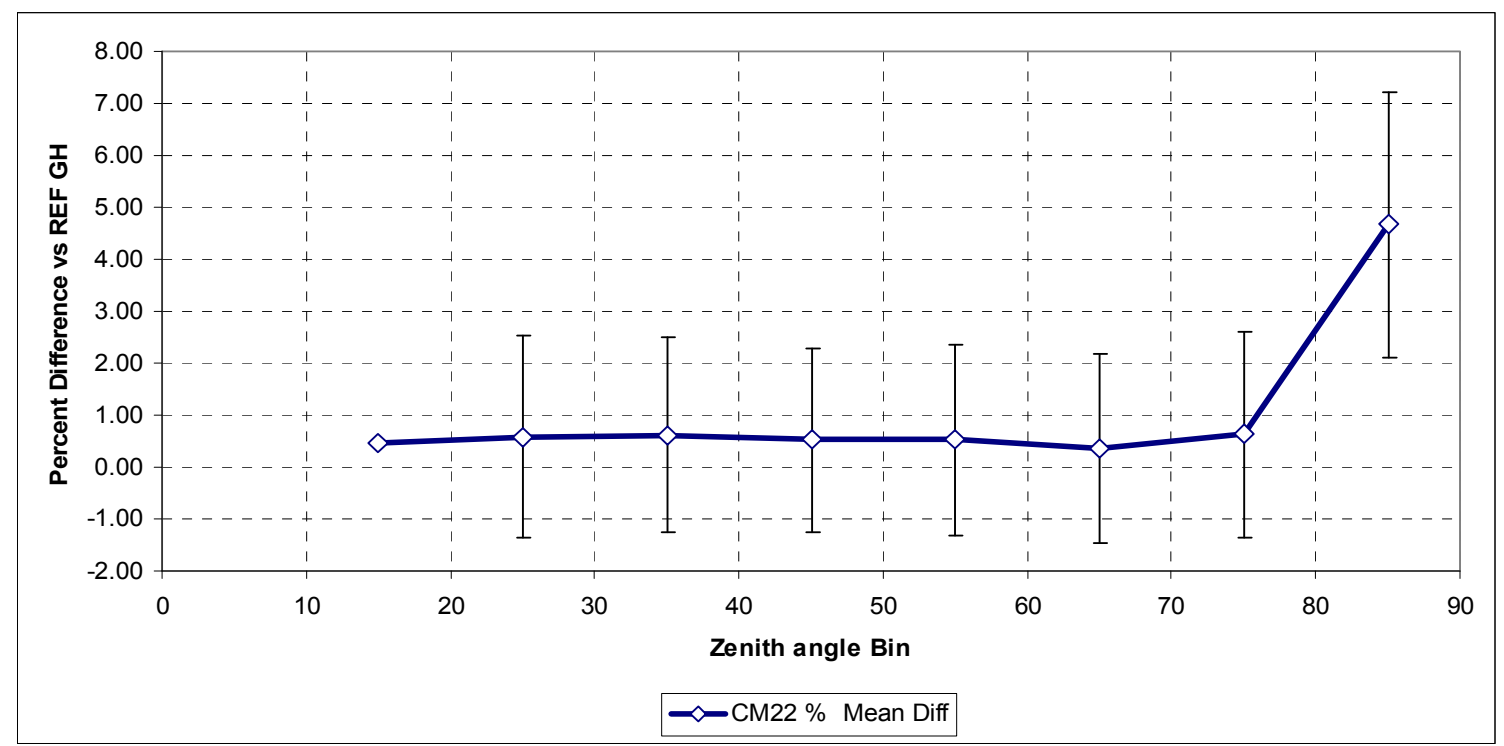

Figure B-5. Kipp \& Zonen CM22 (Ventilated) 010034

Table B-5. Statistical summary 1-minute data by zenith angle bin CM22 010034 (Ventilated)

\begin{tabular}{|r|r|r|r|r|r|r|r|}
\hline CM22 & \multicolumn{1}{l|}{$\begin{array}{l}\text { Count } \\
\text { (N) }\end{array}$} & Sum & $\begin{array}{l}\text { CM22 } \\
\text { Mean } \\
\text { Diff }\end{array}$ & \multicolumn{1}{l|}{$\begin{array}{l}\text { StDev } \\
\text { (sd) }\end{array}$} & Maximum & Minimum & Range \\
\hline 15 & 5497 & 2455.4 & 0.447 & 1.947 & 30.1 & -28.2 & 58.3 \\
\hline 25 & 19111 & 11212.96 & 0.587 & 1.887 & 26.6 & -22.4 & 48.9 \\
\hline 35 & 24260 & 15068.77 & 0.621 & 1.769 & 51.6 & -25.8 & 77.4 \\
\hline 45 & 30018 & 15568.67 & 0.519 & 1.842 & 43.7 & -33.1 & 76.9 \\
\hline 55 & 39487 & 20603.2 & 0.522 & 1.823 & 51.3 & -30.5 & 81.8 \\
\hline 65 & 50754 & 18704.81 & 0.369 & 1.972 & 65.3 & -49.7 & 115.0 \\
\hline 75 & 40634 & 25611.97 & 0.630 & 2.548 & 56.9 & -28.8 & 85.7 \\
\hline 85 & 40339 & 188401.9 & 4.670 & 11.835 & 99.9 & -99.3 & 199.2 \\
\hline
\end{tabular}

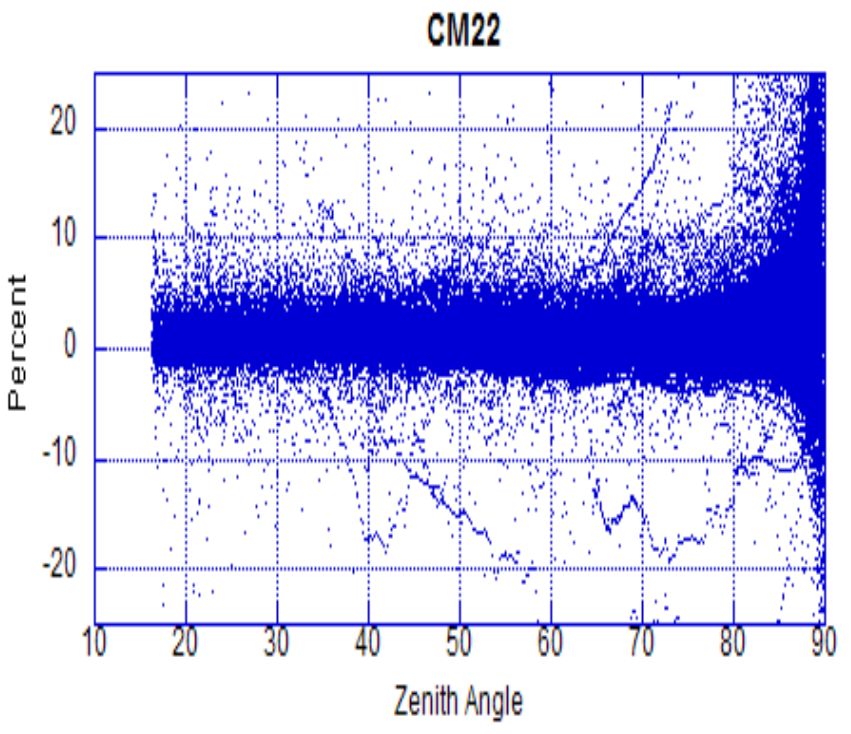

Figure B-5(a). One-minute data set percent difference; CM22, Ventilated.

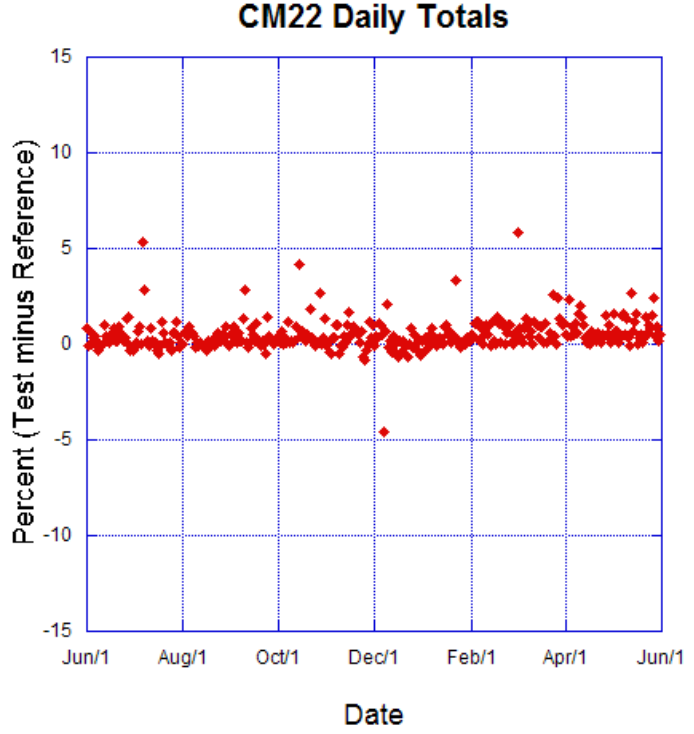

Figure B-5(b). Daily total percent difference; CM22, Ventilated. 


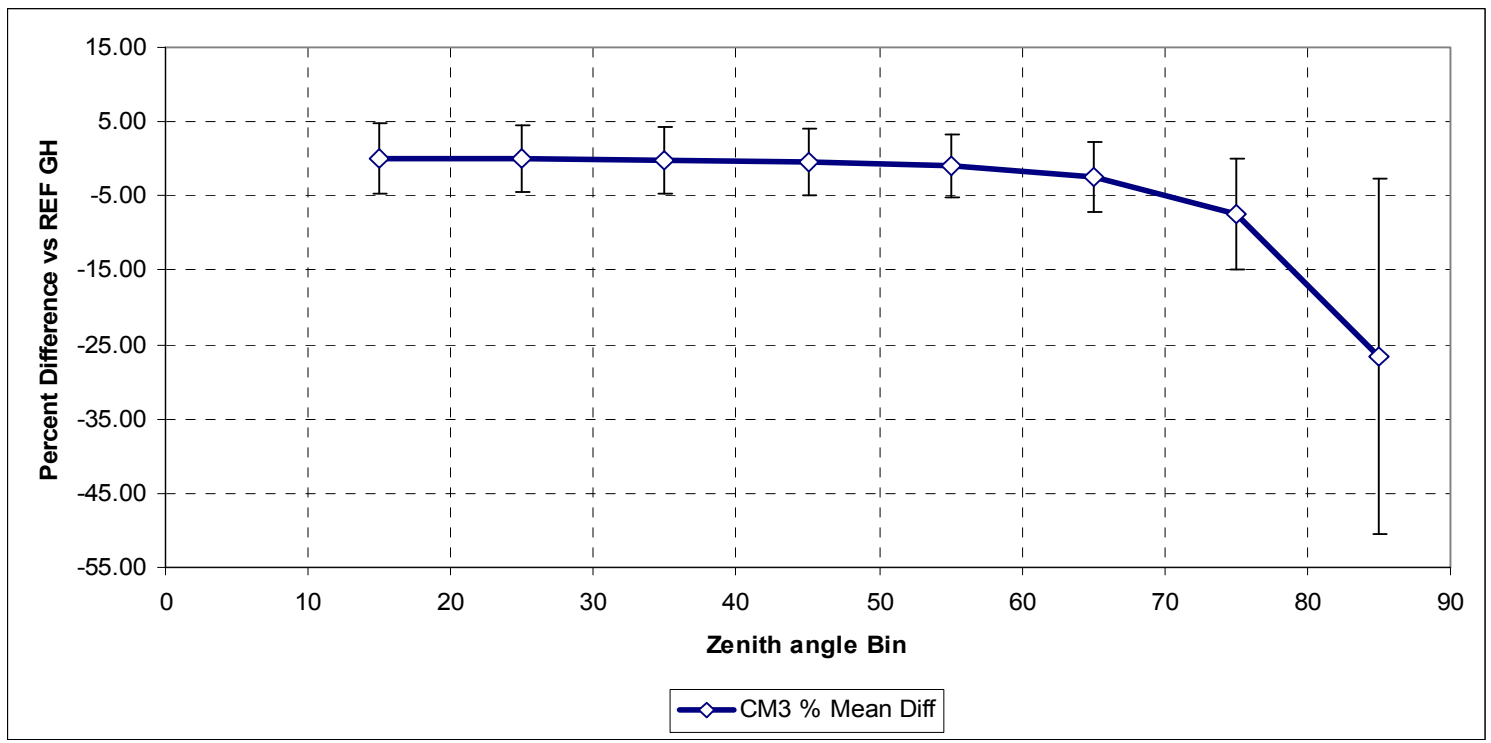

Figure B-6. Kipp \& Zonen CM3 010284

Table B-6. Statistical summary 1-minute data by zenith angle bin CM3 010284

\begin{tabular}{|r|r|r|r|r|r|r|}
\hline \multicolumn{1}{|c|}{ CM3 } & \multicolumn{1}{c|}{ Count (N) } & $\begin{array}{c}\text { CM3 \% } \\
\text { Mean Diff }\end{array}$ & $\begin{array}{c}\text { StDev } \\
\text { (sd) }\end{array}$ & Maximum & Minimum & Range \\
\hline 15 & 5495 & 0.101 & 4.799 & 77.5 & -58.5 & 136.0 \\
\hline 25 & 19111 & 0.085 & 4.554 & 93.0 & -56.5 & 149.5 \\
\hline 35 & 24260 & -0.140 & 4.523 & 71.1 & -53.9 & 125.0 \\
\hline 45 & 30018 & -0.365 & 4.521 & 70.4 & -71.6 & 142.0 \\
\hline 55 & 39487 & -0.967 & 4.315 & 54.8 & -56.1 & 110.8 \\
\hline 65 & 50754 & -2.374 & 4.703 & 94.0 & -57.6 & 151.5 \\
\hline 75 & 40633 & -7.415 & 7.491 & 59.0 & -70.4 & 129.4 \\
\hline 85 & 34843 & -26.587 & 23.896 & 99.5 & -99.9 & 199.4 \\
\hline
\end{tabular}

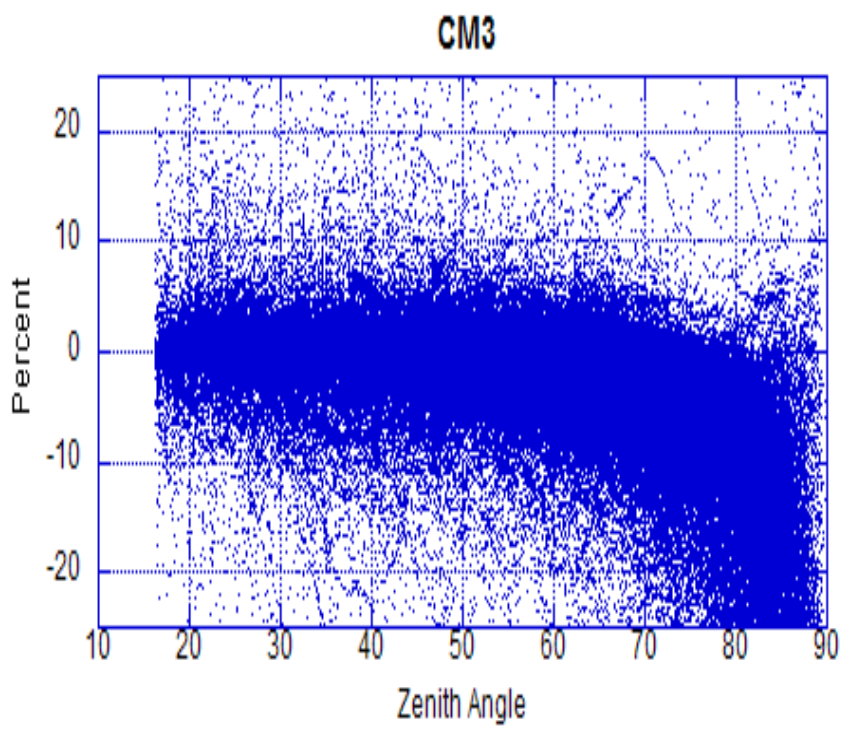

Figure B-6(a). One-minute data set percent differences; CM3.

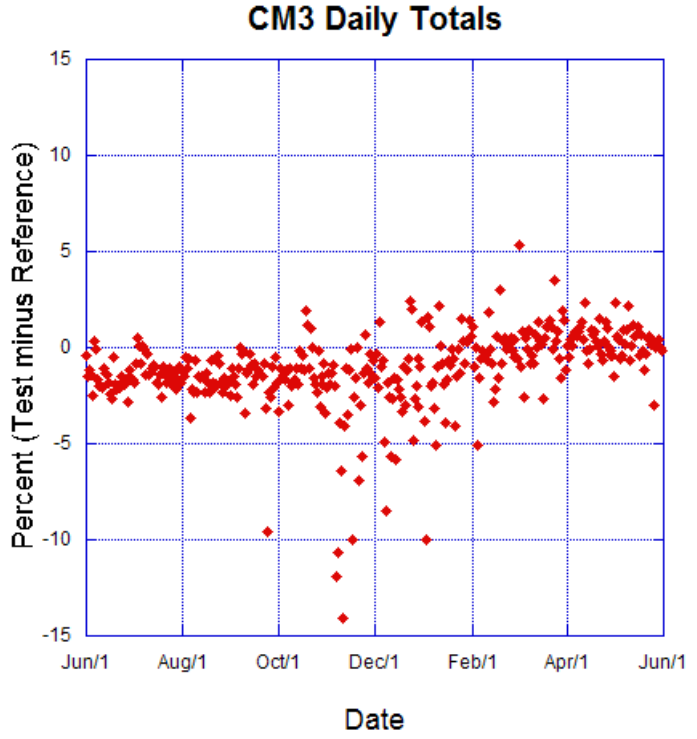

Figure B-6(b). Daily total percent difference; CM3. 


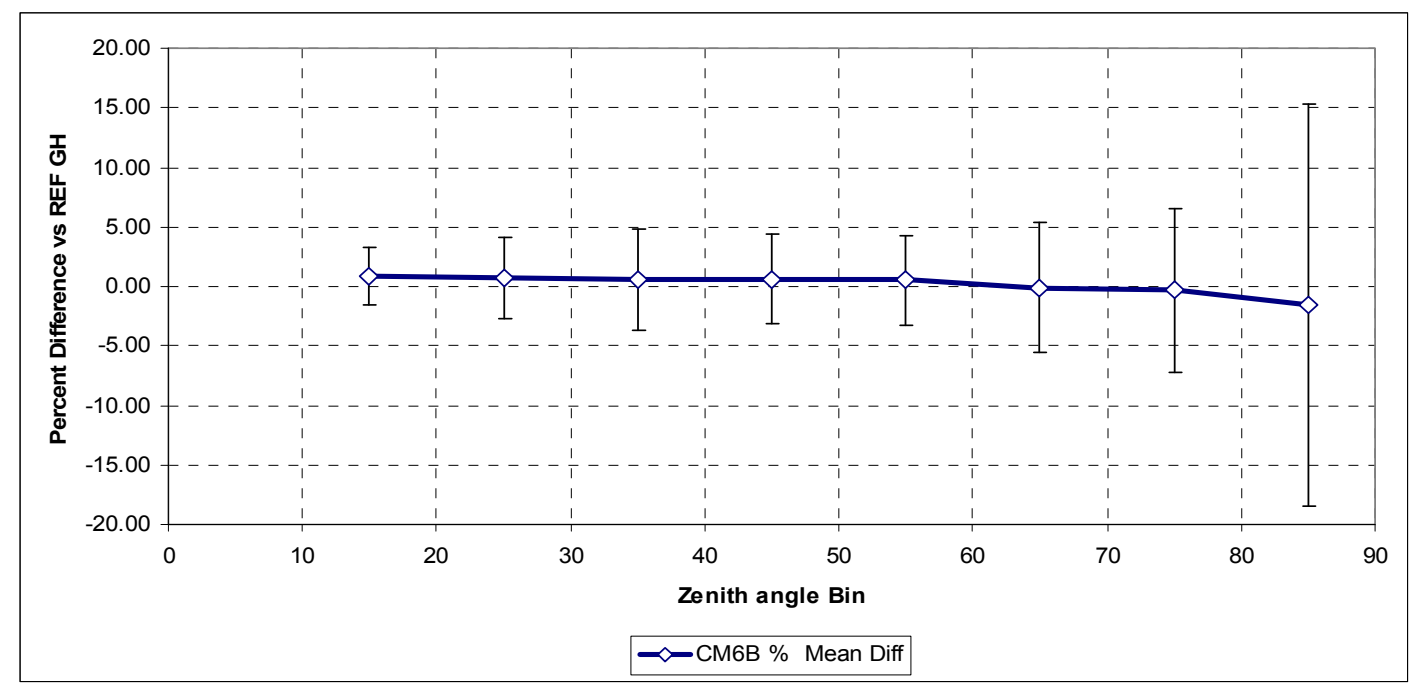

Figure B-7. Kipp \& Zonen CM6B 015189

Table B-7. Statistical summary 1-minute data by zenith angle bin CM6B 015189

\begin{tabular}{|c|c|c|c|c|c|c|}
\hline CM6B & $\begin{array}{c}\text { Count } \\
\text { (N) }\end{array}$ & $\begin{array}{c}\text { CM6B } \\
\text { \% } \\
\text { Mean } \\
\text { Diff }\end{array}$ & $\begin{array}{c}\text { StDev } \\
\text { (sd) }\end{array}$ & Maximum & Minimum & Range \\
\hline 15 & 5497 & 0.852 & 2.346 & 40.6 & -28.1 & 68.7 \\
\hline 25 & 19111 & 0.685 & 3.414 & 34.2 & -53.4 & 87.6 \\
\hline 35 & 24260 & 0.574 & 4.209 & 78.2 & -70.0 & 148.3 \\
\hline 45 & 30018 & 0.627 & 3.746 & 36.3 & -69.8 & 106.1 \\
\hline 55 & 39487 & 0.515 & 3.736 & 72.1 & -62.0 & 134.1 \\
\hline 65 & 50754 & -0.087 & 5.511 & 74.7 & -70.6 & 145.4 \\
\hline 75 & 40634 & -0.338 & 6.831 & 63.2 & -71.9 & 135.1 \\
\hline 85 & 40155 & -1.551 & 16.920 & 99.7 & -99.6 & 199.3 \\
\hline
\end{tabular}

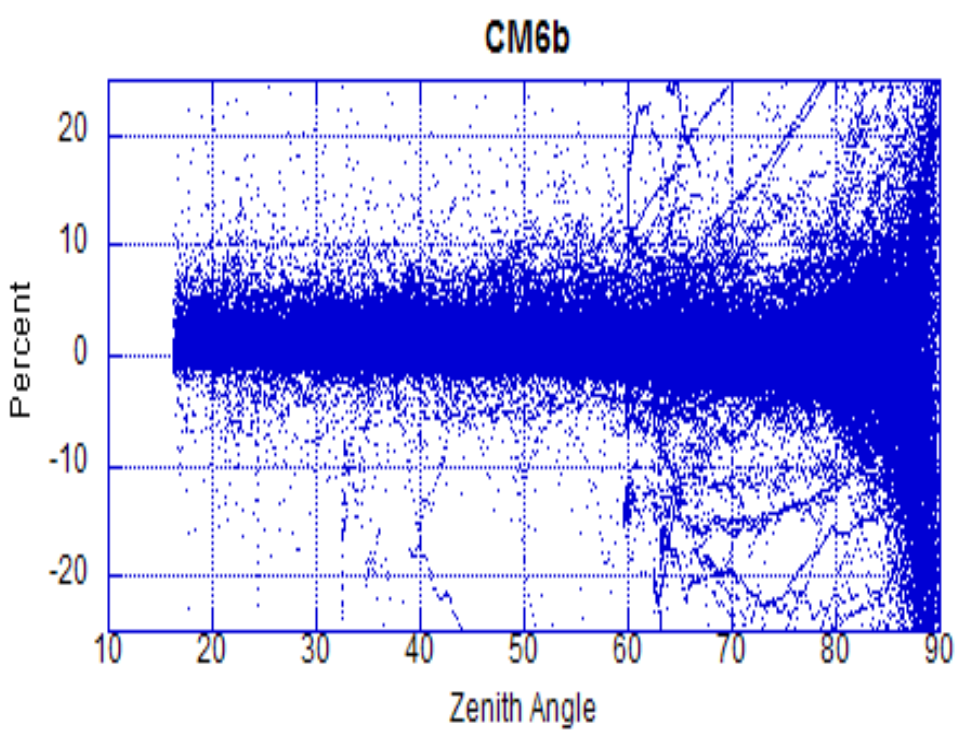

Figure B-7(a). One-minute data set percent differences; CM6B.

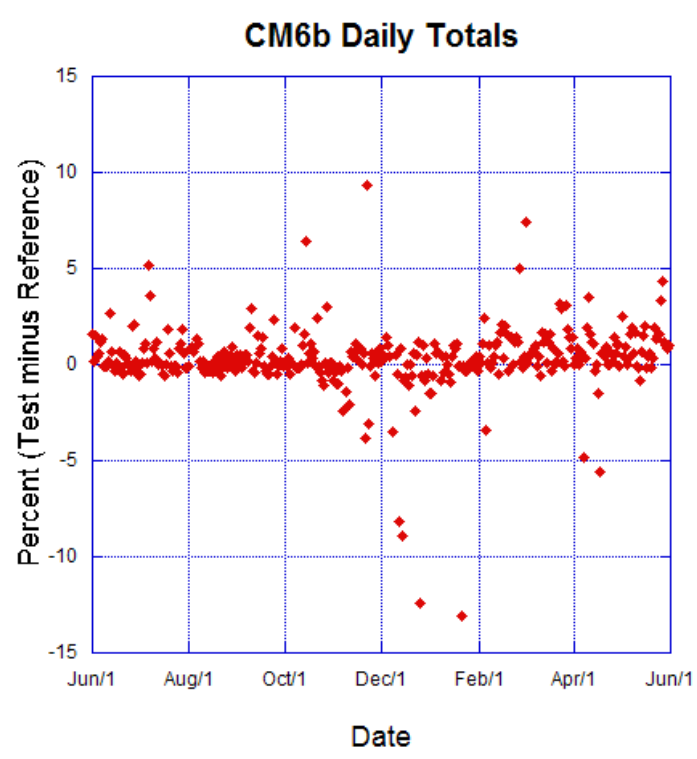

Figure B-7(b). Daily total percent difference; CM6B. 


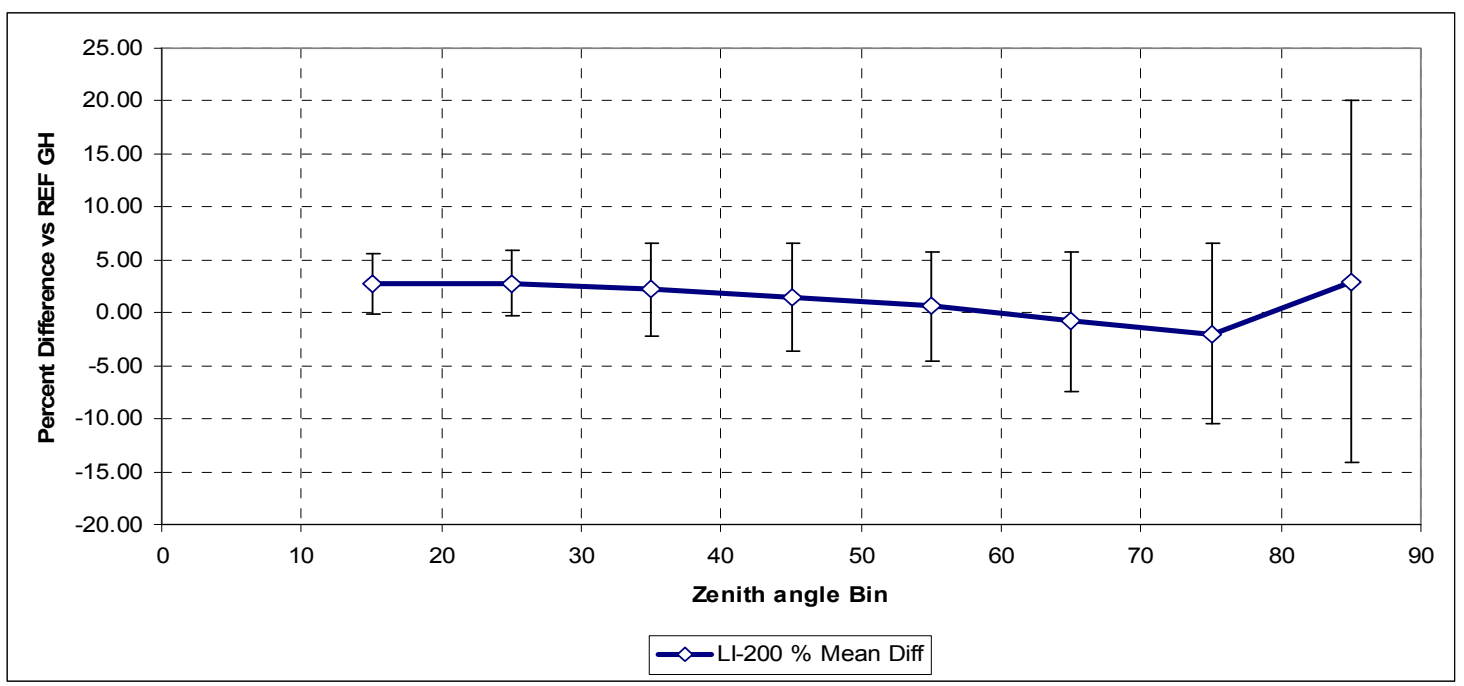

Figure B-8. Li-Cor LI 200 PY28257

Table B-8. Statistical summary 1-minute data by zenith angle bin Li-200 PY28257

\begin{tabular}{|c|c|c|c|c|c|c|}
\hline LI-200 & $\begin{array}{c}\text { Count } \\
(\mathbf{N})\end{array}$ & $\begin{array}{c}\text { LI-200 \% } \\
\text { Mean } \\
\text { Diff }\end{array}$ & $\begin{array}{c}\text { StDev } \\
(\mathbf{s d})\end{array}$ & Maximum & Minimum & Range \\
\hline 15 & 5497 & 2.783 & 2.850 & 37.8 & -33.4 & 71.2 \\
\hline 25 & 19111 & 2.799 & 3.086 & 28.4 & -30.5 & 58.9 \\
\hline 35 & 24260 & 2.221 & 4.342 & 53.1 & -60.8 & 113.9 \\
\hline 45 & 30018 & 1.474 & 5.017 & 29.7 & -64.0 & 93.7 \\
\hline 55 & 39487 & 0.610 & 5.135 & 63.8 & -68.9 & 132.7 \\
\hline 65 & 50754 & -0.801 & 6.601 & 61.6 & -74.3 & 135.9 \\
\hline 75 & 40634 & -1.975 & 8.495 & 69.9 & -74.4 & 144.2 \\
\hline 85 & 39972 & 2.906 & 17.091 & 99.9 & -98.8 & 198.8 \\
\hline
\end{tabular}

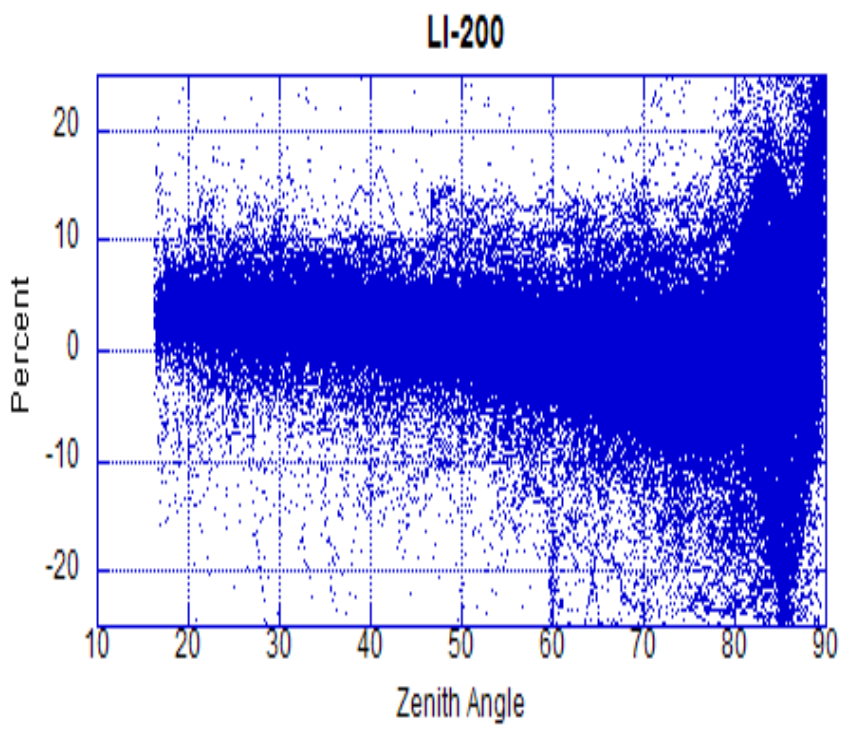

Figure B-8(a). One-minute data set percent diccerens; LI-200 PY.

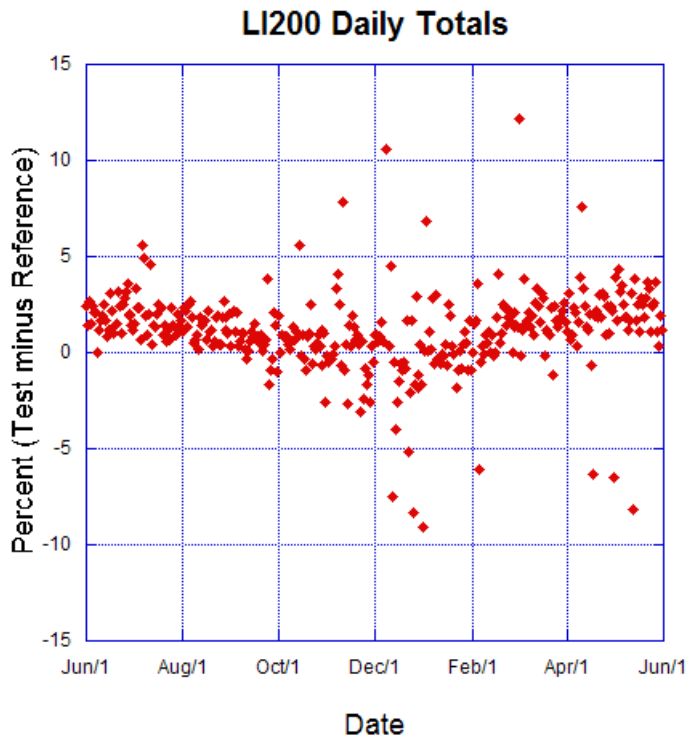

Figure B-8(b). Daily total percent difference Li-200. 


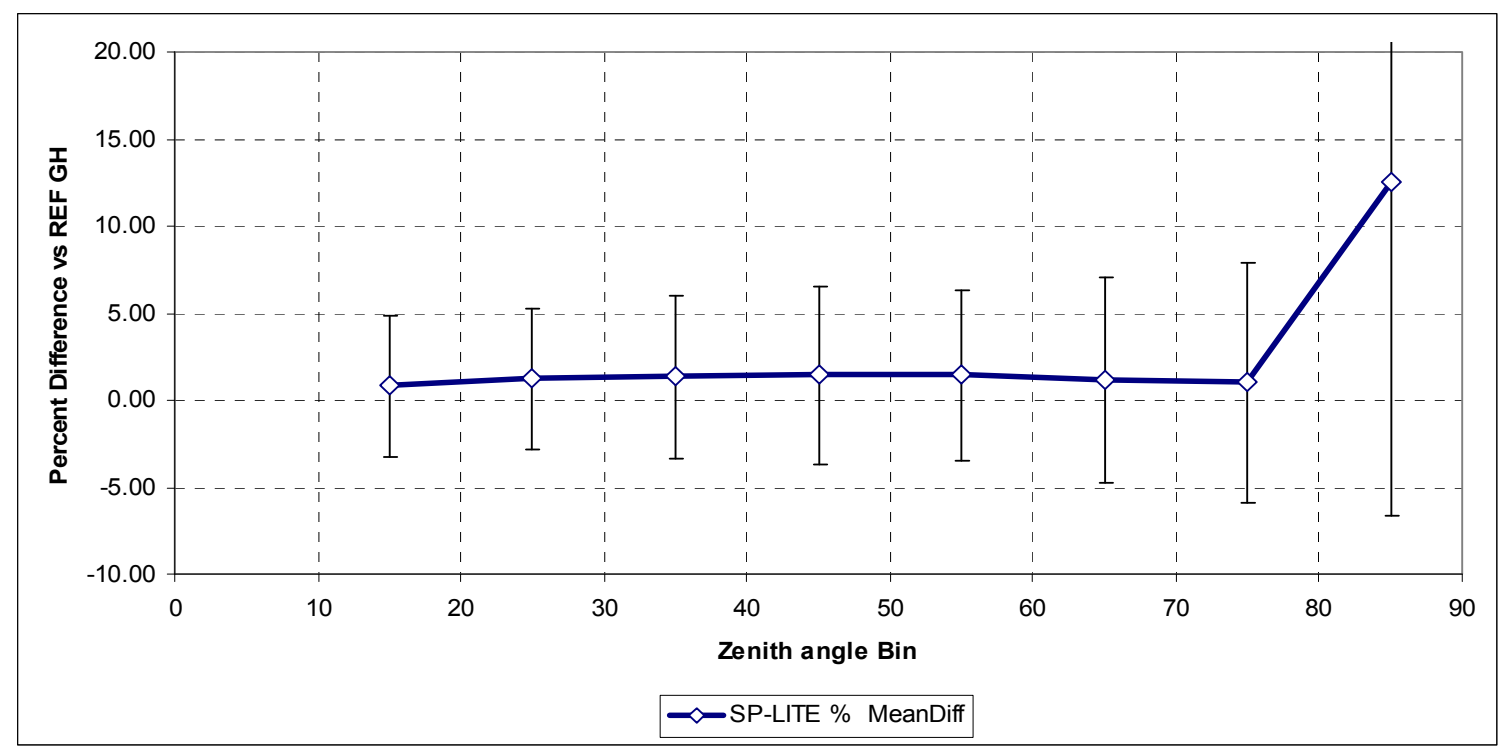

Figure B-9. SP-LITE 970003

Table B-9. Statistical summary 1-minute data by zenith angle bin SP-LITE 970003

\begin{tabular}{|r|r|r|r|r|r|r|}
\hline SPLITE & $\begin{array}{c}\text { Count } \\
\text { (N) }\end{array}$ & $\begin{array}{c}\text { SP-LITE } \\
\text { \% } \\
\text { MeanDiff }\end{array}$ & $\begin{array}{c}\text { StDev } \\
(\mathbf{s d})\end{array}$ & Maximum & Minimum & Range \\
\hline 15 & 5497 & 0.829 & 4.057 & 32.6 & -35.1 & 67.7 \\
\hline 25 & 19111 & 1.214 & 4.019 & 32.3 & -31.7 & 64.0 \\
\hline 35 & 24260 & 1.346 & 4.662 & 49.9 & -65.8 & 115.6 \\
\hline 45 & 30018 & 1.429 & 5.146 & 34.6 & -66.5 & 101.2 \\
\hline 55 & 39487 & 1.435 & 4.873 & 56.2 & -65.0 & 121.2 \\
\hline 65 & 50754 & 1.147 & 5.864 & 68.5 & -78.8 & 147.3 \\
\hline 75 & 40634 & 1.018 & 6.925 & 75.7 & -79.4 & 155.1 \\
\hline 85 & 39685 & 12.479 & 19.067 & 100.0 & -58.3 & 158.2 \\
\hline
\end{tabular}

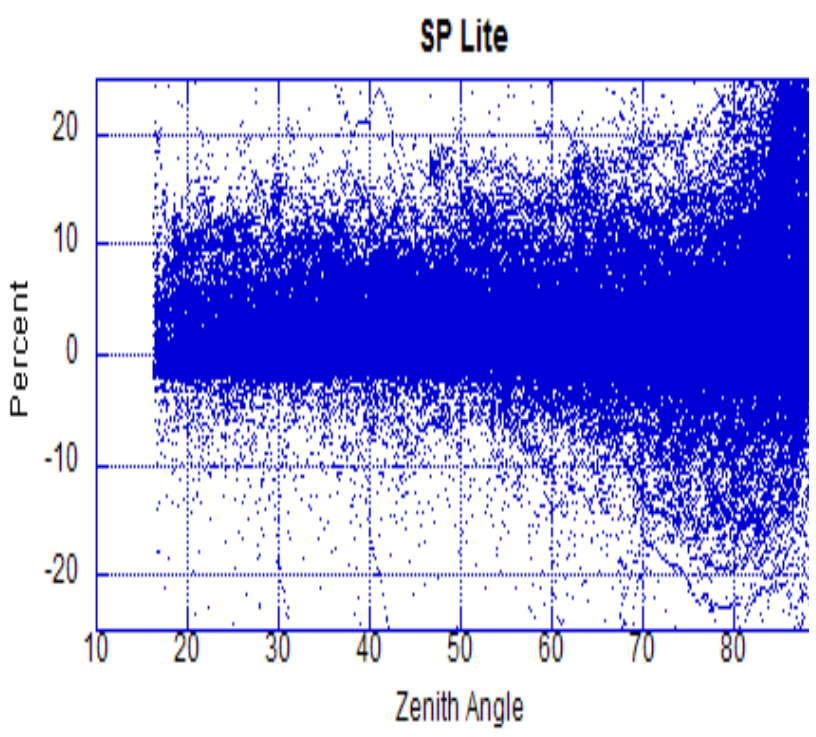

Figure B-9(a). One-minue data set percent differences; SP Lite Global.

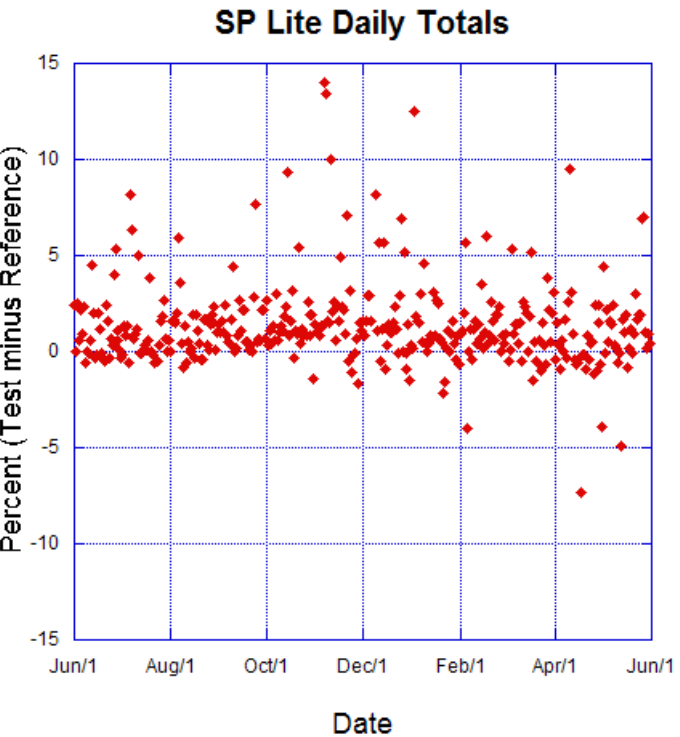

Figure B-9(b). Daily total percent difference; SP Lite Global. 


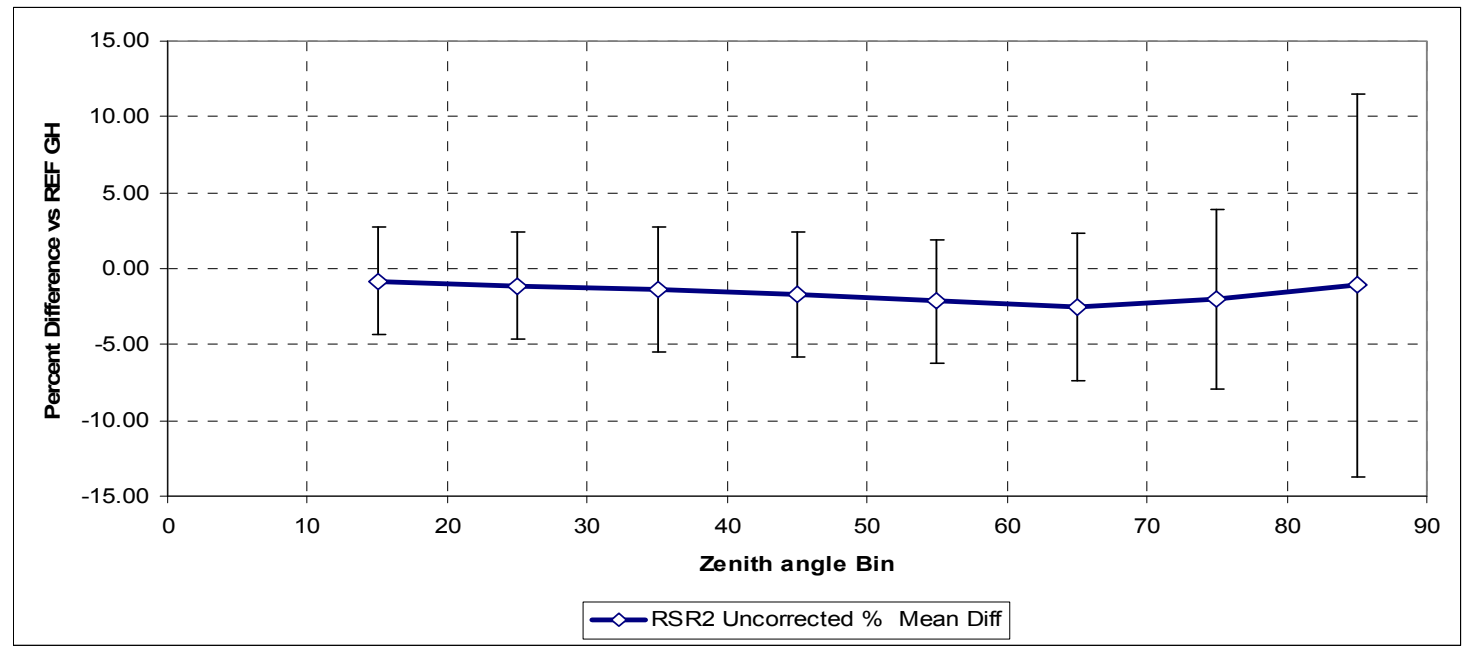

Figure B-10. Irradiance, Inc. RSR2 -Global Uncorrected PY37627 (11 months Jul 2007 -May 2008)

Table B-10. Statistical summary 1-minute data by zenith angle bin RSR2 Global Uncorrected

\begin{tabular}{|r|r|r|r|r|r|r|}
\hline RSR2_U_G & $\begin{array}{c}\text { Count } \\
\text { (N) }\end{array}$ & $\begin{array}{c}\text { RSR2 } \\
\text { Uncorrected } \\
\text { \% Mean Diff }\end{array}$ & $\begin{array}{c}\text { StDev } \\
\text { (sd) }\end{array}$ & Maximum & Minimum & Range \\
\hline 15 & 3007 & -0.808 & 3.543 & 27.6 & -21.4 & 49.0 \\
\hline 25 & 15555 & -1.135 & 3.526 & 28.2 & -60.0 & 88.3 \\
\hline 35 & 21172 & -1.399 & 4.129 & 48.9 & -73.5 & 122.5 \\
\hline 45 & 27137 & -1.703 & 4.125 & 27.6 & -79.9 & 107.5 \\
\hline 55 & 37364 & -2.132 & 4.078 & 24.0 & -66.7 & 90.7 \\
\hline 65 & 48789 & -2.539 & 4.831 & 38.6 & -51.4 & 89.9 \\
\hline 75 & 38434 & -1.986 & 5.906 & 67.1 & -58.5 & 125.6 \\
\hline 85 & 37203 & -1.090 & 12.613 & 99.6 & -96.4 & 196.0 \\
\hline
\end{tabular}

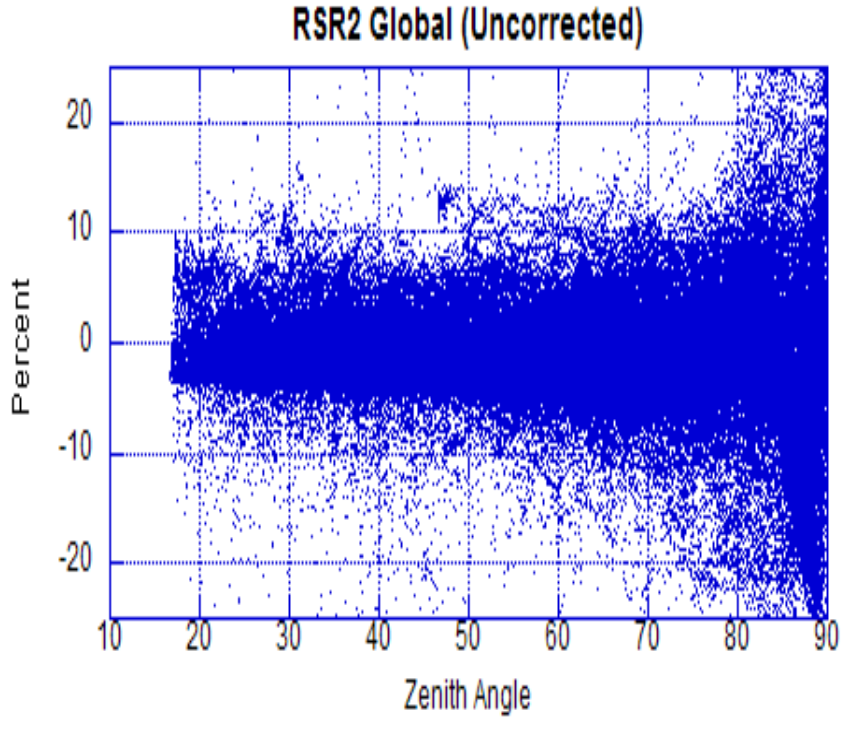

Figure B-10(a). One-minute data set percent differences; RSR2 Global Uncorrected.

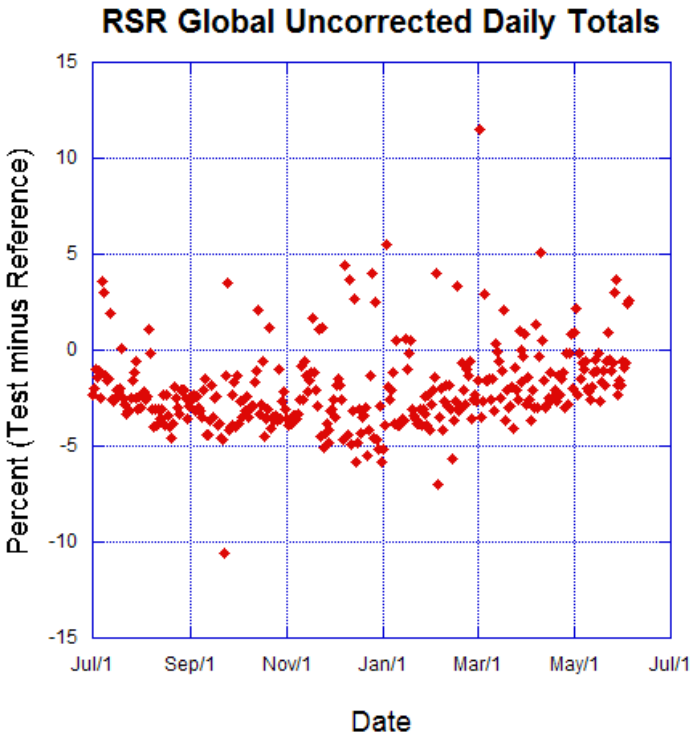

Figure B-10(b). Daily total percent difference; RSR2 Global Uncorrected. 


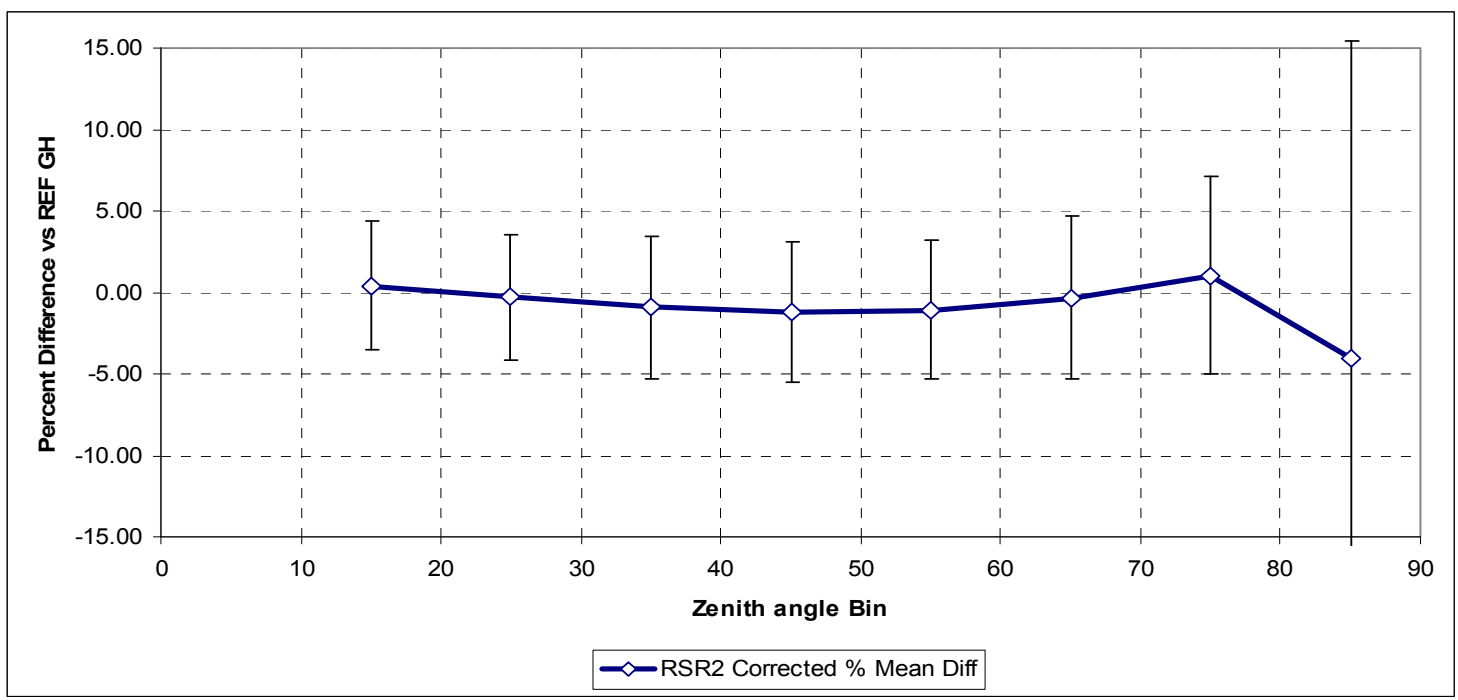

Figure B-11. Irradiance, Inc. RSR2 global Corrected PY37627 (11 months Jul 2007 -May 2008)

Table B-11. Statistical summary 1-minute data by zenith angle bin RSR2 Global Corrected

\begin{tabular}{|r|r|r|r|r|r|r|}
\hline RSR2_C_G & $\begin{array}{c}\text { Count } \\
\text { (N) }\end{array}$ & $\begin{array}{c}\text { RSR2 } \\
\text { Corrected } \\
\text { \% Mean } \\
\text { Diff }\end{array}$ & $\begin{array}{c}\text { StDev } \\
\text { (sd) }\end{array}$ & Maximum & Minimum & Range \\
\hline 15 & 3007 & 0.409 & 3.946 & 29.6 & -20.8 & 50.4 \\
\hline 25 & 15555 & -0.312 & 3.863 & 30.8 & -60.0 & 90.8 \\
\hline 35 & 21172 & -0.934 & 4.404 & 49.1 & -73.6 & 122.6 \\
\hline 45 & 27137 & -1.221 & 4.350 & 28.2 & -79.9 & 108.1 \\
\hline 55 & 37364 & -1.080 & 4.260 & 24.5 & -66.0 & 90.5 \\
\hline 65 & 48789 & -0.351 & 5.008 & 41.6 & -49.6 & 91.2 \\
\hline 75 & 38434 & 1.034 & 6.080 & 67.4 & -57.5 & 124.9 \\
\hline 85 & 37287 & -4.035 & 19.442 & 99.4 & -98.7 & 198.1 \\
\hline
\end{tabular}

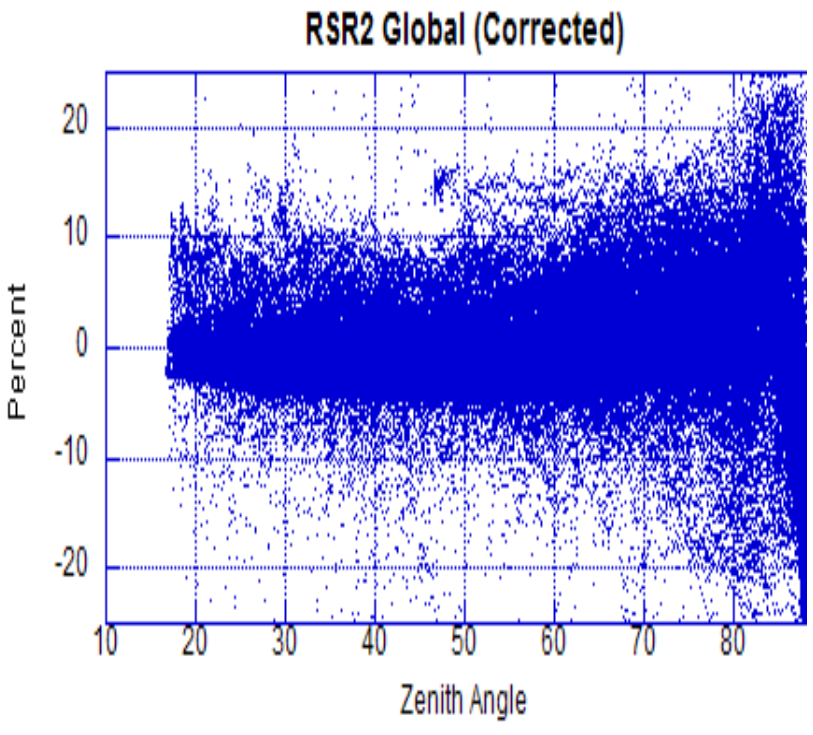

Figure B-11(a). One-minute data set percent differences. RSR2 Global Corrected.

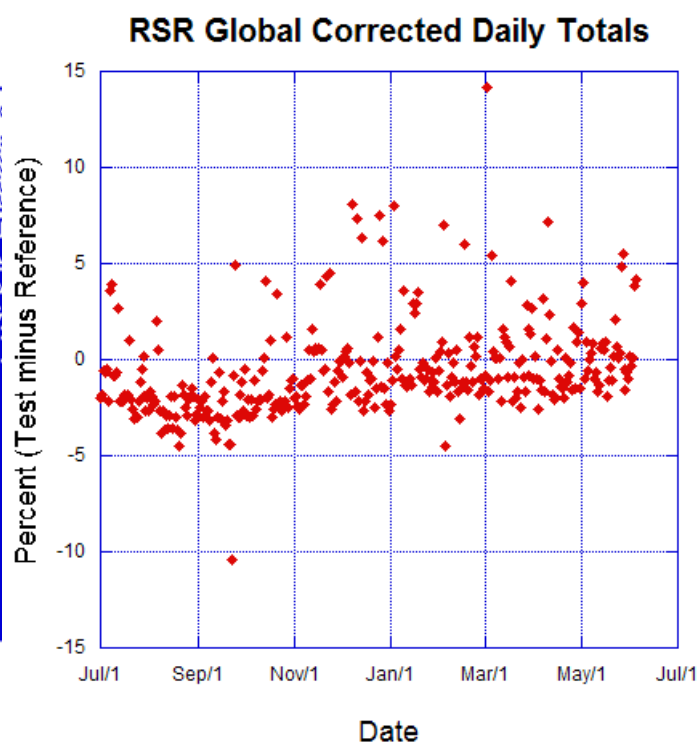

Figure B-11(b). Daily total percent difference RSR2 Global Corrected. 


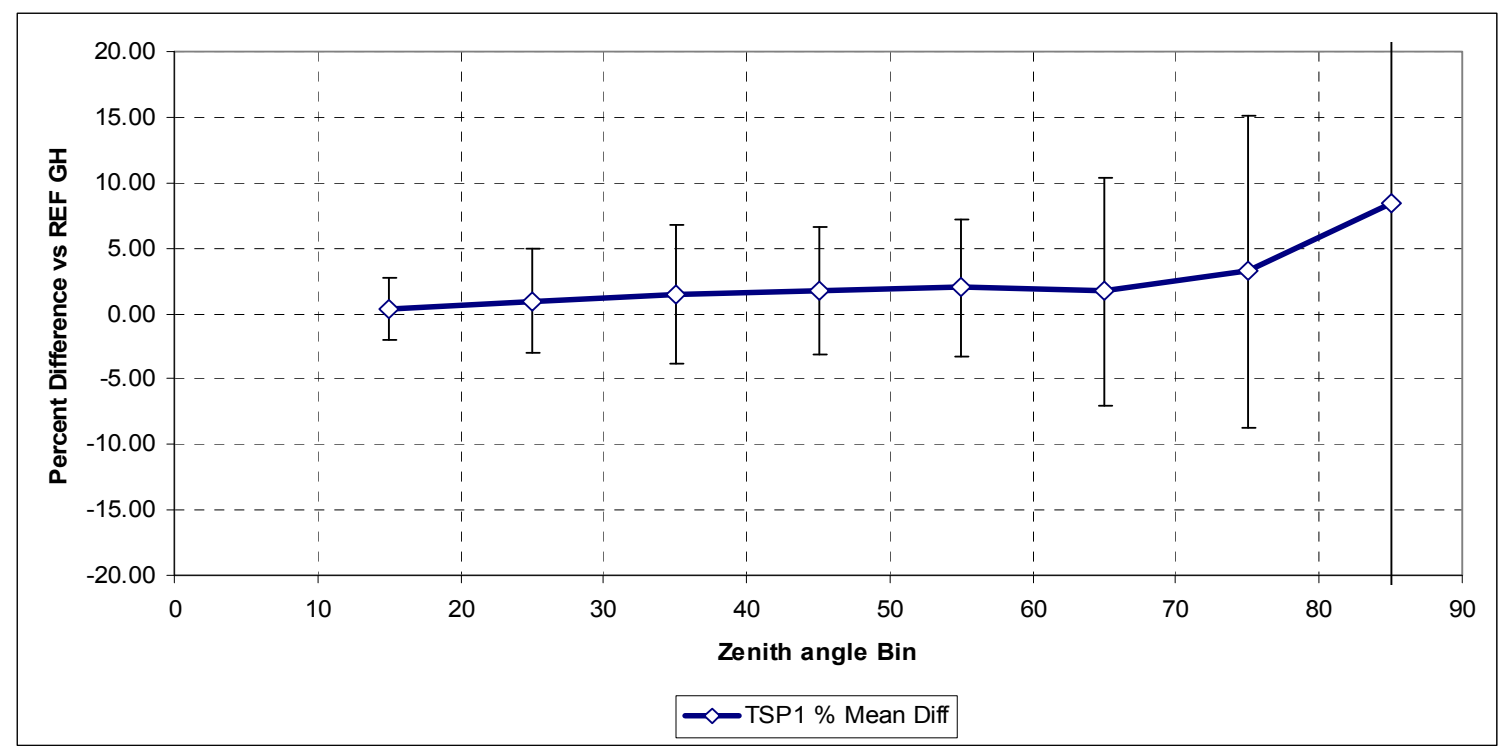

Figure B-12. TSP1 - 940703

Table B-12. Statistical summary 1-minute data by zenith angle bin TSP1 Global

\begin{tabular}{|r|r|r|r|r|r|r|}
\hline \multicolumn{1}{|c|}{ TSP1 } & $\begin{array}{c}\text { Count } \\
(\mathbf{N})\end{array}$ & $\begin{array}{c}\text { TSP1 \% } \\
\text { Mean } \\
\text { Diff }\end{array}$ & $\begin{array}{c}\text { StDev } \\
(\mathbf{s d})\end{array}$ & Maximum & Minimum & Range \\
\hline 15 & 5497 & 0.357 & 2.387 & 31.2 & -24.4 & 55.6 \\
\hline 25 & 19111 & 0.952 & 3.949 & 30.7 & -67.3 & 98.0 \\
\hline 35 & 24260 & 1.489 & 5.267 & 53.1 & -74.2 & 127.3 \\
\hline 45 & 30018 & 1.757 & 4.898 & 36.5 & -74.0 & 110.4 \\
\hline 55 & 39487 & 1.977 & 5.189 & 60.3 & -64.6 & 124.9 \\
\hline 65 & 50754 & 1.693 & 8.685 & 73.8 & -100.0 & 173.8 \\
\hline 75 & 40613 & 3.250 & 11.927 & 90.2 & -100.0 & 190.1 \\
\hline 85 & 36888 & 8.469 & 29.463 & 100.0 & -100.0 & 200.0 \\
\hline
\end{tabular}

TSP1

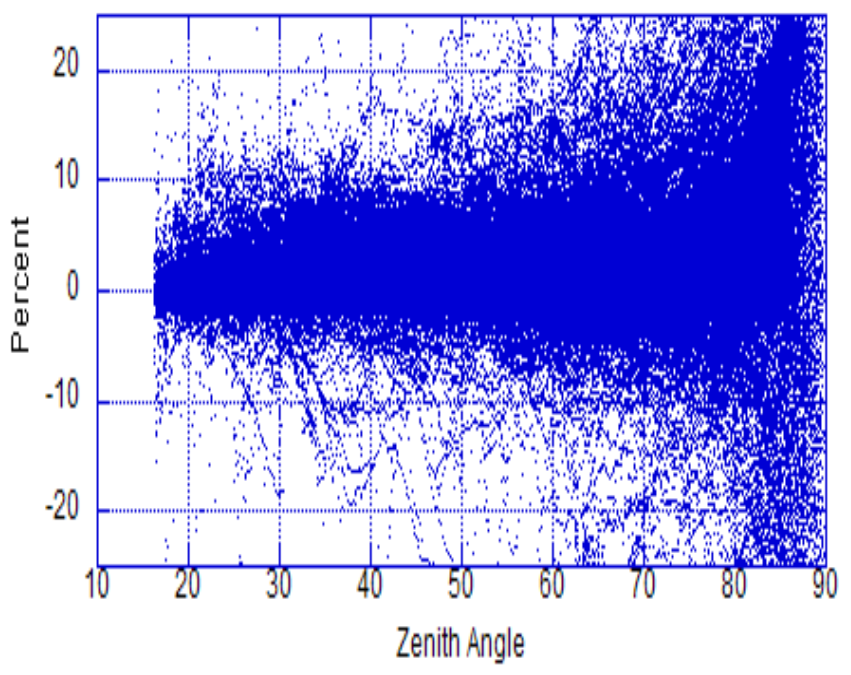

Figure B-12(a). One-minute data set percent differences; TSP1 Global.

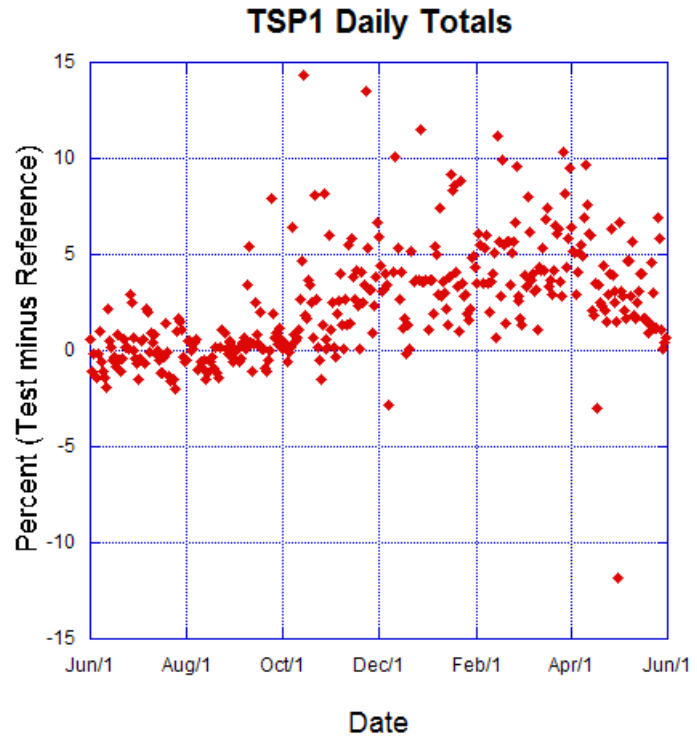

Figure B-12(b). Daily total percent difference TSP1 Global. 


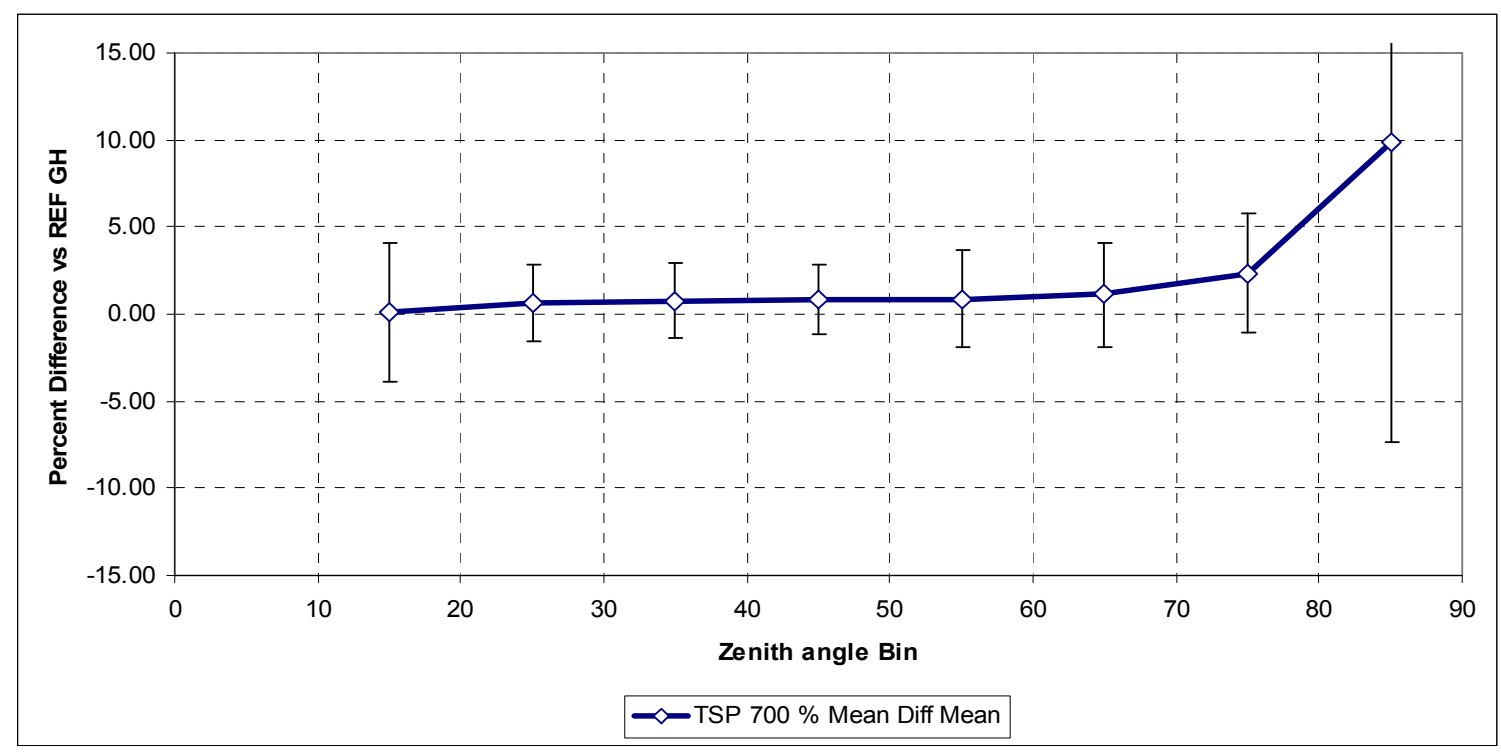

Figure B-13. TSP700 0212-02 (Ventilated)

Table B-13. Statistical summary 1-minute data by zenith angle bin TSP700 Global

\begin{tabular}{|c|c|c|c|c|c|c|}
\hline TSP700 & $\begin{array}{c}\text { Count } \\
\mathbf{( N )}\end{array}$ & $\begin{array}{c}\text { TSP } \\
\mathbf{7 0 0} \% \\
\text { Mean } \\
\text { Diff }\end{array}$ & $\begin{array}{c}\text { StDev } \\
\text { (sd) }\end{array}$ & Maximum & Minimum & Range \\
\hline 15 & 5497 & 0.058 & 3.990 & 29.9 & -51.9 & 81.8 \\
\hline 25 & 19111 & 0.610 & 2.234 & 27.8 & -32.6 & 60.3 \\
\hline 35 & 24260 & 0.750 & 2.146 & 49.4 & -44.1 & 93.4 \\
\hline 45 & 30018 & 0.853 & 1.990 & 33.3 & -32.8 & 66.1 \\
\hline 55 & 39487 & 0.867 & 2.756 & 52.9 & -73.9 & 126.8 \\
\hline 65 & 50680 & 1.104 & 2.992 & 68.5 & -100.0 & 168.5 \\
\hline 75 & 40564 & 2.358 & 3.432 & 69.8 & -95.1 & 164.9 \\
\hline 85 & 39651 & 9.873 & 17.194 & 100.0 & -99.6 & 199.6 \\
\hline
\end{tabular}

TSP700

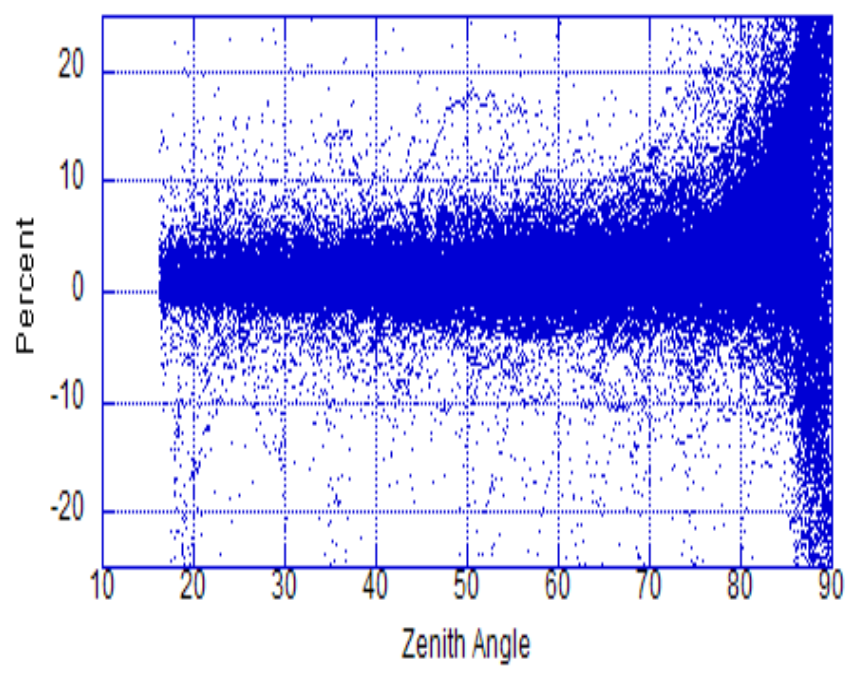

TSP700 Daily Totals

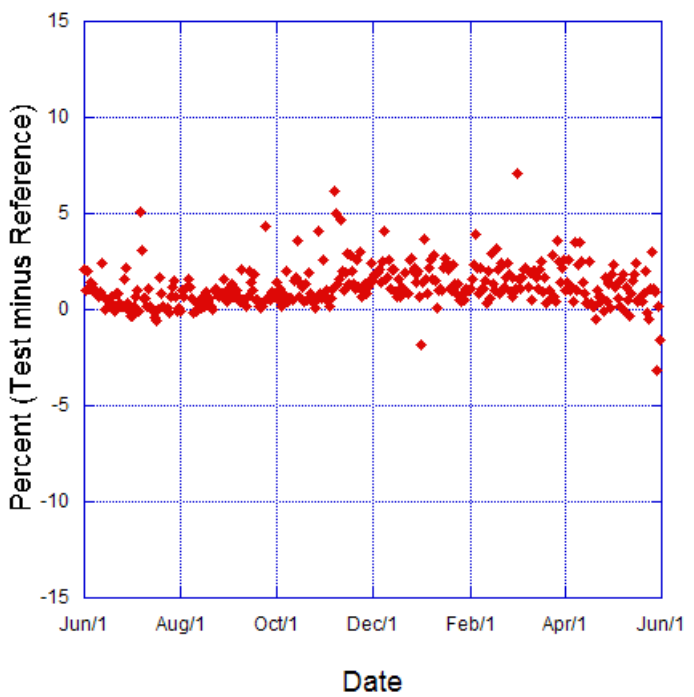

Figure B-13(b). Daily total percent difference; TSP7000 Global, Ventilated. 


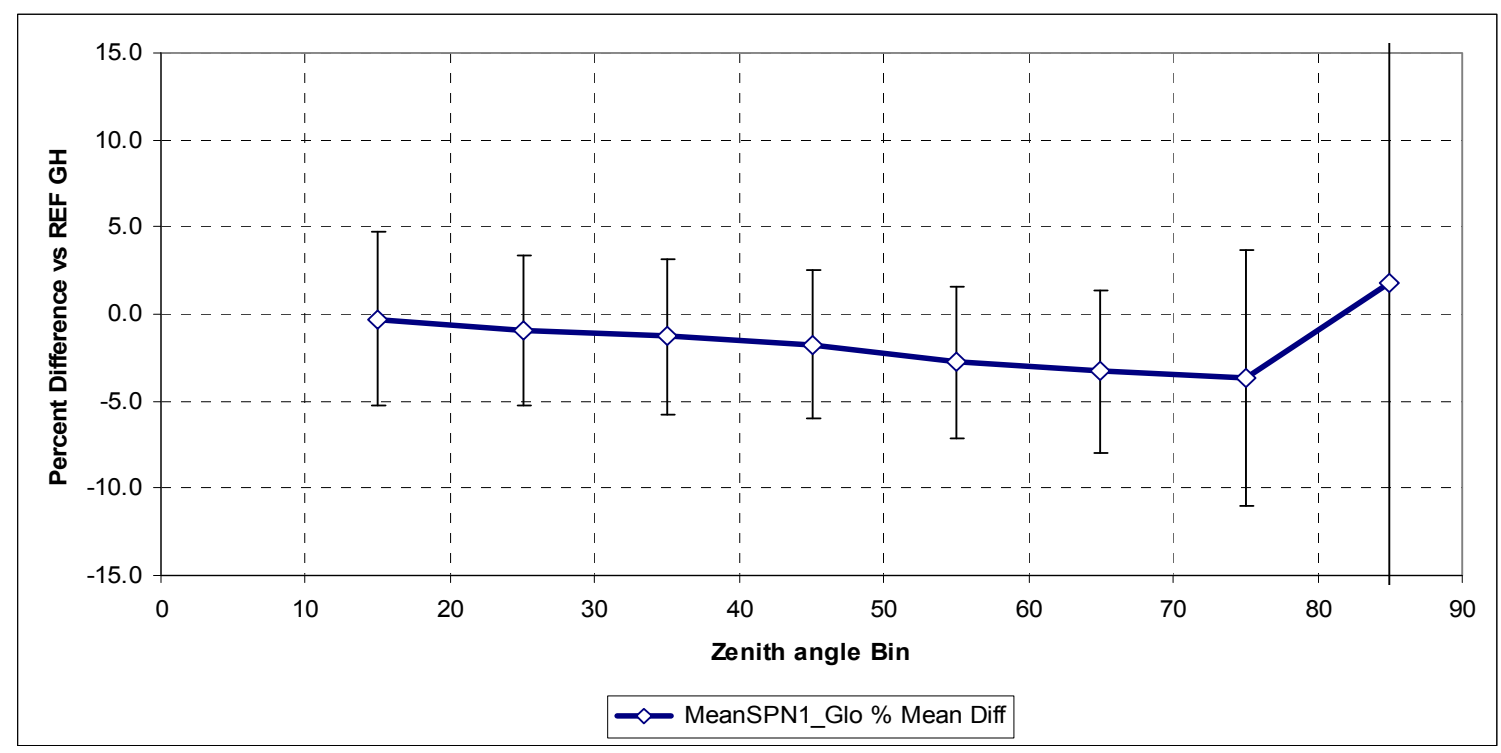

Figure B-14. SPN1 GLOBAL A168 (4 months of data Feb 2008 -May 2008)

Table B-14. Statistical summary 1-minute data by zenith angle bin SPN1 Global

\begin{tabular}{|c|c|c|c|c|c|c|}
\hline SPN1_G & $\begin{array}{c}\text { Count } \\
(\mathbf{N})\end{array}$ & $\begin{array}{c}\text { MeanSPN1_Glo } \\
\text { \% Mean Diff }\end{array}$ & $\begin{array}{c}\text { StDev } \\
(\mathbf{s d})\end{array}$ & Maximum & Minimum & Range \\
\hline 15 & 862 & -0.308 & 4.983 & 15.4 & -15.7 & 31.1 \\
\hline 25 & 7049 & -0.981 & 4.307 & 25.1 & -18.4 & 43.5 \\
\hline 35 & 10244 & -1.297 & 4.489 & 23.7 & -91.9 & 115.6 \\
\hline 45 & 13518 & -1.760 & 4.246 & 23.9 & -100.0 & 123.9 \\
\hline 55 & 18292 & -2.733 & 4.354 & 54.4 & -100.0 & 154.4 \\
\hline 65 & 20881 & -3.269 & 4.667 & 55.7 & -39.9 & 95.6 \\
\hline 75 & 16840 & -3.656 & 7.362 & 67.4 & -35.8 & 103.3 \\
\hline 85 & 15621 & 1.747 & 27.431 & 99.9 & -100.0 & 199.9 \\
\hline
\end{tabular}

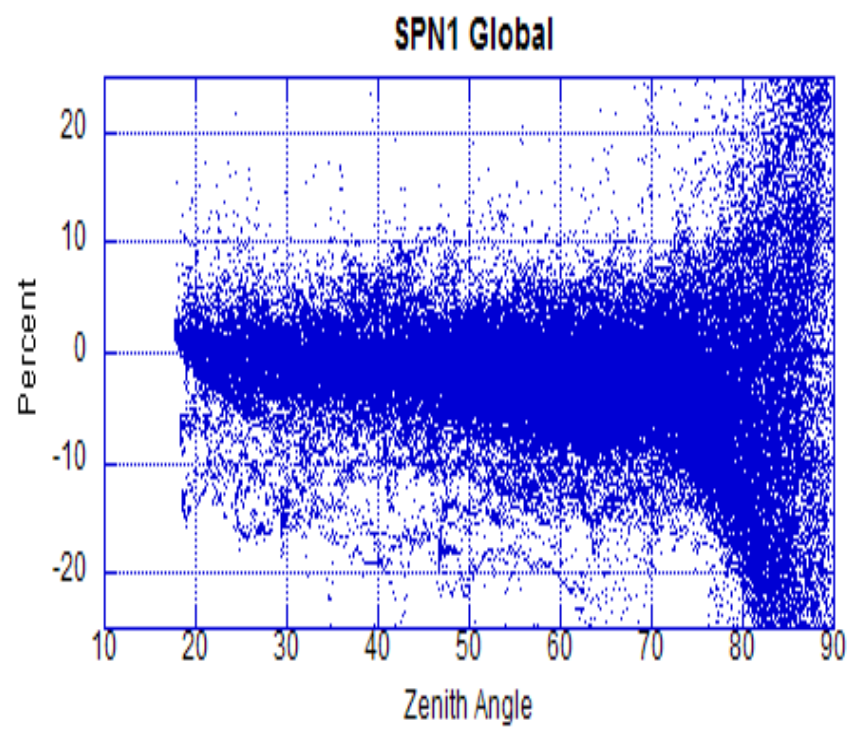

Figure B-14(a). One-minute data set percent differences; SPNI Global.

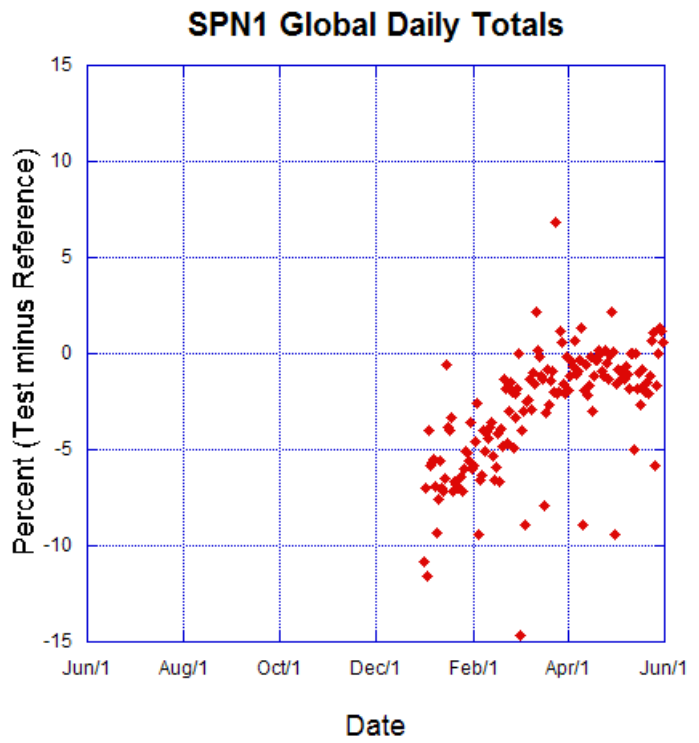

Figure B-14(b). Daily total percent difference; SPN1 Global. 


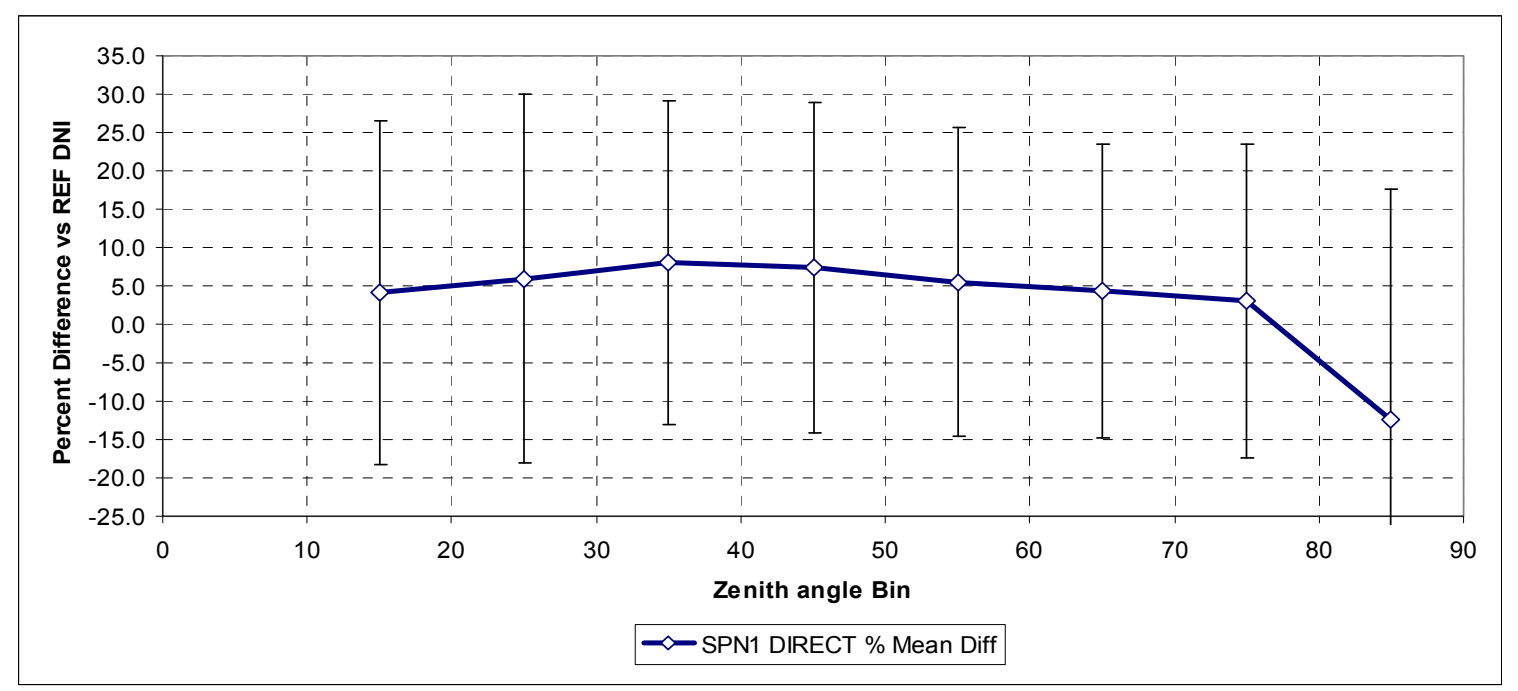

Figure B-15. SPN1 DIRECT A168 (4 months of data Feb 2008 -May 2008)

Table B-15. Statistical summary 1-minute data by zenith angle bin SPN1 Direct

\begin{tabular}{|c|c|c|c|c|c|c|}
\hline SPN1_DIR & $\begin{array}{c}\text { Count } \\
\text { (N) }\end{array}$ & $\begin{array}{c}\text { SPN1 } \\
\text { DIRECT } \\
\text { \% Mean } \\
\text { Diff }\end{array}$ & $\begin{array}{c}\text { StDev } \\
\text { (sd) }\end{array}$ & Maximum & Minimum & Range \\
\hline 15 & 672 & 4.143 & 22.4 & 99.25 & -99.99 & 199.24 \\
\hline 25 & 5732 & 5.905 & 24.0 & 98.5 & -99.99 & 198.49 \\
\hline 35 & 7996 & 8.057 & 21.1 & 99.82 & -99.99 & 199.81 \\
\hline 45 & 10530 & 7.343 & 21.5 & 99.99 & -99.99 & 199.98 \\
\hline 55 & 14304 & 5.489 & 20.1 & 99.81 & -99.99 & 199.8 \\
\hline 65 & 16324 & 4.419 & 19.2 & 99.91 & -99.99 & 199.9 \\
\hline 75 & 12410 & 3.024 & 20.4 & 99.71 & -99.99 & 199.7 \\
\hline 85 & 9259 & -12.472 & 30.1 & 99.1 & -99.99 & 199.09 \\
\hline
\end{tabular}

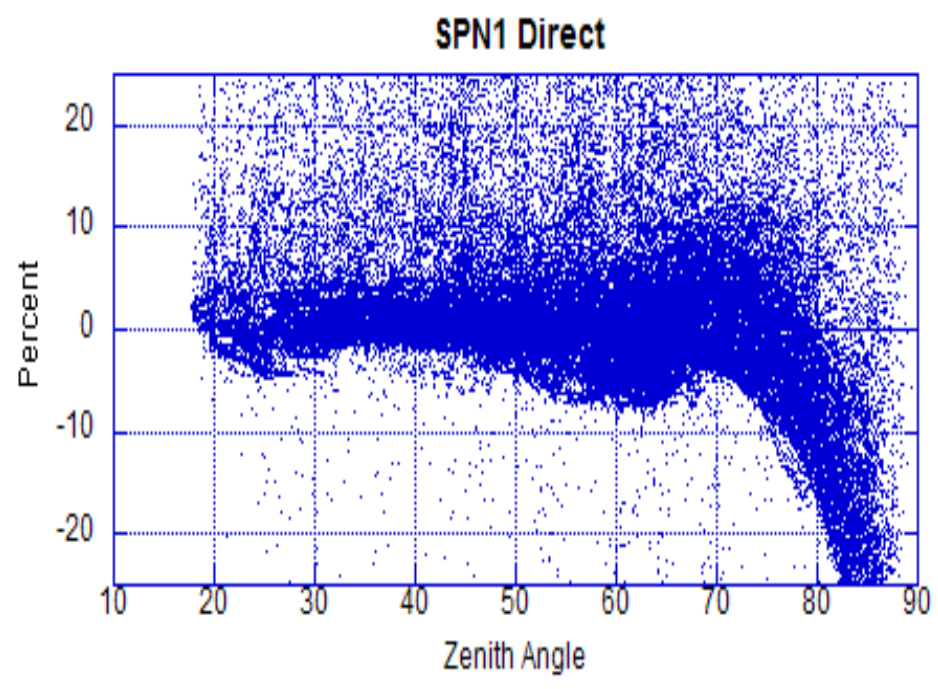

Figure B-15(a). One-minute data set percent differences; SPN1 Direct.

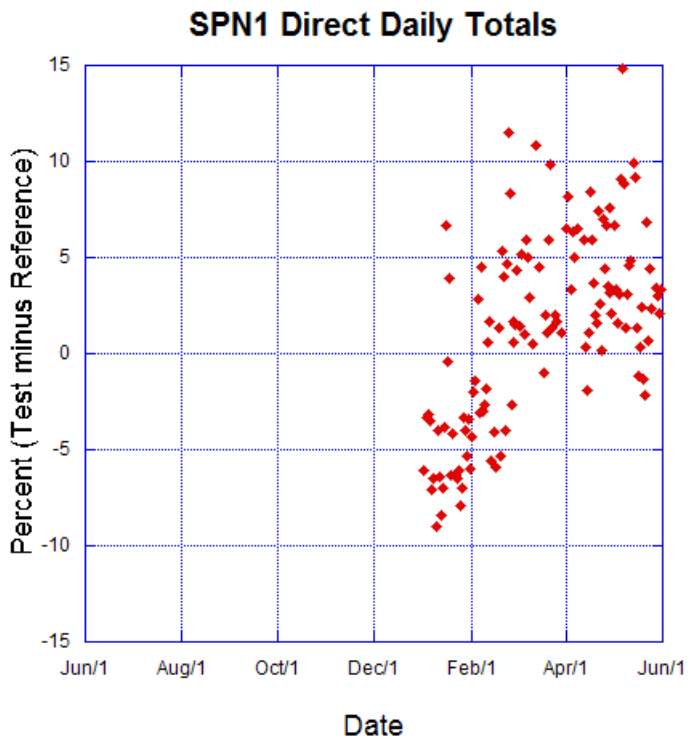

Figure B-15(b). Daily total percent difference; SPN1 Direct. 


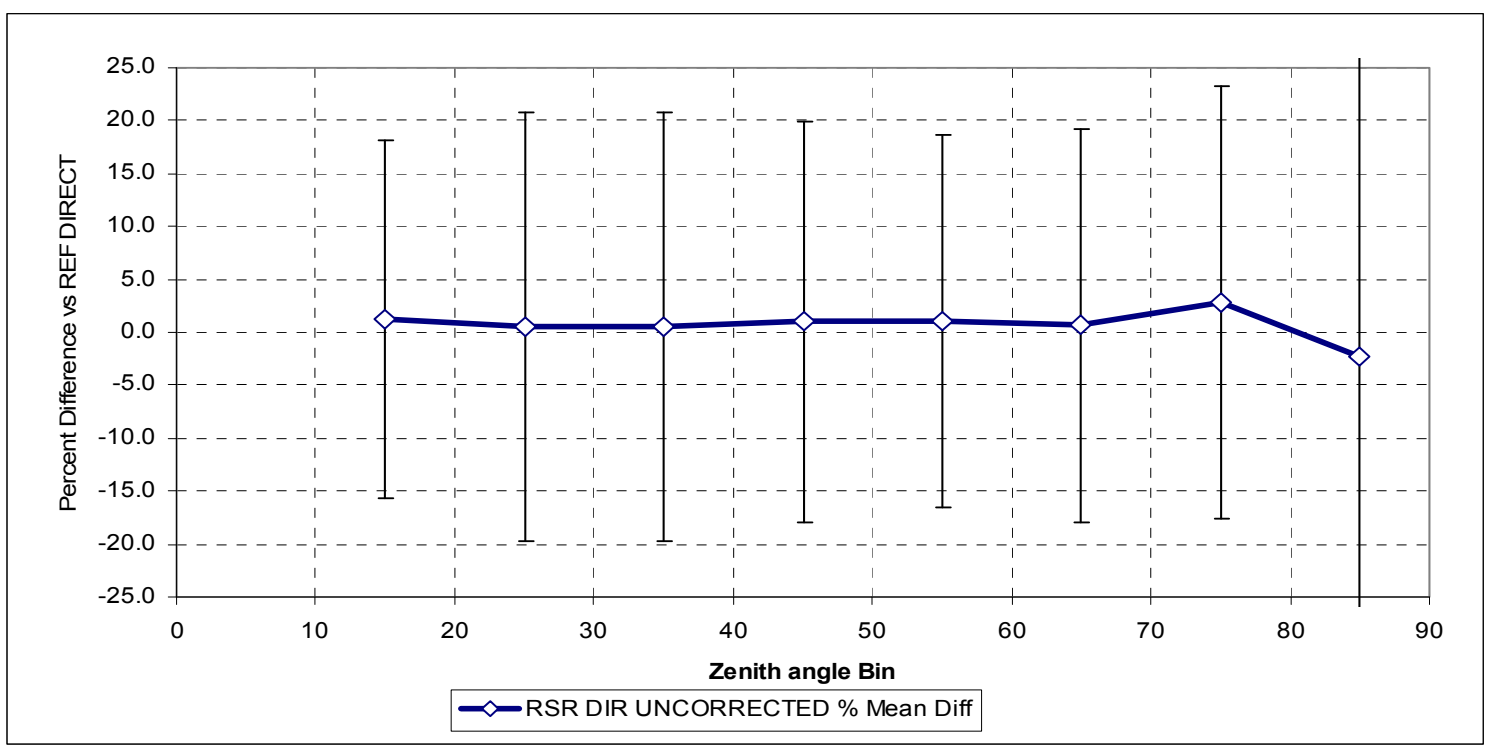

Figure B-16. RSR2 Direct Uncorrected (11 months of data Jul 2007 -May 2008)

Table B-16. Statistical summary 1-minute data by zenith angle bin RSR2 Direct Uncorrected

\begin{tabular}{|c|c|c|c|c|c|c|}
\hline RSR DIR U & $\begin{array}{c}\text { Count } \\
(\mathbf{N})\end{array}$ & $\begin{array}{c}\text { RSR DIR } \\
\text { UNCORRECTED } \\
\text { \% Mean Diff }\end{array}$ & $\begin{array}{c}\text { StDev } \\
(\mathbf{s d})\end{array}$ & Maximum & Minimum & Range \\
\hline 15 & 2599 & 1.251 & 16.8 & 99.09 & -98.08 & 197.17 \\
\hline 25 & 17944 & 0.499 & 20.2 & 99.88 & -99.99 & 199.87 \\
\hline 35 & 17944 & 0.499 & 20.2 & 99.88 & -99.99 & 199.87 \\
\hline 45 & 22645 & 0.976 & 18.9 & 99.85 & -99.99 & 199.84 \\
\hline 55 & 31499 & 1.022 & 17.6 & 99.64 & -99.99 & 199.63 \\
\hline 65 & 40494 & 0.627 & 18.6 & 99.81 & -99.99 & 199.8 \\
\hline 75 & 30449 & 2.875 & 20.4 & 99.74 & -99.99 & 199.73 \\
\hline 85 & 22925 & -2.235 & 33.0 & 99.86 & -99.99 & 199.85 \\
\hline
\end{tabular}

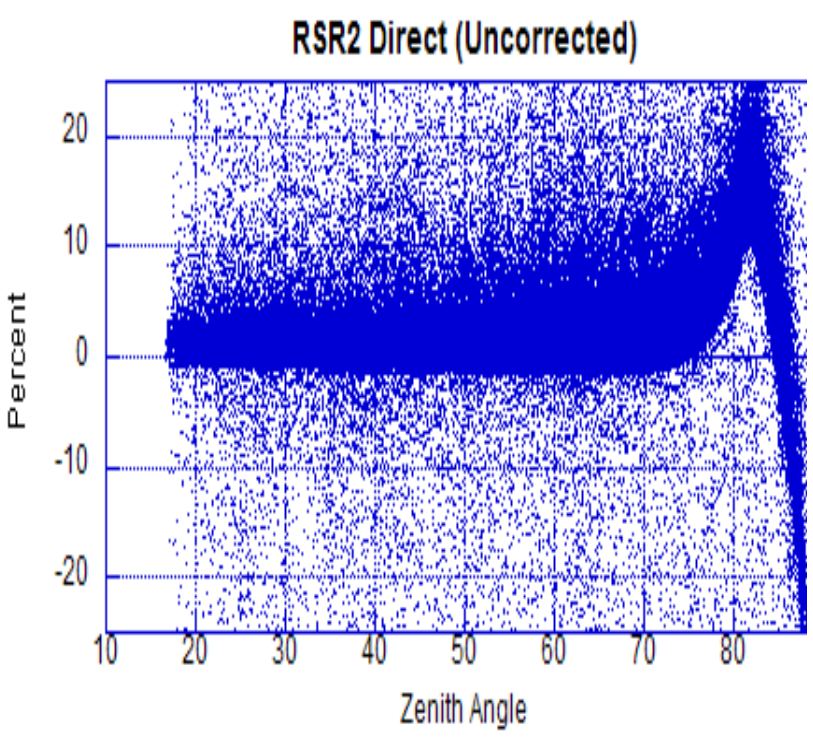

Figure B-16(a). One-minute data set percent differences: RSR2 Direct Uncorrected.

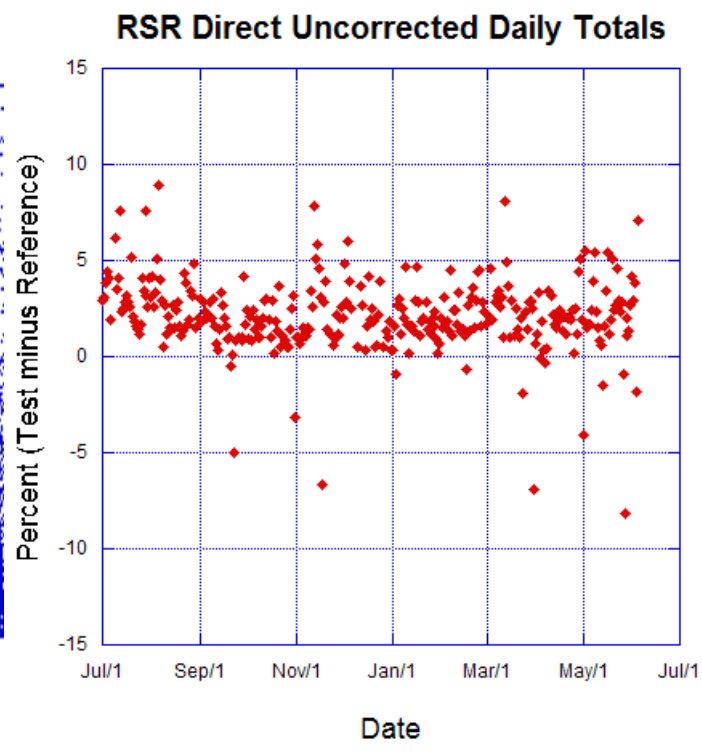

Figure B-16(b). Daily total percent difference RS2 Direct Uncorrected. 


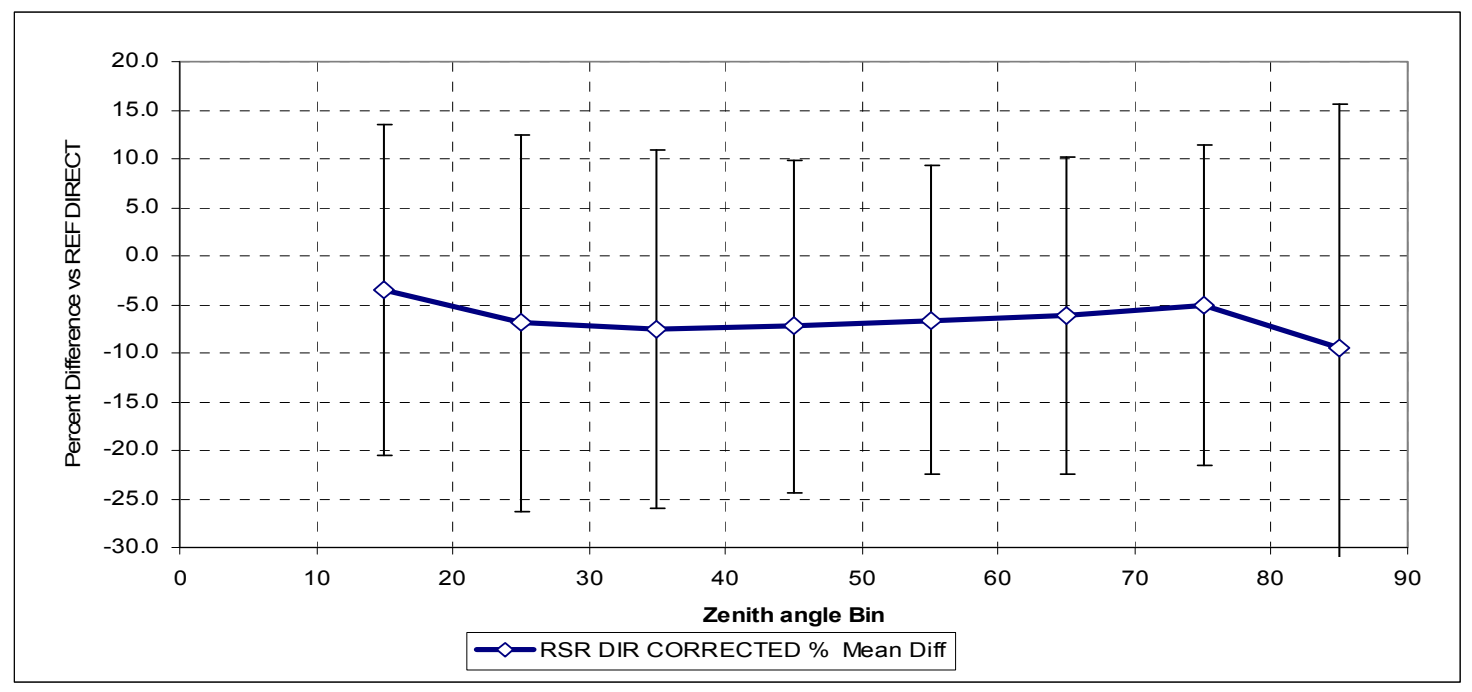

Figure B-17. RSR Direct Corrected (11 months of data Jul 2007 - May 2008)

Table B-17. Statistical summary 1-minute data by zenith angle bin RSR2 Direct Corrected

\begin{tabular}{|c|c|c|c|c|c|c|}
\hline RSR DIR C & $\begin{array}{c}\text { Count } \\
(\mathbf{N})\end{array}$ & $\begin{array}{c}\text { RSR DIR } \\
\text { CORRECTED } \\
\text { \% Mean Diff }\end{array}$ & $\begin{array}{c}\text { StDev } \\
\mathbf{( s d )}\end{array}$ & Maximum & Minimum & Range \\
\hline 15 & 2504 & -3.507 & 17.0 & 97.41 & -99.51 & 196.92 \\
\hline 25 & 12387 & -6.899 & 19.4 & 95.29 & -99.99 & 195.28 \\
\hline 35 & 16643 & -7.509 & 18.4 & 92.79 & -99.99 & 192.78 \\
\hline 45 & 20957 & -7.255 & 17.1 & 99.67 & -99.97 & 199.64 \\
\hline 55 & 29369 & -6.606 & 15.9 & 94.73 & -99.99 & 194.72 \\
\hline 65 & 37428 & -6.189 & 16.3 & 94.61 & -99.97 & 194.58 \\
\hline 75 & 27961 & -5.025 & 16.5 & 86.66 & -99.98 & 186.64 \\
\hline 85 & 18818 & -9.558 & 25.1 & 99.62 & -99.99 & 199.61 \\
\hline
\end{tabular}

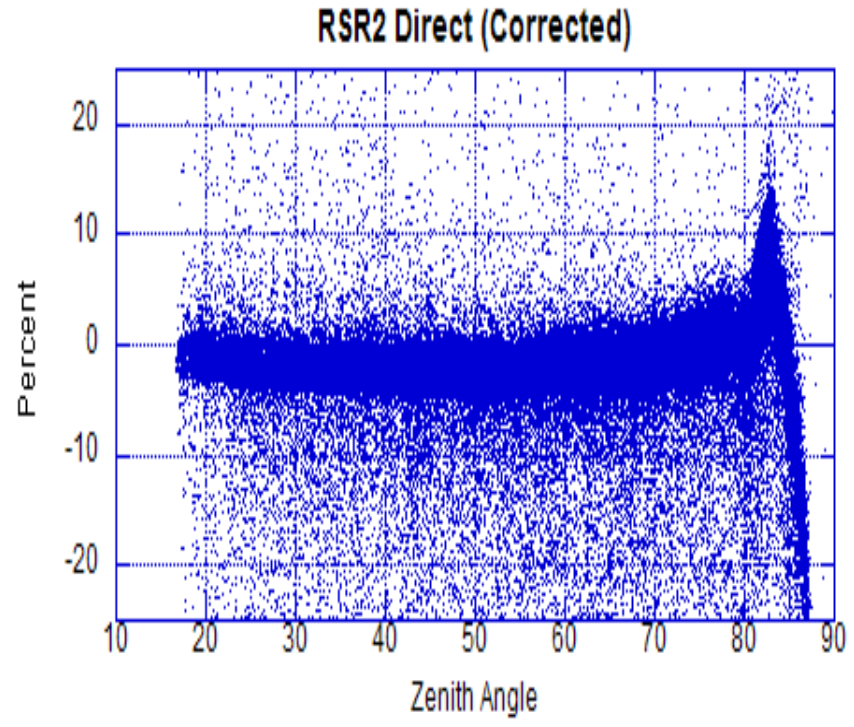

Figure B-17(a). One-minute data set percent differences; RSR2 Direct Corrected.

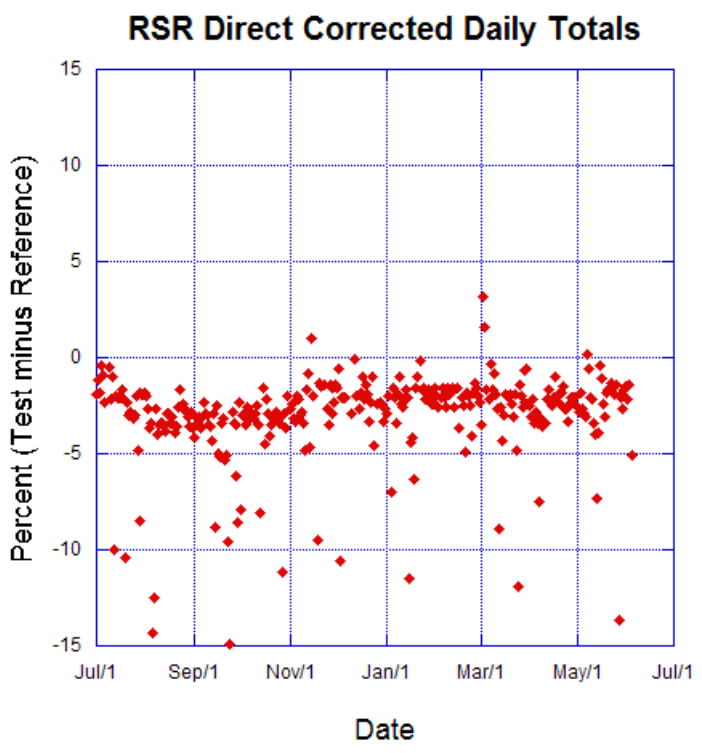

Figure B-17(b). Daily total percent difference; RSR2 Direct Corrected. 


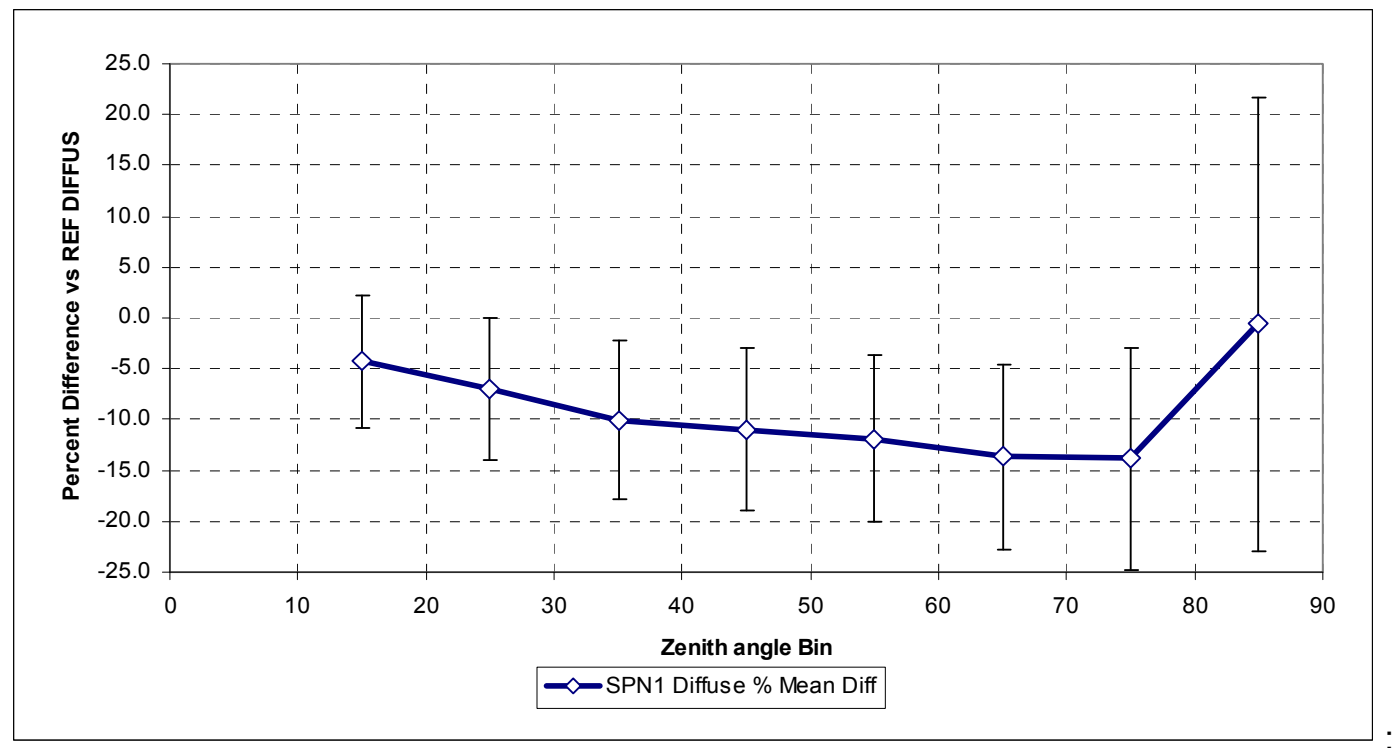

Figure B-18. SPN1 Diffuse A168 (4 months of data Feb 2008 -May 2008)

Table B-18. Statistical summary 1-minute data by zenith angle bin SPN1 Diffuse

\begin{tabular}{|c|c|c|c|c|c|c|}
\hline SPN1 DIF & $\begin{array}{c}\text { Count } \\
(\mathbf{N})\end{array}$ & $\begin{array}{c}\text { SPN1 } \\
\text { Diffuse \% } \\
\text { Mean Diff }\end{array}$ & $\begin{array}{c}\text { StDev } \\
(\mathbf{s d})\end{array}$ & Maximum & Minimum & Range \\
\hline 15 & 862 & -4.277 & 6.5 & 20.43 & -30.08 & 50.51 \\
\hline 25 & 7049 & -6.911 & 7.0 & 23.23 & -37.16 & 60.39 \\
\hline 35 & 10244 & -10.039 & 7.7 & 16.03 & -88.52 & 104.55 \\
\hline 45 & 13517 & -10.966 & 8.0 & 22.6 & -47.6 & 70.2 \\
\hline 55 & 18291 & -11.910 & 8.2 & 44.86 & -39.34 & 84.2 \\
\hline 65 & 20881 & -13.658 & 9.1 & 48.6 & -57.41 & 106.01 \\
\hline 75 & 16840 & -13.873 & 10.9 & 27.11 & -49.79 & 76.9 \\
\hline 85 & 15959 & -0.635 & 22.3 & 99.96 & -96.68 & 196.64 \\
\hline
\end{tabular}

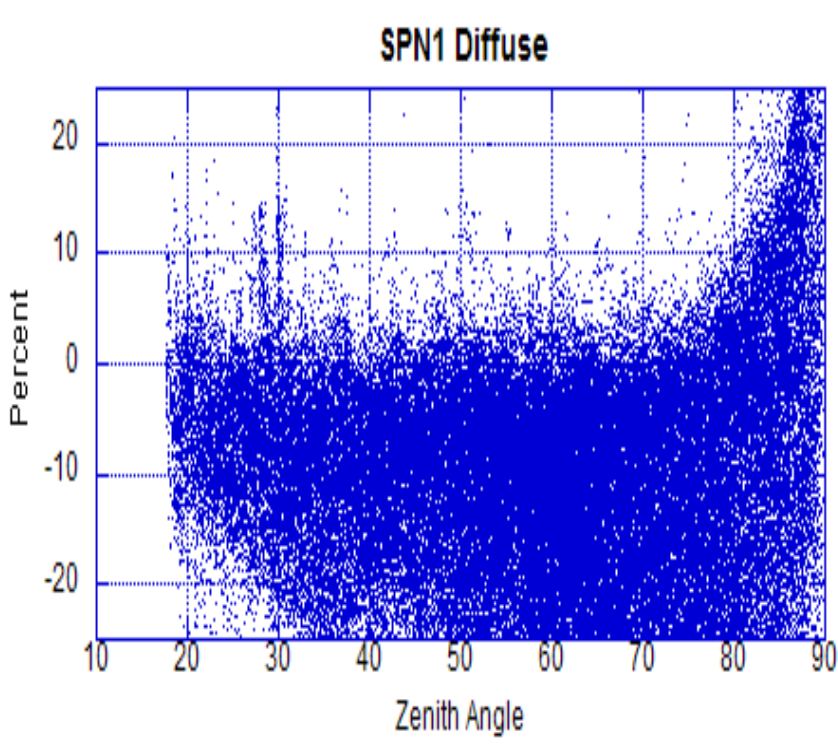

Figure B-18(a). One-minute data set percent differences; SPN1 Diffuse.

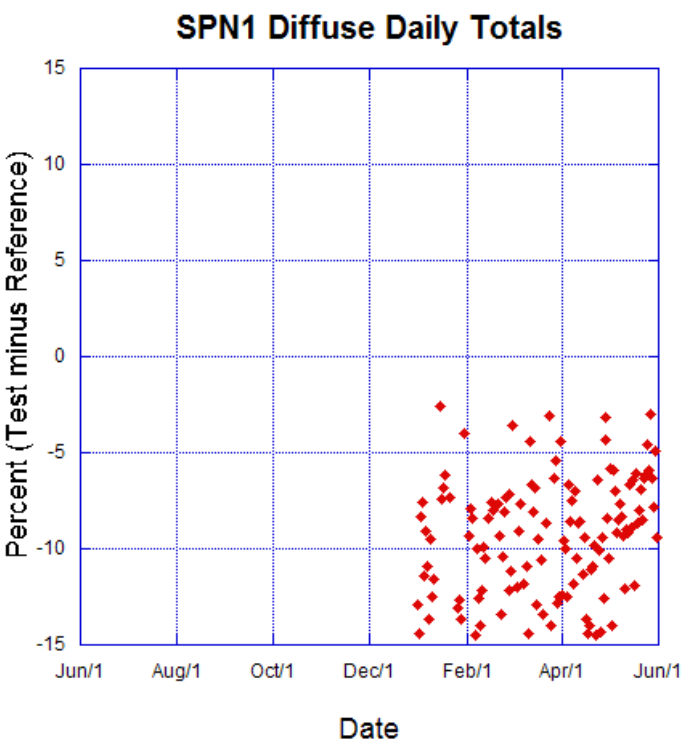

Figure B-18(b). Daily total percent difference; SPN1 Diffuse. 


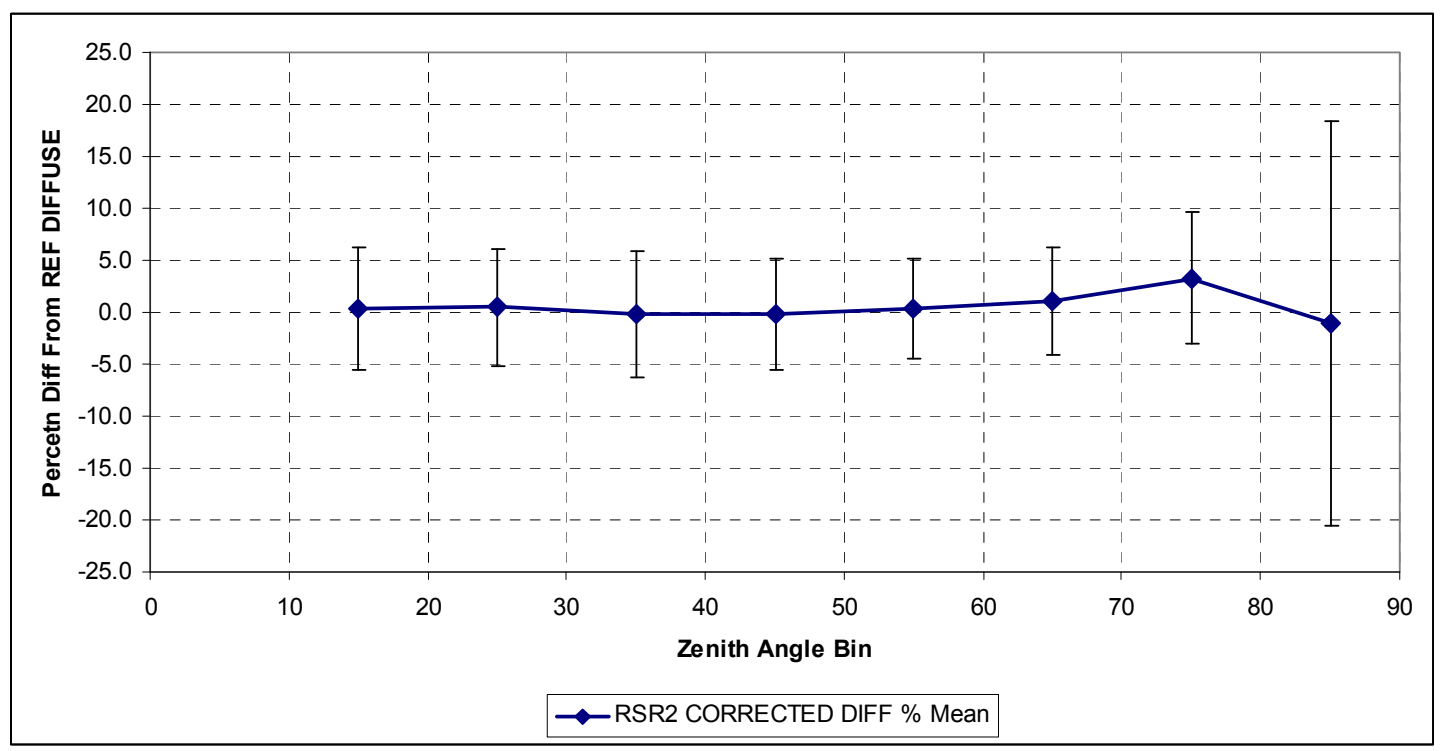

Figure B-19. RSR2 Diffuse Corrected (11 months of data Jul 2007-May 2008)

Table B-19. Statistical summary 1-minute data by zenith angle bin RSR2 Diffuse Corrected

\begin{tabular}{|c|c|c|c|c|c|c|}
\hline RSR DIFF C & $\begin{array}{c}\text { Count } \\
(\mathbf{N})\end{array}$ & $\begin{array}{c}\text { RSR DIFF } \\
\text { CORRECTED } \\
\text { \% Mean Diff }\end{array}$ & $\begin{array}{c}\text { StDev } \\
(\mathbf{s d})\end{array}$ & Maximum & Minimum & Range \\
\hline 15 & 2997 & 0.37 & 5.95 & 39.63 & -78.50 & 118.13 \\
\hline 25 & 15534 & 0.46 & 5.68 & 99.89 & -90.08 & 189.97 \\
\hline 35 & 21144 & -0.23 & 6.10 & 93.37 & -98.45 & 191.82 \\
\hline 45 & 27098 & -0.19 & 5.40 & 74.27 & -99.11 & 173.38 \\
\hline 55 & 37353 & 0.33 & 4.77 & 61.93 & -92.93 & 154.86 \\
\hline 65 & 48783 & 1.09 & 5.23 & 99.94 & -96.01 & 195.95 \\
\hline 75 & 38433 & 3.23 & 6.32 & 61.74 & -68.33 & 130.07 \\
\hline 85 & 37406 & -1.06 & 19.47 & 99.47 & -100.00 & 199.47 \\
\hline
\end{tabular}

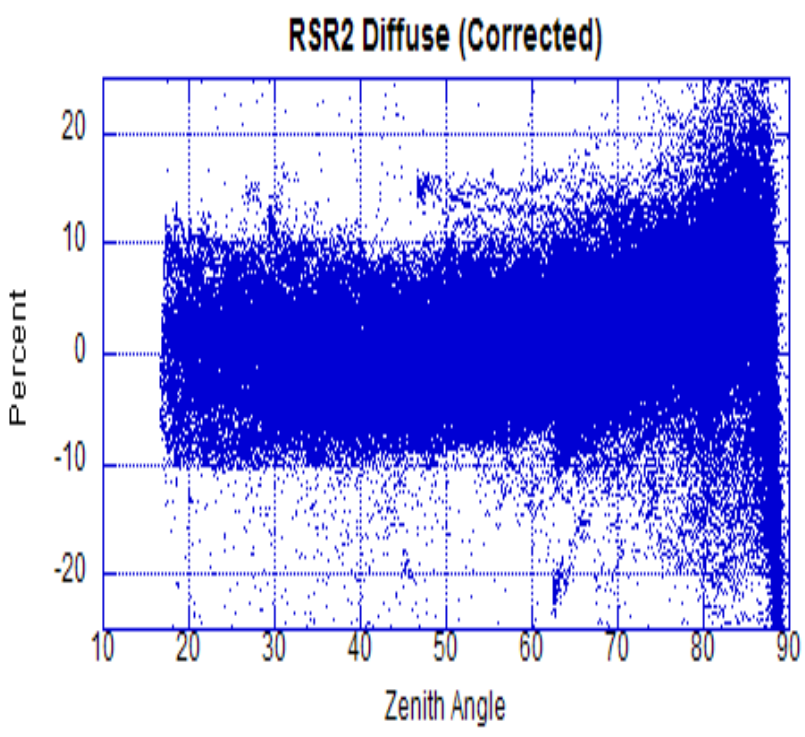

Figure B-19(a). One-minute data set percent differences; RSR2 Diffuse Corrected.

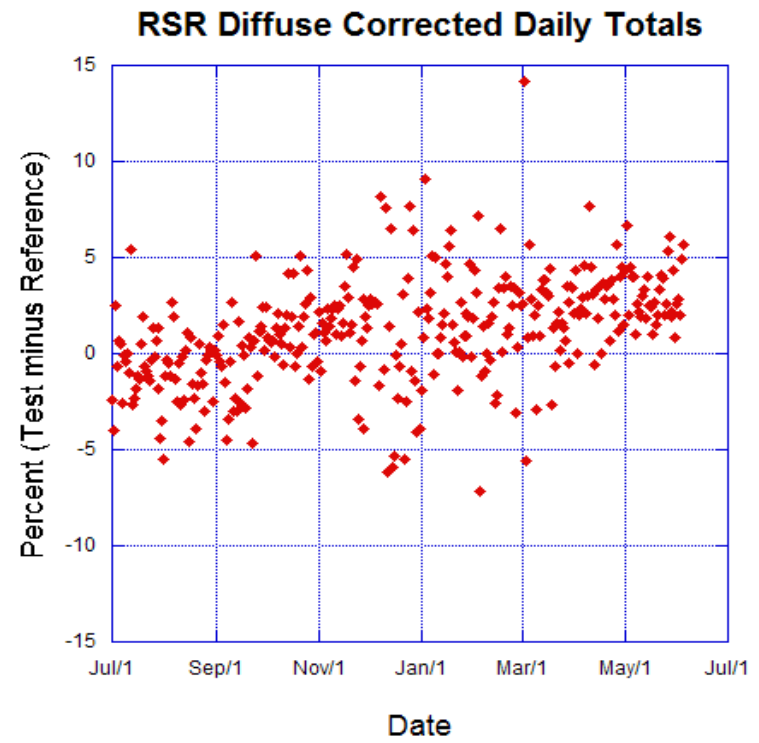

Figure B-19(b). Daily total percent difference RSR2 Diffuse Corrected. 


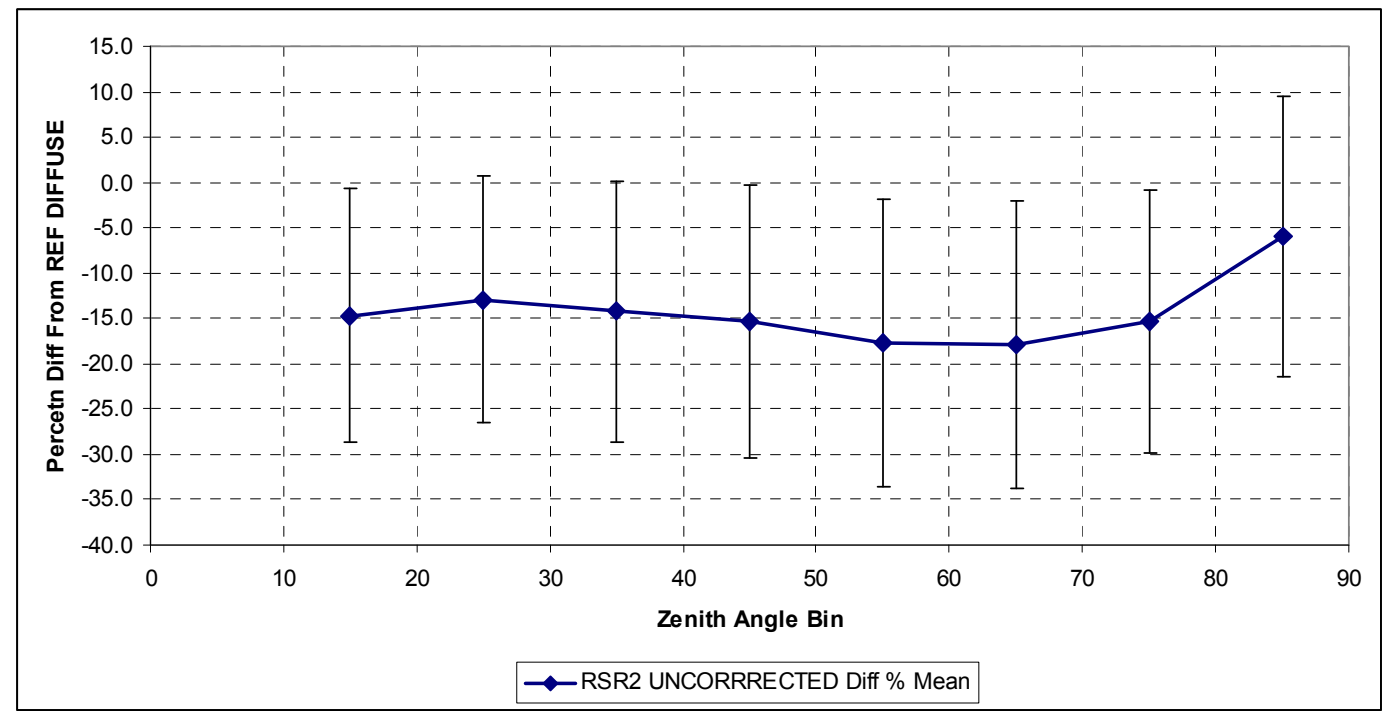

Figure B-20. RSR2 Diffuse Uncorrected (11 months of data Jul 2007 -May 2008)

Table B-20. Statistical summary 1-minute data by zenith angle bin RSR2 Diffuse Uncorrected.

\begin{tabular}{|c|c|c|c|c|c|c|}
\hline RSR DIF U & $\begin{array}{c}\text { Count } \\
(\mathbf{N})\end{array}$ & $\begin{array}{c}\text { RSR DIFF } \\
\text { UNCORRECTED } \\
\text { \% Mean Diff }\end{array}$ & $\begin{array}{c}\text { StDev } \\
(\mathbf{s d})\end{array}$ & Maximum & Minimum & Range \\
\hline 15 & 2996 & -14.69 & 13.96 & 20.71 & -92.50 & 113.21 \\
\hline 25 & 15526 & -12.96 & 13.61 & 98.08 & -92.68 & 190.76 \\
\hline 35 & 21129 & -14.19 & 14.38 & 81.66 & -99.58 & 181.24 \\
\hline 45 & 27087 & -15.31 & 15.12 & 91.72 & -99.29 & 191.01 \\
\hline 55 & 37349 & -17.75 & 15.82 & 32.48 & -99.10 & 131.58 \\
\hline 65 & 48783 & -17.89 & 15.94 & 98.54 & -82.18 & 180.72 \\
\hline 75 & 38432 & -15.34 & 14.57 & 56.72 & -94.77 & 151.49 \\
\hline 85 & 37227 & -5.90 & 15.48 & 99.72 & -99.64 & 199.36 \\
\hline
\end{tabular}

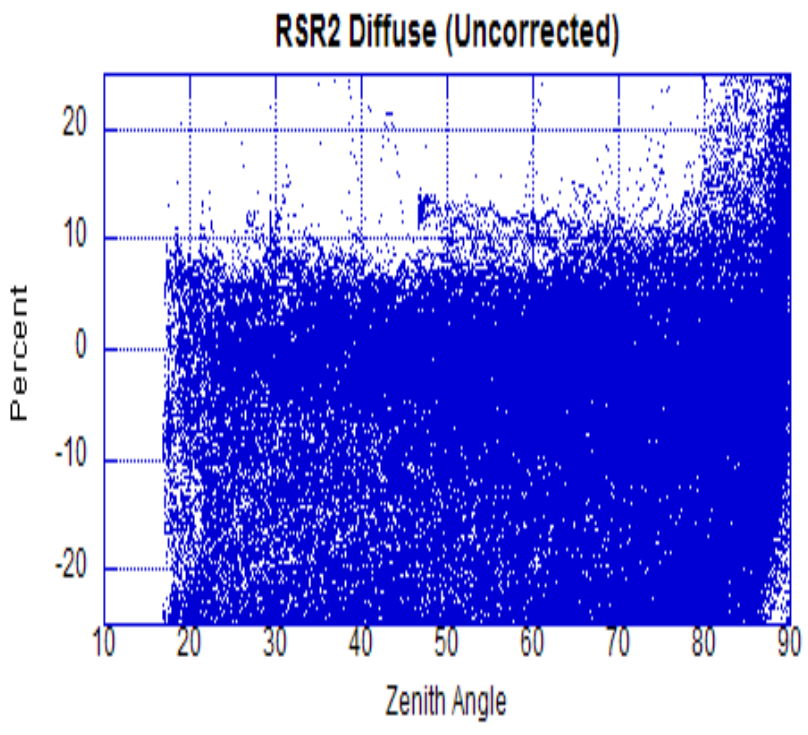

Figure B-20(a). One-minute data set percent differences; RSR2 Diffuse Uncorrected.
RSR Diffuse Uncorrected Daily Totals

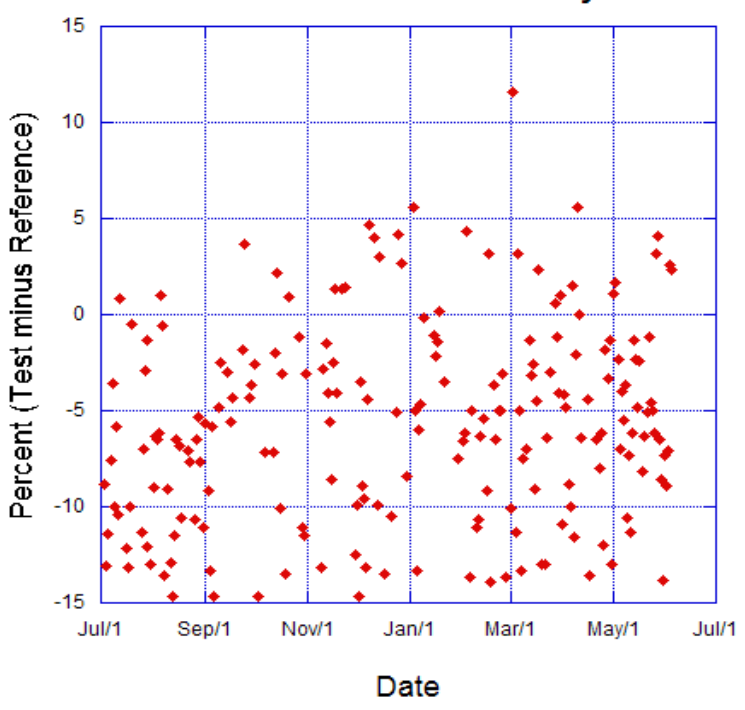

Figure B-20(b). Daily total percent difference RSR2 Diffuse Uncorrected. 


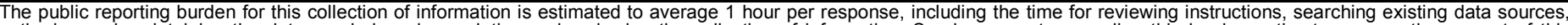

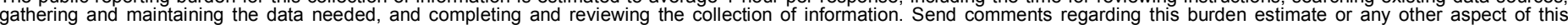

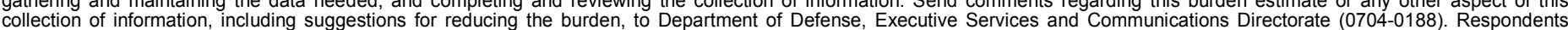

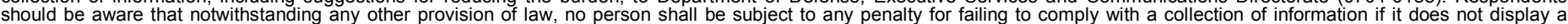

should be aware that notwithstanding

PLEASE DO NOT RETURN YOUR FORM TO THE ABOVE ORGANIZATION.

\begin{tabular}{l|l|l|l} 
1. REPORT DATE $(D D-M M-Y Y Y Y)$ & 2. & REPORT TYPE & 3. DATES COVERED (FrOm - TO)
\end{tabular}

December 2008

Technical Report

4. TITLE AND SUBTITLE

Evaluation of Radiometers in Full-Time Use at the National

Renewable Energy Laboratory Solar Radiation Research Laboratory 5a. CONTRACT NUMBER

DE-AC36-08-GO28308

5b. GRANT NUMBER

5c. PROGRAM ELEMENT NUMBER

5d. PROJECT NUMBER

NREL/TP-550-44627

5e. TASK NUMBER

PVD9.3110; CP09.3310

5f. WORK UNIT NUMBER
7. PERFORMING ORGANIZATION NAME(S) AND ADDRESS(ES)

National Renewable Energy Laboratory

1617 Cole Blvd.

Golden, CO 80401-3393
8. PERFORMING ORGANIZATION REPORT NUMBER

NREL/TP-550-44627

9. SPONSORING/MONITORING AGENCY NAME(S) AND ADDRESS(ES)

10. SPONSOR/MONITOR'S ACRONYM(S) NREL

11. SPONSORING/MONITORING AGENCY REPORT NUMBER

12. DISTRIBUTION AVAILABILITY STATEMENT

National Technical Information Service

U.S. Department of Commerce

5285 Port Royal Road

Springfield, VA 22161

13. SUPPLEMENTARY NOTES

14. ABSTRACT (Maximum 200 Words)

This report describes the evaluation of the relative performance of the complement of solar radiometers deployed at the National Renewable Energy Laboratory (NREL) Solar Radiation Research Laboratory (SRRL). This report presents an analysis of 12 global (total hemispherical) horizontal radiometers, three direct beam pyrheliometers, and two diffuse pyranometers in full-time use at SRRL. Data for 12 months were retrieved from the SRRL Baseline Measurement System and included the test instrument measurements and data for a computed reference data set. This report offers no explicit conclusion about instrument performance, as it is aimed at a very general array of applications with a wide range of instrumentation and accuracy requirements.

15. SUBJECT TERMS

SRRL, Solar Radiation Research Laboratory, radiometers, pyrheliometers, pyranometers; Baseline Measurement System; BSM

\begin{tabular}{|c|c|c|}
\hline \multicolumn{3}{|c|}{ 16. SECURITY CLASSIFICATION OF: } \\
\hline $\begin{array}{l}\text { a. REPORT } \\
\text { Unclassified }\end{array}$ & $\begin{array}{l}\text { b. ABSTRACT } \\
\text { Unclassified }\end{array}$ & $\begin{array}{l}\text { c. THIS PAGE } \\
\text { Unclassified }\end{array}$ \\
\hline
\end{tabular}

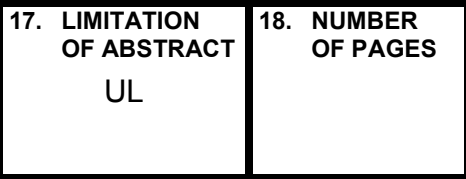

19a. NAME OF RESPONSIBLE PERSON

19b. TELEPHONE NUMBER (Include area code) 